Eliminação de ruídos e retoque digital em imagens com textura via difusão anisotrópica 

Data de Depósito:

Assinatura:

Marcos Proença de Almeida

\title{
Eliminação de ruídos e retoque digital em imagens com textura via difusão anisotrópica
}

\author{
Tese apresentada ao Instituto de Ciências \\ Matemáticas e de Computação - ICMC-USP, \\ como parte dos requisitos para obtenção do título \\ de Doutor em Ciências - Ciências de Computação e \\ Matemática Computacional. VERSÃO REVISADA \\ Área de Concentração: Ciências de Computação e \\ Matemática Computacional \\ Orientador: Prof. Dr. Antonio Castelo Filho \\ Coorientador: Prof. Dr. António Gaspar Lopes \\ da Cunha
}




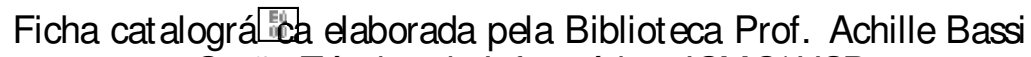
e Seção Técnica de Informática, ICMC/ USP, com os dados fornecidos pelo(a) autor(a)

A447e

Almeida, Marcos Proença de

Eliminação de ruídos e retoque digital em imagens com textura via difusão anisotrópica / Marcos Proença de Almeida; orientador Antonio Castelo Filho; coorientador António Gaspar Lopes da Cunha. - São Carlos - SP, 2017.

?? p.

Tese (Doutorado - Programa de Pós-Graduação em Ciências de Computação e Matemática Computacional) - Instituto de Ciências Matemáticas e de Computação, Universidade de São Paulo, 2017.

1. Eliminação de ruídos. 2. Retoque digitial. 3. Difusão anisotrópica. 4. Síntese de textura. 5. Equações diferenciais. I. Castelo Filho, Antonio, orient. II. Cunha, António Gaspar Lopes da, coorient. III. Título. 
Marcos Proença de Almeida

\section{Denoising and inpainting on textured images via anisotropic diffusion}

Doctoral dissertation submitted to the Instituto de Ciências Matemáticas e de Computação - ICMCUSP, in partial fulfillment of the requirements for the degree of the Doctorate Program in Computer Science and Computational Mathematics. FINAL VERSION

Concentration Area: Computer Science and Computational Mathematics

Advisor: Prof. Dr. Antonio Castelo Filho

Co-advisor: Prof. Dr. António Gaspar Lopes da Cunha

USP - São Carlos

February 2017 

À minha noiva, Amanda,

À minha amada família,

Aos meus queridos amigos,

Dedico. 

Agradeço a todos aqueles que me aj udaram em minha vida acadêmica e pessoal, pois o apoio e ajuda de vocês tornou possível esta conquista.

Foi um período de muito aprendizado e crescimento, com al egria e tristezas, mudanças e viagens, cafezinhos e mais cafezinhos, além de muitas amizades e momentos que serão lembrados com muito af eto.

Uma conqui sta nunca é fruto do trabal ho individual. Há sempre contribuições di retas e indiretas que tornam possível a real ização de nossas tarefas. Neste sentigo, sou extremamente grato a todos aqueles me deram suporte e contribuíram na real ização deste trabal ho de doutoramento.

Contudo, acredito ser de grande valia e certamente muito merecido explicitar meu sentimento de gratidão para com al gumas pessoas em particular.

Agradeço a Deus pelas oportunidades e, principal mente, pelas pessoas que encontrei em meu caminho, pois cada uma del as trouxe mais luz e significado à minha existência.

Agradeço também à minha noiva, A manda Coto, uma pessoa forte e determinada que me ajudou imensamente durante todos os momentos desta etapa tão significante de minha vida, sempre com muita atenção, dedi cação e carinho.

Expresso também minha gratidão ao meu amigo, Prof. Dr. Wal lace Casaca, pela ami zade, companhia e auxílio prestado nas questões acadêmicas e nas experiências de vida.

À minha família, agradeço por todo apoio, suporte e carinho com o qual me recebem toda vez que retorno para casa. Afinal, mesmo distantes sempre estiveram presentes em minha vida.

Agradeço ao Prof. Dr. Antonio Castelo Filho pela orientação deste trabal ho e também por todo apoio e ensinamentos oferecidos durante a execução deste trabal ho e ao Prof. Dr. António Gaspar-Cunha agradeço pela coorientação e auxílio prestado no decorrer de meu de doutoramento. Além disso, agradeço ao Prof. Dr. Alexandre Delbem pela disponibilidade, atenção e auxílio no desenvolvimento deste trabal ho.

Deixo também meus agradecimentos aos membros dabanca, Prof. Dr. Aparecido Nilceu Marana, Prof. Dr. Alagacone Sri Ranga, Profa. Dra. Agma Traina, Prof. Dr. Moacir Antonelli Ponti e Prof. Dr. Rodrigo Fernandes de Mello pel as significantes sugestões e contribui ções feitas a este trabal ho.

Agradeços aos professores do IBILCE/UNESP, Maurílio Boaventura, Eliana Xavier e 
Alagacone Sri Ranga pelas contribuições em minha vida acadêmica.

Agradeço aos amigos de pós-graduação e do LMACC/USP pela companhia e a todas as pessoas do ICMC/USP que trabal ham para que a instituição possa of erecer sua contribuição à sociedade, em especial aos funcionários da Seção de Pós-graduação por todo auxílio com as questões burocráticas.

Preciso agradecer também ao IFTM e a todos os colegas de trabal ho que me acol heram carinhosamente nesta minha nova casa. Em especial, agradeço aos amigos Leandro e Anderson pela disponibilidade e à Dani por me receber como um filho .

Aos amigos Juca e Josi deixo regi strada minha gratidão pel a aj uda e carinho com o qual sempre me acol heram, às amigas A lyne e Manu agradeço por todo apoio e amizade sempre disponível, mesmo que à distância, aos amigos Edinho, Marcão, Cokin e Jul iana agradeço por serem os primeiros a me receberem e acol herem na cidade de São Carlos.

Agradeço por fim às agencias de fomento, Consel ho Nacional de Desenvolvimento Científico e Tecnológico (CNPq) e à Coordenação de Aperfeiçoamento de Pessoal de Nível Superior (CAPES), pelo auxílio e financiamento financeiro deste trabal ho. 


\section{RESUMO}

ALMEIDA, M. P.. Eliminação de ruídos e retoque digital em imagens com textura via difusão ani sotrópica. 2016. 101 f. Tese (Doutorado em Ciências - Ciências de Computação e Matemática Computacional) - Insti tuto de Ciências Matemáticas e de Computação (ICMC/USP), São Carlos-SP.

Neste trabal ho são apresentadas, complementadas e melhoradas duas técnicas de restauração de imagens: uma abordando o problema de retoque digital/remoção de objetos enquanto a segunda é direcionada ao problema deneliminação de ruído. Em ambas as técnicas, a ideia é trabal har com imagens contendo texturas e outras características de interesse para um observador humano como a preservação de padrões, bordas, estruturas e regiões de natureza oscilatória. A técnica descrita sobre retoque di gital de imagens combina difusão ani sotrópica, síntese de texturas, busca dinâmica e um novo termo empregado no mecanismo de atribuição da ordem de prioridade durante o processo de reconstrução. Assim, dada uma imagem com regiões a serem recompostas, uma técnica de difusão ani sotrópica é aplicada à imagem a fim de se obter um mapa de sal iência contendo bordas, estruturas e demais inf ormações de baix a frequência da imagem. Na sequência, um mecanismo de prioridade baseado em um novo termo de confiabilidade regularizado é cal culado a partir da combinação do mapa anteriormente gerado com a equação do transporte. Tal mecanismo é utilizado para determinar a ordem de preenchimento das partes fal tantes da imagem. Para essa tarefa, a abordagem apresentada uti liza uma nova medi da de si milaridade entre bl ocos de pixels (amostrados di namicamente para acelerar o processo), a fim de encontrar os mel hores candidatos a serem al ocados nas regiões danificadas. A técnica destinada à remoção de ruídos al ia a teoria da difusão ani sotrópica, técnicas de análise harmônica e model os numéricos de discretização de EDPs não-lineares em uma equação diferencial parcial regularizada, a qual atua de forma incisiva em regiões mais homogêneas da imagem e de forma mais suave em regiões caracterizadas como textura e bordas, preservando, assim, essas regiões. Além da natureza anisotrópica, a EDP procura recompor partes texturizadas perdidas no processo de eliminação de ruído através da apl icação de técnicas robustas de análise harmônica. Uma val idação teórica e experimental para esta EDP e um estudo do ajuste paramétrico do método de eliminação de ruído baseado nesta EDP foram realizados neste trabal ho. A eficiência e a performance das técni cas propostas são atestadas por meio das análises experimentais quantitativas e qual itativas com outras abordagens clássicas da literatura.

Palavr as-chave: Eliminação de ruídos, Retoque digitial, Difusão anisotrópica, Síntese de textura, Equações diferenciais. 



\section{ABSTRACT}

ALMEIDA, M. P.. Eliminação de ruídos e retoque digital em imagens com textura via difusão ani sotrópica. 2016. 101 f. Tese (Doutorado em Ciências - Ciências de Computação e Matemática Computacional) - Insti tuto de Ciências Matemáticas e de Computação (ICMC/USP), São Carlos-SP.

In this work two techniques of image restoration are presented, complemented and improved: one approaching the problem of image inpainting/object removal problem while the second one dealing with the image denoising problem. In both cases, the core idea is to process images containing textures and other features perceptible to a human observer such as patterns, contours, structures and oscillatory information. The image inpainting technique combines anisotropic diffusion, texture synthesis, dynamic search and a mechanism to set the order of priority during the image completion process. More precisely, given an image and target region to be inpainted, an anisotropic diffusion technique is applied in order to generate a sal iency map containing edges, structures and other low frequency parts of the image. Next, a priority mechanism based on a new biased confidence term is computed from the map previously generated with the transport equation to define the level of priority of the pixels during the filling procedure. To accomplish this task, the presented approach employs a novel measure of similarity wich measures the distance between blocks of pixels (sampled dynamically to speed up the process) in order to find the best candidates to be allocated in the damaged regions. The technique devoted to denoising an image combines the theory of anisotropic diffusion, harmonic analysis techniques and numerical models into a regularized partial differential equation, which diffuses the pixels more incisively on homogeneous regions of the image while still seeking to attenuate regions formed by textures and patterns, thus preserving those information. Moreover, the proposed PDE aims at recovering texturized regions which have been degraded during the denoising process by employing harmonic analysis tools. A theoretical and experimental validation for this EDP and a study of the parametric adjustment of the image denoising method based on this EDP were performed in this work. The effectivenss and performance of the proposed approaches are attested through a comprehensive set of comparisons agai nst other representative techniques in the literature.

Key-words: Denoising, Inpainting, Anisotropic diffusion, Texture synthesis, Diferential Equat tion. 



\section{LISTA DE ILUSTRAÇÕES}

Figura 1 - Eixo para representação de imagens. . . . . . . . . . . . . . . . . . . 28

Figura 2 - Imagem col orida no espaço RGB e seus respectivos canais de cores. . . . . . 29

Figura 3 - Exemplo de domínio de retoque e máscara . . . . . . . . . . . . . . . . . . 30

Figura 4 - Exemplos do processo de síntese de textura. Fonte: (RECAS; HILSMANN; EISERT, 2011). . . . . . . . . . . . . . . . . . . . . . 32

Figura 5 - Restauração inconsi stente devido a probl emas na amostragem, pois texturas de árvores foram introduzidas na região da uma parade de tijolos. (a) Imagem a ser reconstruída (faixa central). (b) Imagem restaurada com preenchimento incoerente. Fonte: (GROSSAUER, 2004).

Figura 6 - Exemplo de decomposição do tipo cartoon e textura: $f=u+$ v. (b) Componente cartoon u. (c) Componente textura v. . . . . . . . . . . . . . . . . 37

Figura 7 - Diagramailustrativo do método de retoque DTAS. . . . . . . . . . . . 38

Figura 8 - Representação do campo de direções em uma imagem. (a) Imagem original f. (b) Componente cartoon u, (c) Região destacada em (a). (d) Região destacada em (b). (e) Campo de direção normalizados de (c) usando o versor de —— f. (f) Campos de direção normalizado de (d) com o versor de $\_$$u$. Fonte: (CASACA et al., 2014). . . . . . . . . . . . . . . . . . . . . . . . .

Figura 9 - (a) Imagem original. (b) Componente cartoon u. (c) Resul tado do operador Laplaciano D quando aplicado na imagem original. (d) Operador Laplaciano $\mathrm{D}$ aplicado no componente cartoon u. (e) Comparação entre o termo de relevância $R$ e o termo de dados de Criminisi et al. (CRIMINISI; PEREZ; TOYAMA, 2004). (f), (g) e (h) Gráfico do termo de confiabilidade proposto C para $\mathrm{k}=0: 5 ; 1: 0 ; 1: 5$, respectivamente, por número de iterações quando apl icamos o retoque na imagem (a). Fonte: (CASACA et al., 2014).

Figura 10 - Esquema parailustrar a amostragem dinâmica e o processo de preenchimento do domínio de retoque W. (a) Os pixels candidatos em $L_{p}$ estão destacados (região mais clara) dentro da região válida, dada pela interseção de $\mathrm{H}_{\mathrm{L}}(\mathrm{p})^{1}$ (quadrado verde) e WC. (b) Comparação entre o conteúdo dos blocos $H_{n}(p)$ e $H_{n}(\mathbf{q})$ (bloco ótimo). (c) Resul tado da restauração após preencher a região de interesse. . . . . . . . . . . . . . . . . . . . . . . . . 
Figura 11 - Comparação entre o uso da amostragem dinâmica e os métodos (CRIMINISI; PEREZ; TOYAMA, 2004) e (WEXLER; SHECHTMAN; IRANI, 2007) na restauração de uma fotografia $1000 \times 1300$. O tempo de processamento é o mesmo para todos os métodos e foi considerado como o tempo gasto para o método DTAS concluir a tarefa de restauração. (a) Fotogragia danificada. (b) Resul tado do método DTAS. (c) Imagem obtida pelo método (CRIMINISI; PEREZ; TOYAMA, 2004). (d) Restauração por meio do método (WEXLER; SHECHTMAN; IRANI, 2007). Fonte: (CASACA et al., 2014). . . . . . . .

Figura 12 - Características do método DTAS: transferência indevida de padrões e contribuição individual de cada termo $\mathrm{C} ; \mathrm{R}$ e $\mathrm{P}$. Fonte: (CASACA et al., 2014). . . . . . . . . . . . . . . . . . . . .

Figura 13 - Características do método DTAS: passo-a-passo do método e efetividade do esquema de ordem de preenchimento. Fonte: (CASACA et al., 2014). . . .

Figura 14 - Características do método DTAS: explorando uma imagem com texturas ricas em detal hes. Fonte: (CASACA et al., 2014). . . . . . . . . . . . . .

Figura 15 - Efeito da variação do parâmetro de janelamento da técnica DTAS x (CRIMINISI; PEREZ; TOYAMA, 2004). Segundalinha, método DTAS com: (d) janelamento de 3; (e) janelamento de 5; (f) janelamento de 7. Terceiralinha, (CRIMINISI; PEREZ; TOYAMA, 2004) com os níveis de: (g) janelamento de 3; (h) janelamento de 5; (i) janelamento de 7. Quartalinha, método DTAS com: (j) janelamento de 9; (k) janelamento de 11. Quarta e quinta linha, (CRIMINISI; PEREZ; TOYAMA, 2004) com os níveis de: (I) janelamento de $9 ;(m)$ janelamento de $11 . \ldots \ldots \ldots$. . . . . . . . . . .

Figura 16 - Comparação com métodos do estado-da-arte considerando-se uma fotografia digital contendo textura e regiões homogêneas, a qual foi danificada artificialmente. (a) Imagem original. (b) Imagem danificada (c) Síntese pura de textura (EFROS; LEUNG, 1999). (d) Mumford-Shad (SCHöNLIEB, 2015). (e) Replicação por blocos (CRIMINISI ; PEREZ; TOYAMA, 2004). (f) Blocos com prioridade remodel ada (L.J.; T.Z.; X.L., 2015). (g) Adobe CAW (WEXLER; SHECHTMAN; IRANI, 2007; BARNES et al., 2009). (h) Método DTAS. . . . . . . . . . . . . . . . . . . . . . . .

Figura 17 - Comparações qual itativas em imagens danificadas artificial mente. (a) Imagem original. (b) Imagem danificada. (c) Síntese pura de textura (EFROS; LEUNG, 1999). (d) Mumford-Shad (SCHöNLIEB, 2015). (e) Replicação por blocos (CRIMINISI; PEREZ; TOYAMA, 2004). (f) Blocos com prioridade remodelada (L.J.; T.Z.; X.L., 2015). (g) Adobe CAW (WEXLER; SHECHTMAN; IRANI, 2007; BARNES et al., 2009). (h) Técnica DTAS. . 
Figura 18 - Comparações qualitativas visando a aplicação de remoção de objetos em imagens di gitais. (a) Imagem original. (b) Imagem contendo os objetos delineados. (c) Síntese pura de textura (EFROS; LEUNG, 1999). (d) MumfordShad (SCHöNLIEB, 2015). (e) Replicação por blocos (CRIMINISI; PEREZ; TOYAMA, 2004). (f) Blocos com prioridade remodel ada (L.J.; T.Z.; X.L., 2015). (g) Adobe CAW (WEXLER; SHECHTMAN; IRANI, 2007; BARNES et al., 2009). (e) Técnica DTAS. . . . . . . . . . . . . . . . . . . 52

Figura 19 - Comparações qual itativas visando a apl icação de remoção de objetos em imagens digitais. (a) Imagem original. (b) Imagem contendo o objeto delineado (criança). (c) Síntese pura de textura (EFROS; LEUNG, 1999). (d) MumfordShad (SCHöNLIEB, 2015). (e) Replicação por blocos (CRIMINISI; PEREZ; TOYAMA, 2004). (f) Blocos com prioridade remodelada (L.J.; T.Z.; X.L., 2015). (g) Adobe CAW (WEXLER; SHECHTMAN; IRANI, 2007; BARNES et al., 2009). (h) Técnica DTAS. . . . . . . . . . . . . . . . . . .

Figura 20 - Comparações qual itativas acerca da tarefa de remoção de objetos em imagens digitais. (a) Imagem original. (b) Imagem contendo o objeto delineado (porta). (c) Síntese pura de textura (EFROS; LEUNG, 1999). (d) MumfordShad (SCHöNLIEB, 2015). (e) Replicação por blocos (CRIMINISI; PEREZ; TOYAMA, 2004). (f) Blocos com prioridade remodel ada (L.J.; T.Z.; X.L., 2015). (g) Adobe CAW (WEXLER; SHECHTMAN; IRANI, 2007; BARNES et al., 2009). (h) Técnica DTAS. . . . . . . . . . . . . . . . . . 54

Figura 21 - Comparações qual itativas para a tar efa remoção de objetos em uma fotografia texturizada. (a) Imagem original. (b) Imagem contendo o objeto delineado (janela). (c) Síntese pura de textura (EFROS; LEUNG, 1999). (d) MumfordShad (SCHöNLIEB, 2015). (e) Replicação por blocos (CRIMINISI; PEREZ; TOYAMA, 2004). (f) Blocos com prioridade remodel ada (L.J.; T.Z.; X.L., 2015). (g) Adobe CAW (WEXLER; SHECHTMAN; IRANI, 2007; BARNES et al., 2009). (h) Técnica DTAS. . . . . . . . . . . . . . . . . .

Figura 22 - Comparações qual itativas levando-se em conta a remoção de um objeto em meio a diversas classes de texturas. (a) Imagem original. (b) Imagem contendo o objeto delineado (pessoa). (c) Síntese pura de textura (EFROS; LEUNG, 1999). (d) Mumford-Shad (SCHöNLIEB, 2015). (e) Replicação por blocos (CRIMINISI; PEREZ; TOYAMA, 2004). (f) Blocos com prioridade remodelada (L.J.; T.Z.; X.L., 2015). (g) Adobe CAW (WEXLER; SHECHTMAN; IRANI, 2007; BARNES et al., 2009). (h) Técnica DTAS. . 
Figura 23 - Comparações qual itativas considerando-se uma imagem contendo diversas regiões de textura (a) Imagem original. (b) Imagem contendo região a ser restaurada. (c) Síntese pura de textura (EFROS; LEUNG, 1999). (d) Mumford-Shad (SCHöNLIEB, 2015). (e) Replicação por blocos (CRIMINISI; PEREZ; TOYAMA, 2004). (f) Blocos com prioridade remodelada (L.J.; T.Z.; X.L., 2015). (g) Adobe CAW (WEXLER; SHECHTMAN; IRANI, 2007; BARNES et al., 2009). (h) Técnica DTAS. . . . . . . . . . . .

Figura 24 - Comparação com métodos de retoque baseados em representação esparsa. (a) Imagens de entrada ("Tissue", "Eaves", "parte da Barbara" e "Fur"). (b) Guleryuz (GULERYUZ, 2006). (c) Elad et al. (ELAD et al., 2005). (d) Fadili et al. (FADILI; STARCK; MURTAGH, 2009). (e) Xu e Sun (XU; SUN, 2010). (f) Li (LI, 2011). (g) Método DTAS. (h) Imagem original. Fonte: (CASACA et al., 2014). . . . . . . . . . . . . . . . . . . 58

Figura 25 - Imagens com diferentes níveis de ruído e seus respectivos contornos. . . . . 62

Figura 26 - Exemplo de fotografia capturada com rúido. . . . . . . . . . . . . 63

Figura 27 - Alterações geradas em uma determinada imagem pela ação dos ruídos gaussiano e impul sivo. (a) Imagem original. (b) Representação no espaço RGB da imagem original com círcul os vermel hos. (c) Imagem af etada pelo ruído gaussiano. (d) Visual ização no espaço RGB daimagem com ruído gaussiano em círcul os verdes. (e) Imagem deteriorada pelo ruído impulsivo. (f) Gráfico em coordenadas RGB da imagem com ruído impulsivo indicado por círculos azuis. Fonte: (ALMEIDA; BOAVENTURA, 2010) . . . . . . . . . . .

Figura 28 - Exemplo clássico de imagem contendo informações geométricas e texturas complexas. (a) mostra a imagem original. (b) apresenta a imagem com ruído

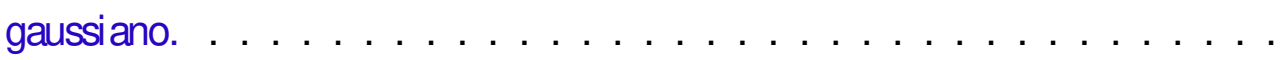

Figura 29 - Representação dos vetores tangencial e ortogonal em uma determinada imagem. Fonte: (CASACA; ALMEIDA; BOAVENTURA, 2013) . . . . . . . .

Figura 30 - Exemplo de eliminação de ruído utilizando a abordagem EDP-NAR. (a) Fotografia ${ }^{2}$ com ruído; (b) imagem restaurada; (c) imagem residual (diferença entre a eb); e (d) representação gráfica do termo de h. . . . . . . . . . . . .

Figura 31 - Ilustração do termo h. O mapeamento definea cor pretapara val ores próximos de zero e branco para o valor 1 . (a) Fotografia ${ }^{3}$ com texturas e regiões homogêneas. (b) Fator regularizador $h=h_{m}(x)$. (c) Termo $t_{s}$. (d) Termo $t_{u}$.

Figura 32 - Di agramailustrando um al goritmo genético e suas princi pais etapas de execução na busca por sol uções ótimas. . . . . . . . . . . . . . . . .

Figura 33 - Eliminação de ruído de imagem colorida. (a) Imagem original, (b) versão com ruído, (c) imagem restaurada pela EDP-NAR e (d) componente residual. Fonte: (CASACA; ALMEIDA; BOAVENTURA, 2013). . . . . . . . . . . 
Figura 34 - Eliminação de ruído de imagem colorida (a) Imagem original, (b) imagem com ruído, (c) versão restaurada pela EDP-NAR e (d) componente residual. Fonte: (CASACA; ALMEIDA; BOAVENTURA, 2013). . . . . . . . . . . .

Figura 35 - Eliminação de ruído de imagem colorida. (a) Imagem original, (b) versão com ruído, (c) imagem restaurada epal EDP-NAR e (d) componente residual. Fonte: (CASACA; ALMEIDA; BOAVENTURA, 2013). . . . . . . . . . . .

Figura 36 - Resultados experimentais obtidos pelo método da EDP-NAR aplicado em uma fotografia com textura. (a) Imagem original, (b) versão deteriorada por ruído com grande intensi dadee (c) imagem restaurada pela EDP-NAR. Fonte: (CASACA; ALMEIDA; BOAVENTURA, 2013). . . . . . . . . . . . .

Figura 37 - Resultados experimentais pelo método EDP-NAR. (a) Imagem original, (b) versão deteriorada por ruído com grande intensidade e (c) imagem restaurada pela EDP-NAR. Fonte: (CASACA; ALMEIDA; BOAVENTURA, 2013). . .

Figura 38 - Comparação dos resultados da fotografia Barbara. (a) Imagem alvo, (b) restaurada por curvelets, (c) por wave atoms, (d) por difusão com termo de fidelidade adaptativa, (e) por difusão TV combinada com curvelet e $(f)$ pela EDP-NAR. Fonte: (CASACA; ALMEIDA; BOAVENTURA, 2013). . . . . 90 



\section{LISTA DE TABELAS}

Tabela 1 - Aval iação quantitativa usando PSNR (em dB) para os resul tados si ntéticos apresentados na seção anterior. . . . . . . . . . . . . . . . . . . . . . . . 56

Tabela2 - Avaliação quantitativa usando SSIM (Structural Similarity Metric) para os resultados si ntéticos apresentados na seção anterior. . . . . . . . . . . . . . 57

Tabela 3 - Avaliação quantitativa usando PSNR (em dB) para todas as comparações com as imagens da Figura 24. . . . . . . . . . . . . . . . . . . . . . 59

Tabela 4 - Tabela contendo as propriedades das imagens utilizadas nos testes. Todas as imagens danificadas foram geradas artificial mente a partir da sua versão original sem ruído. O vetor v representa os parâmetros utilizados no modelo EDP-NAR (veja Equação (3.24)). Fonte: (CASACA; ALMEIDA; BOAVENTURA, 2013).

Tabela 5 - Medida quantitativa cal cul ada para as imagens restauradas com todos os métodos, em comparação com a imagem original Barbara. PSNR entre a imagem original e a imagem com ruído é 22:69 dB. Fonte: (CASACA; ALMEIDA; BOAVENTURA, 2013). . . . . . . . . . . . . . . . . . . . . 89 

INTRODUÇÃO . . . . . . . . . . . . . . . . . 23

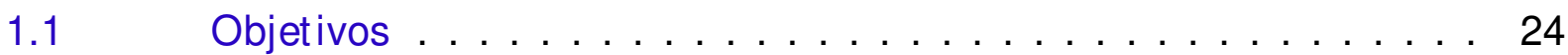

$1.2 \quad$ Contribuições. . . . . . . . . . . . . . . . . . 25

$1.3 \quad$ Organização da tese $\ldots \ldots \ldots \ldots \ldots \ldots \ldots$

2 RETOQUE DIGITAL DE IM AGENS . . . . . . . . . . . . . 27

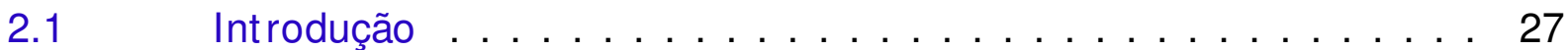

$2.2 \quad$ Métodos destinados ao retoque digital de imagens . . . . . . . . 31

2.2.1 Retoque digital baseado em replicação por blocos . . . . . . . . . 32

2.2.2 Retoque digital baseado em EDPs . . . . . . . . . . . . 33

2.2.3 Retoque digital baseado em representação esparsa . . . . . . . . . . 34

2.2.4 Retoque digital baseado em métodos híbridos e outras abordagens 35

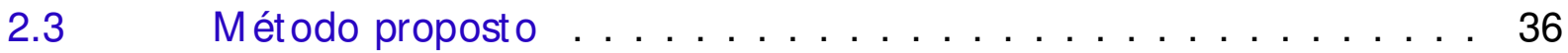

2.3.1 Retoque digital via EDP anisotrópica, equação de transporte e síntese de textura . . . . . . . . . . . . . . . . . . . . . . 37

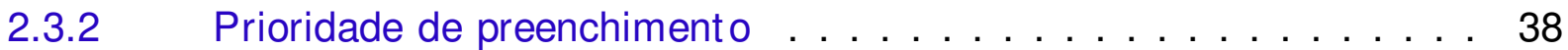

2.3.3 Amostragem dinâmica . . . . . . . . . . . . . . 43

2.3.4 Replicação baseada em blocos . . . . . . . . . . . . . . . . . . 44

$2.4 \quad$ Resultados experimentais . . . . . . . . . . . . . 46

2.4.1 Transferência de padrões e contribuições de $\mathrm{C} ; \mathrm{R}$ e $\mathrm{P} \ldots \ldots$. . . 46

2.4.2 Preenchimento guiado por cartoon . . . . . . . . . . . . 46

2.4.3 retoque de texturas detalhadas . . . . . . . . . . . . . . . 47

2.4.4 Robustez à variação de parâmetros . . . . . . . . . . . . . . 47

2.4.5 Resultados comparativos . . . . . . . . . . . . . 48

2.5 Discussões e limitações . . . . . . . . . . . . . . . . . . . . . 59

3 ELIMINAÇÃO DE RUÍDOS . . . . . . . . . . . . . . 61

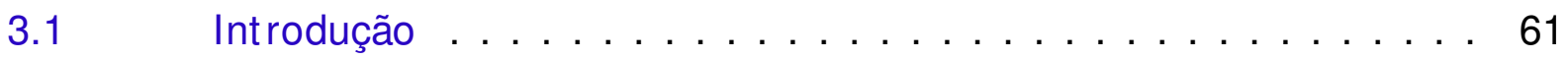

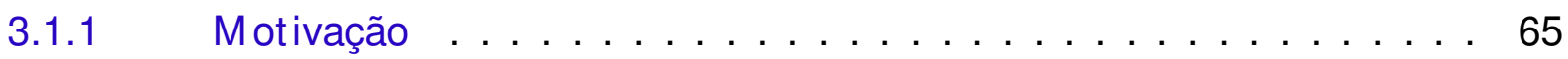

3.1.2 Trabalhos relacionados em eliminação de ruído usando EDPs . . . 67

3.2 Eliminação de rúidos via EDP não-linear anisotrópica regularizada . 72

3.3 Discretização numérica . . . . . . . . . . . . . . . . 80

$3.4 \quad$ Result ados experimentais $\ldots \ldots \ldots \ldots$. . . . . . . . 84 
Referências ........................ 93 
CAPÍTULO

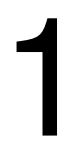

1

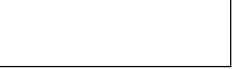

INTRODUÇÃO

Reconstruir imagens digitais com precisão e si gnificativa performance representa nos dias de hoje uma complexa tarefa investigada tanto por comunidades científicas diversas quanto por grandes conglomerados do setor privado e entidades governamentais. Corporações de grande renome nas áreas de tecnologia e visão como Google, Microsoft e o Adobe tem recrutado parte de seu ef etivo para investigar o problema, as quais tem direcionado seus esforços para a criação de novos mecani smos de reconstrução como, também, no aprimoramento das tecnologias já existentes em seus softwares profissionais de edição de imagens tais como o PatchWorks (CRIMINISI; PEREZ; TOYAMA, 2003; CRIMINISI; PEREZ; TOYAMA, 2004) (Microsoft Photo Editor) e o PatchMatch (BARNES et al., 2009; NEWSON et al., 2013) (Adobe Photoshop 6), por exemplo.

O processo de recuperação de uma imagem danificada pode ser interpretado como um problema assistido de visão computacional onde o propósito final é obter uma imagem de boa qual idade levando-se em conta a percepção visual humana, isto é, de forma a minimizar possíveis imperfeições e o surgimento de artefatos na imagem restaurada (GU et al., 2009; MAHALINGAM, 2010; CASACA et al., 2014; CASTRO, 2015). De fato, tal processo requer habilidades artísticas por parte do usuário em termos de familiaridade com a interface gráfica e as ferramentas básicas do editor de imagem em uso, além de ser uma tarefa manual mente dirigida pelo usuário.

Ainda dentro deste contexto, a frente de remoção de objetos em imagens tem também ganhado ampla visibilidade na área de visão por computador. A ideia é extrair um objeto específico da imagem a fim de preservar o máximo possível seu aspecto natural visual. Embora tratar imagens danificadas e o processo de remover um dado objeto diferem em termos da natureza da aplicação, ambos os problemas podem ser tratados da mesma forma quanto à teoria matemática empregada e às ferramentas computacionais envolvidas. De fato, a única diferença aparece na análise quantitativa dos resultados, pois a imagem inicial (ground-truth) pode ser 
usada como parâmetro de avaliação no caso da aplicação de remoção de objetos. Como, a mai oria dessas imagens geral mente são fotografias, é natural esperar a presença de várias regiões compostas por diferentes texturas. Neste caso, a técnica de retoque digital escol hida deve ser capaz de retratar essas regiões adequadamente, visto que muitas abordagens da literatura não são projetadas para tratar regiões texturizadas.

Outro tópico de interesse relacionado à área de restauração de imagens é o de elimi nação de ruídos, em particular o ramo que investiga imagens contendo texturas. De fato, tal problema pode ser interpretado como um problema inverso mal condicionado, jáque a partir da imagem degradada (com ruído), tem-se como objetivo determinar uma estimativa da imagem inicial, na mai oria das vezes sem ter, a priori, nenhuma informação do processo de contaminação por ruído. Em geral, nas aplicações práticas, parte-se da premissa de que a distribuição do ruído na imagem tem características isotrópicas, isto é, não assume-se que determinadas regiões da imagem tenha maior incidência de ruído do que nas demais. Neste caso, é razoável adotar um modelo gaussiano/normal para caracterizar o ruído tal como é relatado na literatura recorrente (PERONA; MALIK, 1990; AZZABOU; PARAGIOS; GUICHARD, 2007; CASACA, 2010; CASACA; ALMEIDA; BOAVENTURA, 2013; YIN; ZHOU, 2010).

Embora o problema de reconstrução de imagens com texturas tenha recebido contribuições importantes nos últimos anos (DEMANET; YING, 2007b; CASACA; ALMEIDA; BOAVENTURA, 2013; ZUO et al., 2014; CHANJUAN et al., 2015), a natureza do problema "textura + ruído" em si dificulta a util lização da mai oria das técnicas tradicionais da literatura, pois do ponto de vista da classificação estatística, ruído e textura apresentam comportamentos bastante similares, ambos caracterizados como regiões de ampla oscil ação local na imagem. Assi m, técnicas de remoção de ruído que, de al guma forma, procuram diferenciar ruído de textura, como nos filtros anisotrópicos, são fundamentais para a obtenção de resultados satisfatórios, tanto em termos de preservação de texturas, bordas e outros el ementos bási cos da imagens como, também, da qualidade visual geral da reconstrução.

\subsection{Objetivos}

Esta tese tem como principal objetivo propor mel horias, estudar, investigar e avaliar duas novas técnicas de restauração de imagens: uma abordando o probl ema de retoque di gital/remoção de obj etos e a segunda direcionada ao problema de el iminação de ruído. Em ambas as abordagens, a ideia é trabal har com imagens contendo texturas e outras características de interesse para um observador humano como a preservação de padrões, bordas, estruturas e regiões de natureza oscilatória

A técnica sobre retoque digital de imagens, inicial mente descrita em (CASACA, 2010) e posteriormente complementada e aperfeiçoada com as mel horias propostas neste trabal ho e descrita em (CASACA et al., 2014), combina difusão ani sotrópica, síntese de texturas e 
busca dinâmica. Assim, dada uma imagem com regiões a serem recompostas, a técnica de difusão ani sotrópica é aplicada à imagem a fim de se obter um mapa de saliência contendo bordas, estruturas e demais informações de baixa frequência da imagem. Na sequência, um novo termo de prioridade baseado em um operador de produto interno é cal culado a partir da combinação do mapa gerado anteriormente com a equação do transporte (BERTALMíO et al., 2000). Tal mecanismo é utilizado para determinar a ordem de preenchimento das partes fal tantes da imagem. Para essa tarefa, a abordagem em questão utiliza uma nova medida de similaridade entre blocos/exemplares de pixels (amostrados di namicamente para acel erar o processo) a fim de encontrar os melhores candi datos a serem al ocados nas regiões danificadas. A eficiência e performance da técni ca proposta são atestadas por meio de anál i ses experimentais qual itativas e quantitativas com outras metodol ogias da literatura.

No contexto de remoção de ruídos, a técnica apresentada inicial mente em (CASACA; BOAVENTURA, 2009) e posteriormente val idada e compl ementada com os resultados obtidos neste trabal ho e aprensentados em (CASACA; ALMEIDA; BOAVENTURA, 2013), alia a teoria da difusão anisotrópica, técnicas de anál ise harmônica e modelos numéricos de discretização de Equações Diferenciais Parciais (EDPs) não-lineares em uma equação diferencial parcial regularizada, a qual atua de forma intensa em regiões mais homogêneas da imagem e de forma mais suave nas regiões caracterizadas como textura e/ou bordas, desse modo é possível preservar tai s características presentes nessas regiões. Além da natureza ani sotrópica, esta EDP procura recompor partes texturizadas perdidas no processo de eliminação de ruído por meio da aplicação de técnicas robustas de análise harmônica (Wave Atoms (DEMANET; YING, 2007b)).

No capítulo destinado à técnica de eliminação de ruído, é apresentada uma descrição em termos de um espaço de escal as para a técnica de eliminação de ruídos, aspectos teóricos e experimentai s fundamentais da equação diferencial. Testes experimentai scom métodos correl atos do estado-da-arte evidenciam a eficácia do método de el iminação de ruído quando aplicado em diversas imagens experimentais contendo texturas.

\subsection{Contribuições}

A relação a seguir sumariza as principais contribuições originadas durante a execução do doutorado e dos trabal hos publicados e apresentados em conferências sobre o tema pesquisado:

(ALMEIDA, 2011; CASACA; BOAVENTURA; ALMEIDA, 2011; CASACA; ALMEIDA; BOAVENTURA, 2013; CASACA et al., 2014).

As principais contribuições desta tese compreendem duas novas metodologias de restauração de imagens digitais com texturas, sendo a primei ra destinada ao problema de retoque digital e a segunda visando sol uções sobre o tópico de elimi nação de ruído. 
Retoque digital de imagens

O método de retoque destinado à restauração de imagens digitais combina:

- Um novo termo de confiabilidade regularizado usado para estabel ecer a prioridade dos pixels no processo de restauração ef etuada por meio da EDP não-linear anisotrópica regularizada;

- Uma nova métrica induzida por um produto interno para cal cular a similaridade entre os bl ocos candidatos e a vizinhanças dos pixels a serem preenchidos.

Eliminação de ruído

O método para remover ruídos em imagens com texturas emprega uma equação diferencial parcial direcionada à restauração de imagens com grande nível de detal hes e contaminadas por ruído gaussiano:

- A qual é fundamentada e val idada de modo teórico e experimental;

- Um estudo dos parâmetros empregados na EDP regularizada;

Uma interpretação da técnica em termos de um espaço de escal as.

Na seção subsequente é apresentado a organi zação dos capítulos deste trabal ho.

\subsection{Organização da tese}

1. Capítulo 2:: Apresenta os fundamentos e al guns conceitos prel imi nares necessários para um melhor entendimento dos tópicos centrais deste trabal ho, a saber, retoque digital e eliminação de ruído.

2. Capítulo 3:: Descreve o método para retoque digital em imagens contendo texturas a partir de uma equação diferencial de difusão ani sotrópica, bem como uma revisão bibliográfica do estado-da-arte, a ém de comparar o desempenho desta metodol ogia com demais técnicas presentes na literatura.

3. Capítulo 4:: Apresenta o método de el iminação de ruídos em i magens com texturas por meio de uma EDP regularizada, bem como uma revisão dos principais trabal hos nessa área e também uma aval iação dos resul tados obtidos com a EDP regul arizada.

4. Capítulo 5:: Sintiza os assuntos abordados nesta tese e suas princi pai s contribuições, bem como as conclusões desta tese e os trabal hos futuros. 


\section{RETOQUE DIGITAL DE IMAGENS}

O problema de retoque digital (inpainting) em imagens e as principais técnicas presentes na literatura dentro deste contexto são apresentadas neste capítulo. A Seção 2.3 descre as ideias fundamentais presente nos métodos de retoque digital. Nas Seções 2.3.1-2.3.4 são descritos todos os detal hes sobre o método de retoque digital que combina difusão anisotrópica, equação do transporte, amostragem dinâmica e síntese de textura (DTAS); na Seção 2.4 são apresentados os resultados exerimentais real izados com a técnica DTAS e também comparações com diversas técnicas do estado da arte; Na Seção 2.5 são di scutidas al gumas características elimitações da técnica DTAS.

\subsection{Int rodução}

Em 1964 iniciou-se a utilização de técnicas de computação para o melhoramento de imagens, produzi das por uma sonda espacial, quando imagens da Lua foram processadas para corrigir vários tipos de distorções inerentes às câmeras de televisão a bordo (GONZALEZ; WOODS, 2007). Com o crescimento da área de processamento de imagens, al ém de aplicações no programa espacial, técnicas de restauração de imagens vem sendo empregadas com sucesso para resolver uma grande variedade de problemas práticos. Alguns exemplos são os probl emas presentes nas frentes de nanotecnol ogia, biologia, edição artística, eradiografia, entre outras mais. A fim de anal isar e real izar uma interpretação dos resultados dessas aplicações, a intervenção humana geral mente se faz necessária para o auxílio e aprimoramento de técnicas capazes de melhorar a qualidade da informação presente em uma imagem.

Em termos matemáticos, uma imagem pode ser considerada como uma aplicação $f$ de uma região do plano na reta. Cada ponto $(x ; y)$ desta região do plano é associado a um pixel da imagem e cada val or $f(x ; y)$ indica a intensi dade lumi nosa (também chamada de bril ho ou nível de cinza) da imagem. No caso de uma imagem col orida no espaço de cores RGB, sistema que utiliza como cores básicas o vermel ho (R), o verde (G) e o azul (B), a aplicação $f$ associa 
cada ponto do domíni o a uma intensi dade lumi nosa para cada componente de cor. Dessa forma, podemos considerar uma imagem como uma aplicação

$$
f: D \subset R^{2} \rightarrow R^{k}
$$

na qual $D$ é a região do plano onde a imagem está definida (em geral adotase um retângulo de forma a ter uma anal ogia com a representação da imagem no computador). Para $k=1$ temos uma imagem monocromática ou em escala de cinza e para $\mathrm{k}=3$ estamos lidando com uma imagem colorida no espaço RGB.

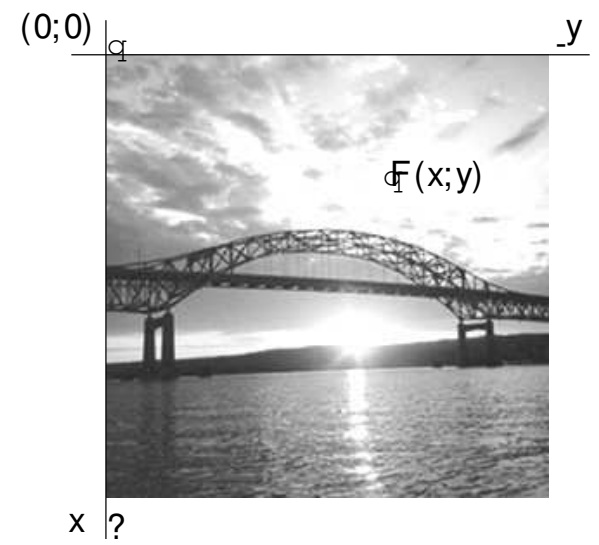

Figura 1 - Eixo para representação de imagens.

A Figura 1 ilustra umaimagem em escal a de cinza, naqual um ponto $(x ; y) \in D$ representa a local ização, ou coordenadas espaciais, de um ponto na imagem e seu val or $f(x ; y) \in R$ indica o nível de cinza da imagem $f$ do ponto $(x ; y)$. Os eixos $x$ e y utilizados na representação de uma imagem são trocados em relação ao eixo cartesiano usual, assim como o sentido crescente no eixo vertical.

No caso das imagens coloridas, os valores $f(x ; y)=\left(f_{1}(x ; y) ; f_{2}(x ; y) ; f_{3}(x ; y)\right) \in R^{3}$ representam a intensidade luminosa da imagem $f$ no ponto $(x ; y)$. As componentes $f_{1}(x ; y)$, $f_{2}(x ; y)$ e $f_{3}(x ; y)$ correspondem, respectivamente, ao brilho daimagem $f$ para oscanais vermelho, verde e azul no ponto $(x ; y)$. Cada canal de cor é considerado como uma imagem em escal a de cinza, isto é, $f_{1} ; f_{2} ; f_{3}: D \subset R^{2} \rightarrow R$. A Figura 2 mostra uma imagem colorida e seus canais representados por imagens em escal a de cinza.

Para adequar o conceito de imagem ao processamento computacional, a aplicação f deve ser digitalizada tanto espacialmente quanto em brilho. A região na qual a imagem está definida geral mente é constituída por um retângulo com um vértice na origem earestas nos eixos, como ilustra a Figura 1. Uma di scretização usual deste retângulo é real izada com uma mal ha igual mente espaçada em ambas as coordenadas, utilizando-se um passo de comprimento igual a 1 , isto é, $x_{i}=i-1$, com $i=1 ; 2 ;:: ; ; m$ e $y_{j}=j-1$, com $j=1 ; 2 ;:: ; n$. Os valores $m$ e $n$ referem-se, respectivamente, ao tamanho da imagem na vertical e na horizontal. A quantidade de níveis de cinza é dada geral mente em termos de potências de 2 . Uma prática comum é utilizadar 


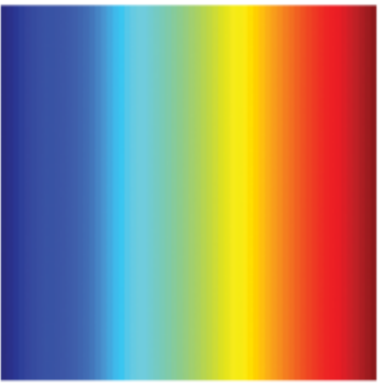

(a) Imagem colorida

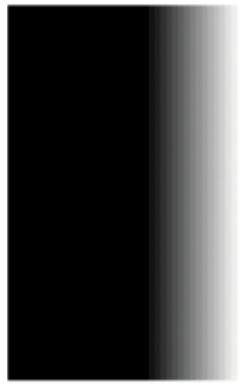

(b) Canal vermelho.

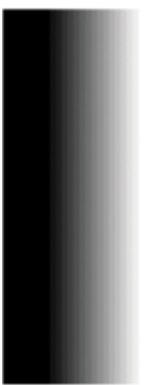

(c) Canal verde.
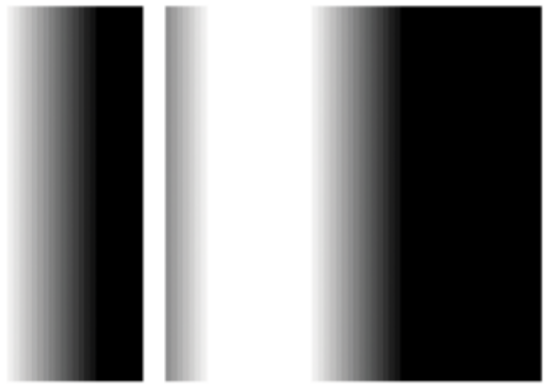

(d) Canal azul.

Figura 2 - Imagem col orida no espaço RGB e seus respectivos canais de cores.

256 níveis de cinza. Sua discretização é feita com uma mal ha de passo igual a um, na qual o val or 0 representa o nível de cinza correspondente a cor preta e o 255 a cor branca.

Dessa forma, uma imagem digital em escal a de cinza pode ser considerada como uma matriz [ $\left.f_{i j}\right]_{m \times n}$, cujos índices das linhas e das colunas identificam a posição de um ponto na imagem e o correspondente val or do elemento indica o seu nível de cinza, como ilustra a Equação (2.2).

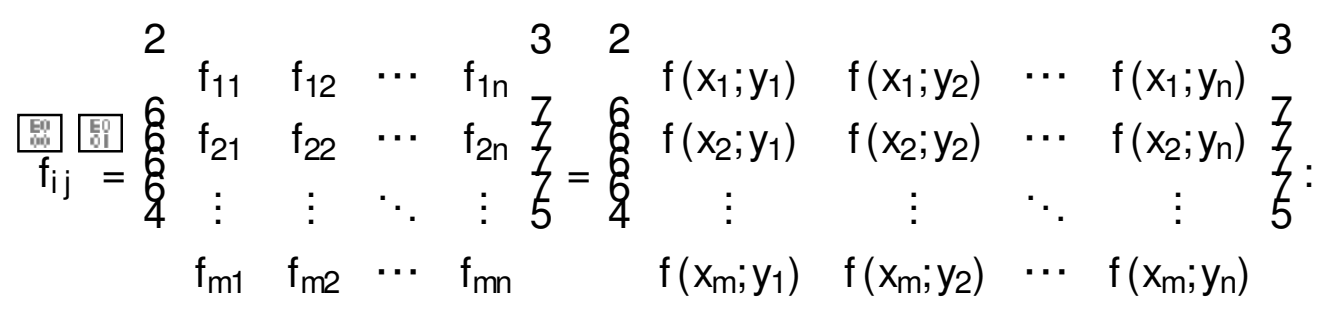

Para uma imagem digital colorida, cada canal de cor é representado por uma matriz. Os métodos descritos neste trabal ho partem do princípio de que as imagens consideradas são imagens digitais discretizadas.

Conceitos básicos de retoque digital de imagens

O termo retoque refere-se à prática artística de restaurar pinturas antigas, quando ge ral mente era necessário completar uma determinada região cujas informações foram perdidas. Assi $m$, a ideia chave do retoque di gital é traduzir o conceito de retoque para o ambito digital, de forma a simular o processo de restauração manual por meio de um programa de computador.

Com o intuito de utilizar técnicas de retoque em imagens digitais, éimportante descrever al guns conceitos básicos destas abordagens (GONZALEZ; WOODS, 2007):

Borda, beira ou extremidade: é o limite entre duas regiões com propriedades distintas de brilho/lumi nosidade, diretamente rel acionadas à mudanças bruscas dos níveis de cinza entre tais regiões; 
- Fronteira ou contorno: é a linha que "fecha" ou "limita" exteriormente uma determinada região $\mathrm{R}$, que é denotada por $\partial \mathrm{R}$;

- Domínio de retoque: é a região que deverá ser restaurada/recomposta por meio do processo de retoque, a qual será denotada por W;

- Máscara: é uma imagem auxiliar bi nária que delimita apenas a região do domínio de retoque (1 na região de retoque e 0 no restante da imagem).

Na Figura 3a tem-se a famosa fotografia de Abraham Lincoln tirada por Alexander Gardner, em 1865. Nesta imagem, um provável domínio de retoque é a marca presente na parte superior dafoto. A Figura 3b ilustra a máscara desse domínio de retoque, na qual a região de cor branca representa a região a ser restaurada.

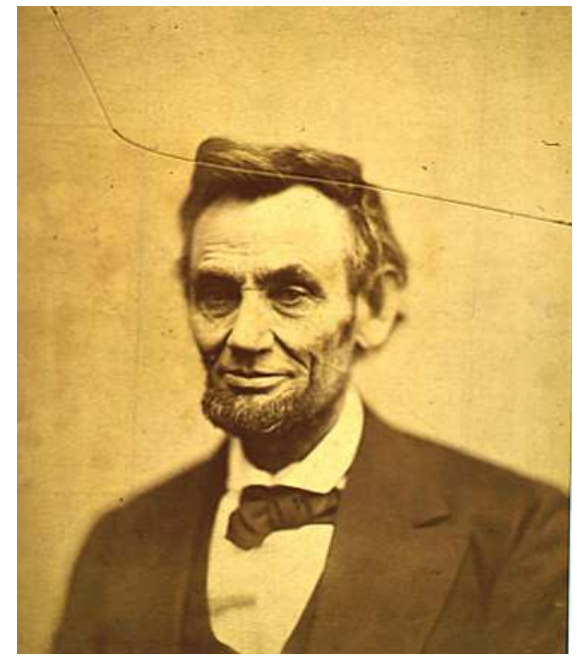

(a) Fotografia com vinco.

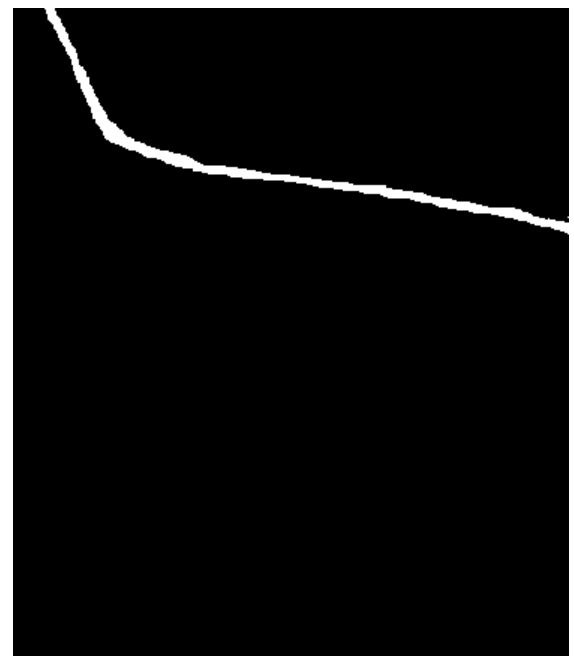

(b) Máscara da região danificada.

Figura 3 - Exemplo de domínio de retoque e máscara.

\section{Retoque digital por equações diferenciais parciais}

Em geral, model os de retoque digital formulados a partir de equações diferenciais têm se destacado nesse cenário na intenção de produzir al goritmos práticos para tratar problemas de recomposição, desoclusão ou edição de imagens e fotografias digitais. Matematicamente, o retoque por equações diferenciais fundamenta-se no processo de evolução temporal dessas equações, isto é, a partir da imagem inicial f , cal cula-se a sol ução da equação em sucessivos instantes da escal a temporal, gerando assim, versões subsequentes da imagem f "mel horadas" a cada nível progredido no tempo. Numericamente, este problema pode ser interpretado da seguinte forma:

Seja f uma imagem discreta em níveis de cinza O objetivo do retoque digital é gerar uma família de imagens $\mathrm{f}_{\mathrm{ij}}(\mathrm{t}): \mathrm{D} \times \mathrm{R} \rightarrow \mathrm{R}$, tal que 


$$
f_{i j}(0)=f_{i j} \quad e \quad \lim _{t \rightarrow \bullet} f_{i j}(t)=f_{i j}^{R}
$$

em que $\mathrm{f}_{\mathrm{i} j}^{\mathrm{R}}$ é a imagem obtida após aplicarmos um determinado processo recursivo originado a partir de um modelo de retoque. De modo geral, esses al goritmos assumem a forma

$$
f_{i j}(t+D t)=f_{i j}(t)+D t L ;
$$

na qual L é um operador que envolve a equação central do modelo a ser considerado.

Dessa forma, após ser aplicado um número considerável de iterações, isto é, para t suficientemente grande, obtemos

$$
f_{i j}(t)=f_{i j}^{R}
$$

sendo $f_{i j}^{R}$ a imagem restaurada gerada pel o modelo de retoque a partir da imagem inicial $f$.

\subsection{Métodos destinados ao retoque digital de imagens}

O problema de retoque digital de imagens tem recebido grande atenção por parte da comunidade científica na úl tima década, pri ncipal mente devido ao crescimento de importantes aplicações no cenário foto-artístico, tais como reconstituição e edição de imagens, as quais dependem fortemente de mecanismos de retoque para serem eficazes. As técni cas de retoque podem ser organizadas de diferentes formas, isto é, de modo a levar em conta características intrínsecas tanto da model agem matemática associada quanto à interface de interação com o usuário para a execução final do retoque (SUN et al., 2005; KWOK; WANG, 2009; CASACA et al., 2014; CASACA et al., 2015). Neste trabal ho, vamos separar os métodos de retoque em quatro grupos principais:

- Métodos baseados em replicação por blocos;

- Métodos baseados em EDP e modelagem variacional;

- Métodos baseadas na transf ormação do espaço e em representação esparsa; e

- Outros métodos e técnicas que combinam as abordagens anteriores.

A seguir, apresentamos uma visão geral dos métodos de retoque organizados de acordo com os grupos citados. 


\subsubsection{Retoque digital baseado em replicação por blocos}

O objetivo na síntese de textura é restaurar as informações perdi das da imagem por meio de uma estratégia de "copiar e colar" real izada após buscar por padrões de textura presentes na imagem segundo uma medida de si milaridade entre os pixels (EFROS; LEUNG, 1999; EFROS; FREEMAN, 2001; ASHIKHMIN, 2001; WEI, 2002). A avaliação de texturas sintetizadas é feita, em geral , de forma subjetiva, uma vez que não há um critério formal bem definido para sua aval iação em abordagens práticas. A Figura 4 ilustra o processo de síntese de textura em imagens digitais ao considerá-lo como sendo a tarefa de criar uma nova textura, de qual quer tamanho, que quando apreciada por um observador pareça ter sido obtida a partir de uma textura inicial (WEl, 2002).

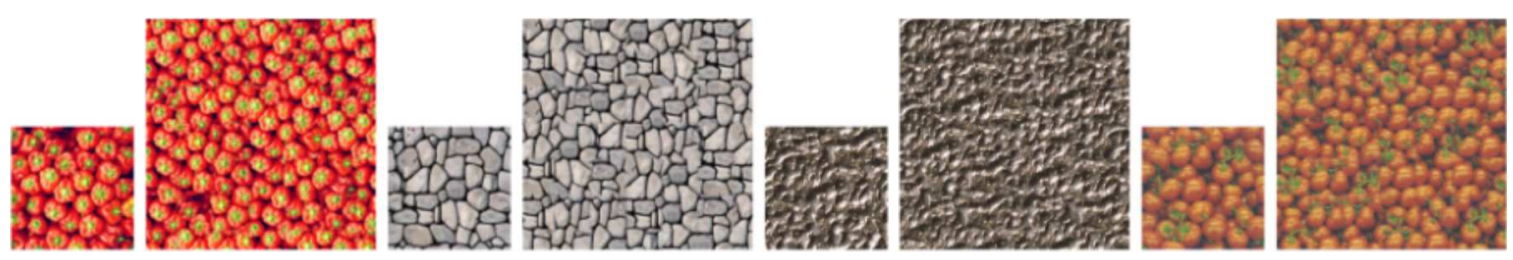

Figura 4 - Exemplos do processo de síntese de textura. Fonte: (RECAS; HILSMANN; EISERT, 2011).

Neste contexto, uma medida da si milaridade entre um grupo de pixel s da imagem e os pixels que estão no limite do domíno de retoque pode ser utilizada para descobrir um grupo de pixels que mel hor se encaixa em uma determi nada região a ser preenchida. Técnicas de síntese de textura são eficazes quando a imagem é formada por um único padrão de textura, mas são propensas a fal har quando a imagem contém mais de um padrão de textura ou ainda, quando a mesma apresenta estruturas e regiões de naturezas mais homogêneas. Além disso, o custo computacional envolvido nos al goritmos baseados em síntese de textura também é um obstáculo em aplicações práticas na área.

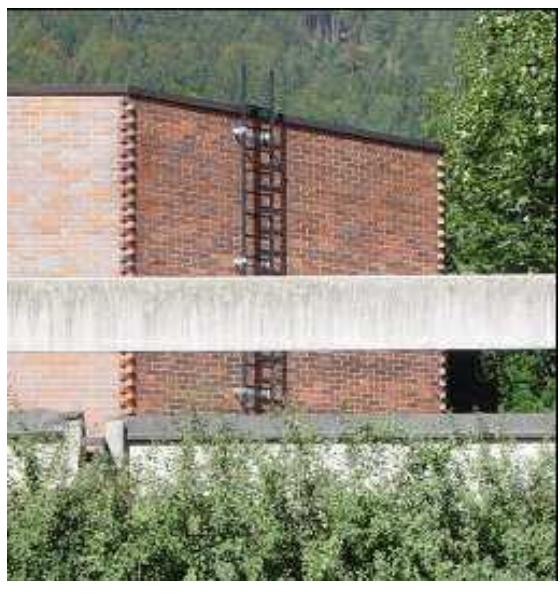

(a)

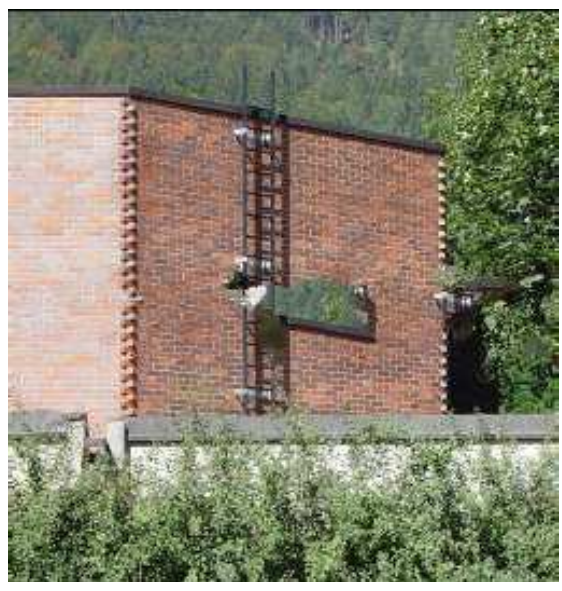

(b)

Figura 5 - Restauração inconsistente devido a problemas na amostragem, pois texturas de árvores foram introduzidas na região da uma parade de tijolos. (a) Imagem a ser reconstruída (faixa central). (b) Imagem restaurada com preenchimento incoerente. Fonte: (GROSSAUER, 2004). 
Algoritmos de síntese de textura foram modernizados significativamente pelas técnicas de retoque baseadas em repli cação de blocos. Esta classe de técnicas utili za o mecanismo de síntese de textura em blocos de pixels, além de também impor uma ordem de prioridade durante o processo de restauração, conforme descrito em (KOMODAKIS; TZIRITAS, 2007; LI; ZHAO, 2011; CAO et al., 2011; CRIMINISI; PEREZ; TOYAMA, 2004; SUN et al., 2005).

Um bloco (também chamado de vizinhança ou janela), de modo geral, é um conjunto contendo el ementos de uma matriz quadrada com dimensão pequena, ou seja, uma vizinhança de tamanho $n$ centrado no pixel $p=f_{i j}$ é um bloco com dimensões $m \times m$, com $n=(m-1)=2$. O tamanho $\mathrm{m}$ do bloco é tomado como sendo um número natural ímpar para que o pixel p seja o centro do bloco. Desse modo, um bloco de dimensões $m \times$ m centrado no pixel p é o conjunto de pontos

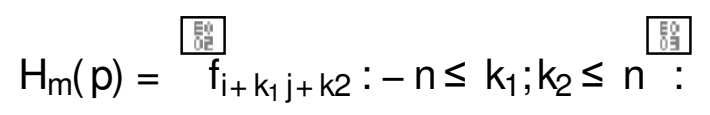

No trabalho clássico (CRIMINISI; PEREZ; TOYAMA, 2004), os autores definem a ordem de preenchimento com base nas isófotas da imagem (linhas de mesma tonalidade na imagem). Dado o domínio de retoque We o pixel $p \in \partial W$ a ser restaurado, o algoritmo real iza uma busca global em toda a extensão válida da imagem $W \mathcal{C}$ para sel ecionar o bloco de pixels mais adequado para preencher a vizinhança de p. Melhorias em (CRIMINISI; PEREZ; TOYAMA, 2004) foram propostas em diversos trabal hos da literatura tais como (CHENG et al., 2005; CHEN; ZHANG; LIU, 2007; CAI; CHAN; SHEN, 2008). A pesar das técni cas baseadas em replicação por blocos consegui rem produzir bons resultados, el as são mais suscetíveis a gerar incongruências visuais ao executar uma busca em toda extensão da imagem, como ilustra a Figura 5 (GROSSAUER, 2004). Além disso, o mecanismo de busca é oneroso em termos computacionai s e propenso a obter resul tados não-real istas, uma vez que blocos de pixels que estão longe do domínio de retoque também são considerados na etapa de busca.

\subsubsection{Retoque digital baseado em EDPs}

Ao contrário das abordagens baseadas em síntese de textura, métodos baseados em EDPs são eficazes quando aplicados em imagens não texturizadas, apresentando também um custo computacional menos restritivo. O uso de equações diferenciais no contexto de retoque foi introduzido por Bertal mi o et al. (BERTALMíO et al., 2000), propondo uma equação diferencial de tercei ra ordem que simula o processo manual de restauração realizado por restauradores artísticos profissionais em obras de arte. A EDP transporta informações por meio de curvas isófotas da imagem ao aplicar um filtro de difusão ani sotrópica para corrigir a evolução da direção do retoque. Na linha de (BERTALMíO et al., 2000), os autores em (SHEN; CHAN, 2002) apresentaram uma EDP de difusão usando o princípio de mi ni mização da variação total 
(TV), a qual minimiza os gradientes da imagem de forma a preservar o padrão de tonal idade dos pixels periféricos do domínio de restauração. Uma melhoria de (SHEN; CHAN, 2002) foi proposta em (DEMANET; SONG; CHAN, 2003) a fim de resolver o problema relacionado com o Princípio de Conectividade (KANIZSA, 1979), o qual al ega que linhas quebradas tendem a ser ligadas de uma forma inconsciente pela mente humana. Dessa forma, os autores fazem uso do fluxo de curvatura média para modificar o coeficiente de condutividade da EDP resultante da modelagem tradicional de (SHEN; CHAN, 2002).

Outras abordagens baseadas em EDP também foram propostas, como o método descrito em (TSCHUMPERLÉ; DERICHE, 2005), o qual produz bons resul tados quando aplicado em pequenas regiões de retoque, masé mui to sensível à escol ha de parâmetros. Em (BORNEMANN; MäRZ, 2007), foi proposta uma técnica rápida e eficaz combinando uma equação de transporte não iterativa e um al goritmo de "marcha rápida" (fast marching scheme). No entanto, esta técnica exige o ajuste adequado de um grande número de parâmetros. Uma abordagem baseada na variação total de subgradiente que resul ta em uma boa recuperação da imagem foi apresentada em (BURGER; HE; SCHöNLIEB, 2009), mas seu uso élimitado à imagens em tons de cinza. Em (WEN-ZE; ZHI-HUI, 2008) foi proposta uma EDP bastante interessante que preserva mui to bem as bordas ao restaurar imagens não texturizadas, porém, tais resultados satisfatórios são apenas atingidos para essa classe de imagens.

Uma desvantagem comum dos métodos baseados em EDPsé o ef ei to intensivo de suavização introduzido na região restaurada. De fato, esses métodos são mais eficazes quando aplicados em regiões pequenas de retoque, mas costumam fal har em áreas de dimensões moderadas ou grandes.

\subsubsection{Retoque digital baseado em represent ação esparsa}

Os chamados métodos baseados em representação esparsa foram introduzidos com grande aceitação no contexto de retoque. Este grupo de técni cas não opera no domínio cartesiano da imagem, mas sim em domíni os transformados, tais como os obtidos por DCT (Discrete Cosi ne Transform), wavel ets (MALLAT, 2008), curvel ets (CANDèS et al., 2006) e wave atoms (DEMANET; YING, 2007b). Métodos baseados em representação esparsa assumem que é possível representar uma imagem por uma combinação esparsa de um determinado conjunto de transformações, na qual os pixels não preenchidos são hierarquicamente ordenados e estimados por tais transformações.

O trabal ho pioneiro de Guleryuz (GULERYUZ, 2006) computa de forma adaptativa os dados a serem restaurados ao atual izar a correspondente representação esparsa da imagem através da DCT ou de uma transformada do tipo wavelet. Em (ELAD et al., 2005), a tarefa de reconstrução é real izada por meio de um esquema de decomposi ção que divide a imagem a ser restaurada em duas camadas, chamadas de cartoon e componentes de textura. Desse modo, o retoque é realizado em ambas as camadas, usando uma técnica de representação esparsa. Em 
(XU; SUN, 2010) também foi utilizada uma representação esparsa para propagar trechos de acordo com a combi nação linear esparsa de "trechos candidatos" a preencher esta região.

Técni cas de retoque nesta categoria baseadas na anál ise de di spersão podem ser utilizadas sob a perspectiva estatística de modelagem bayesiana. Fadili et al. (FADILI; STARCK; MURTAGH, 2009) realizaram o retoque resolvendo um problema de estimação de dados perdidos com base em uma abordagem bayesiana combinada com um al goritmo de EM (Expectation Maximization). Um modelo bayesiano utilizando, simultaneamente, representações esparsas locais e não-locais foi proposto em (LI, 2011), no qual um esquema de otimização DA (Deterministic Annealing) é empregado para reduzir a carga computacional da técnica. De um ponto de vista prático, embora os métodos baseados em decomposi ção esparsa possam produzir resul tados agradáveis (especial mente para restaurar regiões geométricas bem definidas como blocos/retângulos), eles tendem a apresentar borramento ao restaurar regiões grandes e não regulares. Além disso, o custo computacional em geral também é visto como um obstáculo para esses métodos.

2.2.4 Retoque digital baseado em métodos híbridos e outras abordagens

Com o objetivo de preservar as estruturas relevantes da imagem, abordagens híbridas têm si do propostas na literatura a fim de explorar as propriedades de cada uma das três metodologias de retoque descritas anteriormente. Um exemplo interessante é a associação entre as abordagens de replicação de textura, EDP e model os variacionais tal como proposto em (KOMODAKIS; TZIRITAS, 2007; CAO et al., 2011; BUGEAU; BERTALMÍO, 2009; BERTALMíO et al., 2003; GROSSAUER, 2004; AUJOL; LADJAL; MASNOU, 2010; BUGEAU et al., 2010). Em (BERTALMÍO et al., 2003), por exemplo, o objetivo é decompor uma dada imagem $f$ em dois componentes: o cartoon u e a textura $v$, e processar cada componente de forma independente. Os componentes u e v preservam estruturas geométricas e padrões de textura de $\mathrm{f}$, respectivamente. Assim, a decomposição deve satisfazer a relação a priori

$$
f=u+v \text {, }
$$

de acordo com o model o de decomposição teórica cartoon/textura si multâneo (MEYER, 2002), o qual foi discretizado em (VESE; OSHER, 2003; VESE; OSHER, 2006) e mais tarde empregado como um esquema numérico para garantir a val idade da equação (2.7). Depois da decomposi ção, o método de retoque (BERTALMíO et al., 2000) e o al goritmo de síntese de textura (EFROS; LEUNG, 1999) são aplicados em u e v, respectivamente. Ambos os resultados são combinados usando a equação (2.7), de modo a gerar o resultado final. O custo computacional é al to para real izar tais processamentos, principal mente quando a lacuna a ser recuperada é grande. Ainda nessa linha, em (AUJOL; LADJAL; MASNOU, 2010) os autores propõem uma formulação com base em model os variacionai s contínuos em um esforço para adaptar al goritmos de repl icação por blocos para lidarem com características geométricas enquanto restauram texturas. 
Existem também métodos que expl oram o problema de retoque por meio de técnicas de otimização/minimização de funcionais de energia tais como em (WEXLER; SHECHTMAN; IRANI, 2007; KAWAI; SATO; YOKOYA, 2009; KOMODAKIS; TZIRITAS, 2007; LIU; CASELLES, 2013). Wexler et al. (WEXLER; SHECHTMAN; IRANI, 2007) formulam o processo de reconstrução como um probl ema de otimização o qual emprega uma combinação de estruturas deárvore e dinâmicas do tipo espaço-tempo (space-time). Em (KAWAI; SATO; YOKOYA, 2009) foram feitas modificações no funcional de energia proposto em (WEXLER; SHECHTMAN; IRANI, 2007) para melhorar a localização espacial dos pesos de si milaridade e a invariância a brilho. A técnica apresentada em (KOMODAKIS; TZIRITAS, 2007) usa variações do al goritmo de soma e produto para grafos com ciclos (loopy belief propagation) associados à programação de mensagens baseada em prioridade (priority-based message scheduling) durante o processo de restauração. Ainda na direção de resol uções via oti mização, o model o baseado em blocos descrito em (DEMANET; SONG; CHAN, 2003) foi reformulado em (LIU; CASELLES, 2013) como um probl ema de otimização gl obal que codifica as informações de textura e estrutura, no qual o minimizador é obtido ao resolver um problema de particionamento de grafos.

Outros métodos interessantes de retoque têm sido propostos com sucesso na literatura Em (HAYS; EFROS, 2008) e (LI et al., 2010) foi usado um enorme banco de imagens criado a partir da web para descobrir o melhor conjunto de imagens que se aproxima da imagem danificada. Este conjunto é então usado para identificar cores, texturas e padrões na imagem danificada, al ém de viabilizar também operações de correspondência entre a respectiva lacuna na imagem alvo e suas partes correspondentes nas imagens de referência.

\subsection{Método proposto}

Motivados pelas ideias apresentadas em (CRIMINISI; PEREZ; TOYAMA, 2004; BERTALMíO et al., 2000; BERTALMÍO et al., 2003; CALVETTI; SGALLARI; SOMERSALO, 2006) naintenção de lidar com os efeitos adversos descritos anteriormente, propomos as seguintes modificações e mel horias no método de retoque descrito em (CASACA, 2010) :

- Um novo termo de confiança regularizado para definir a ordem de preenchimento dos pixels na fronteira da região W;

- Uma nova métrica de si milaridade induzida por um produto interno e guiada pela imagem componente cartoon para melhor avaliar a semel hança entre os pixels a serem preenchidos na região We os seus possíveis candidatos. 
2.3.1 Retoque digital via EDP anisotrópica, equação de transporte e sínt ese de textura

O método de retoque que combina difusão ani sotrópica, equação do transporte, amostragem dinâmica e síntese de textura (DTAS) empregado para restaurar imagens com texturas e proposto inicial mente em (CASACA, 2010) é apresentado a seguir. A contribuição desta pesquisa consiste em propor melhorias e aperfeiçoar este método de retoque de modo a torná-lo mais eficiente e eficaz na tarefa de retoque digital de imagens com texturas. Os resultados obtidos no decorrer deste trabal ho foram publicados em (CASACA et al., 2014).

Inicial mente, o método de retoque considera o componente cartoon u obtido a partir de uma decomposição da imagem digital f . Conforme citado anteriormente, o propósito da decomposição cartoon e textura é separar a informação de natureza geométrica (cartoon) das regiões caracterizadas pel a presença de textura e/ou outros detal hes de caráter oscilatório presentes naimagem. Dessa forma, uma imagem pode ser representada por uma soma de dois componentes bem definidos: o componente contendo o cartoon u e o componente $v$ mapeando as texturas presentes na imagem inicial $f$, de modo que

$$
f=u+v \text {. }
$$

A Figura 6 mostra uma decomposição do tipo cartoon e textura. A imagem 6b mostra o componente $u$ que representa o cartoon da imagem inicial $f$ (apresentada em 6a). O componente $v$ contendo as texturas é também ilustrado em $6 \mathrm{c}$.

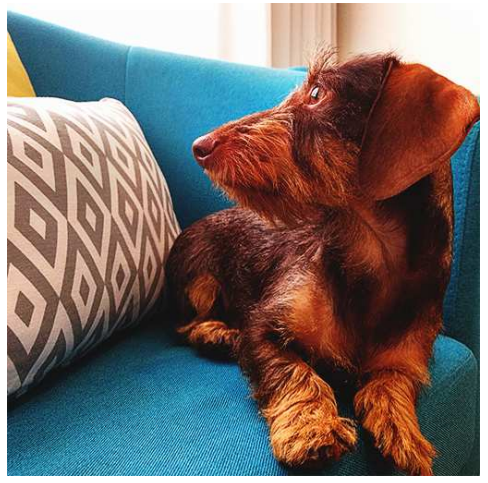

(a)

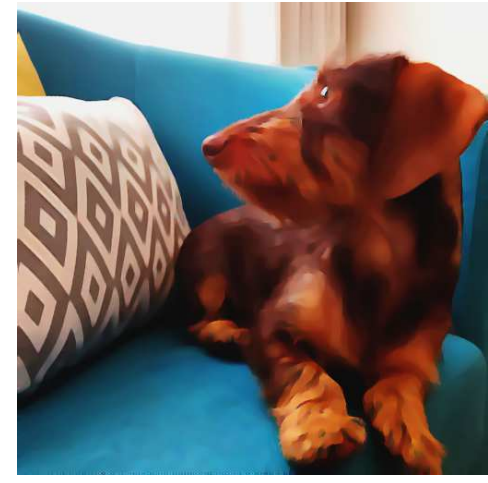

(b)

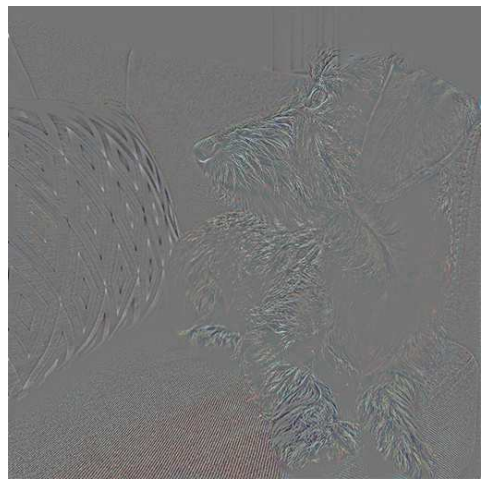

(c)

Figura 6 - Exemplo de decomposição do tipo cartoon e textura: $f=u+v$. (b) Componente cartoon u. (c) Componente textura $v$.

As técnicas para obter uma decomposição cartoon e textura podem ser classificadas em: simultânea e não-simultânea. As técnicas simultâneas (MEYER, 2002; VESE; OSHER, 2003; AUJOL; CHAMBOLLE, 2005; LEVINE et al., 2005; LIEU, 2005; YIN; GOLDFARB; OSHER, 2005; ESEDOGLUY; CHAN; PARKY, 2007; GARNETTA J. B.; LEA, 2007) visam obter de uma única vez tanto o termo estrutural u quanto o termo oscilatório v. Nas técnicas nãosi mul tâneas, obtem-se inicial mente uma aproximação para u para depois obter $v=f-u$. Nesta 
categoria, várias abordagens foram derivadas de model os inicial mente propostos para remover ruído, como é o caso do modelo variacional clássico proposto em (RUDIN; OSHER; FATEMI, 1992) e de outras metodologias existentes na literatura que podem ser utilizadas para esta mesma final idade (MA; PLONKA, 2007; BURGER et al., 2006; BARCELOS; BOAVENTURA; JR, 2003; STARCK; CANDèS; DONOHO, 2002; CHAN; OSHER; SHEN, 2001; PERONA; MALIK, 1990).

A decomposição cartoon e textura empregada no método de retoque digital DTAS é do tipo não-simultânea e utiliza uma equação de difusão ani sotrópica proposta em (BARCELOS; BOAVENTURA; JR, 2003). Em seguida, um novo termo de confiança regularizado é utilizado para definir a ordem de preenchimento dos pixels na frontei ra da região W. Para ef etivamente prencher a região W, um bloco de pixel s ótimo é atribuído dinamicamente a cada bl oco fal tante por meio da amostragem di nâmica. Neste processo dinâmico, uma nova métrica orientada pelo cartoon é utilizada para quantificar a semelhança entre os blocos de pixels. A Figura 7 apresenta um esquema para representar as etapas do método de retoque DTAS.

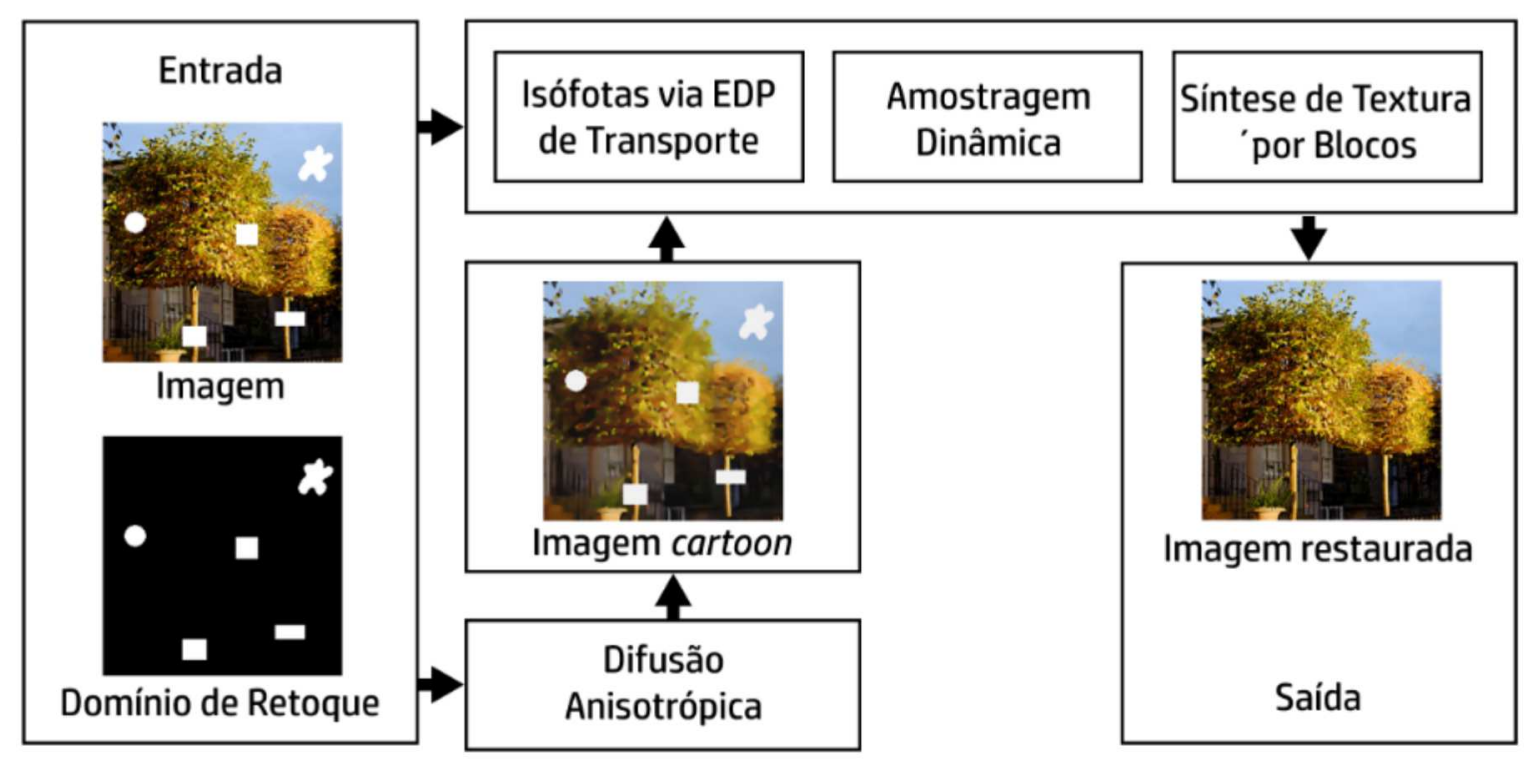

Figura 7 - Diagramailustrativo do método de retoque DTAS.

\subsubsection{Prioridade de preenchimento}

Considere uma imagem $f$, em escal a de cinza ou col orida no sistema RGB, Wa região da imagem ser restaurada e $\partial W$ sua fronteira.

Abordagens baseadas no operador Laplaciano

$$
D=\frac{\partial^{2}}{\partial x^{2}}+\frac{\partial^{2}}{\partial y^{2}}
$$


podem ser utilizadas para identificar estruturas em uma imagem. Por ser um operador de segunda ordem, geralmente o Laplaciano (2.9) fornece uma imagem suavizada que retem bordas e descarta detal hes oscilatórios (PARAGIOS; CHEN; FAUGERAS, 2005).

O operador Laplaciano foi explorado com sucesso em (BERTALMíO et al., 2000) para obter um método de retoque baseado na equação de transporte

$$
\frac{\partial \mathrm{I}}{\partial \mathrm{t}}=-(\mathrm{DI}) \cdot-\stackrel{\perp}{-} \mathrm{I}
$$

Como consequência do processo de suavização, o operador Laplaciano D pode ser utilizado para obter uma imagem I sem textura. Além disso, a Equação (2.10) realiza o transporte de informações na direção do vetor —-I. Segundo (BORNEMANN; MäRZ, 2007) a Equação (2.10) pode ser reescrita como:

$$
\frac{\partial \mathrm{I}}{\partial \mathrm{t}}=-\stackrel{\perp}{-}(\mathrm{DI}) \cdot \rightarrow \text { : }
$$

Dessa forma, ela descreve o transporte de I ao longo do campo de vetores —- (DI). Este campo representa o modelo de Marr-Hildreth (MARR; HILDRETH, 1980) para detecção de bordas e define a ori entação dos isófotos de DI . Isto permi te que o operador Laplaciano seja usado na identificação linhas de nível e no transporte de informações de uma imagem.

O transporte de inf ormações em uma ordem inadequada pode prejudicar o processo de restauração de uma imagem di gital (CRIMINISI; PEREZ; TOYAMA, 2004; HARRISON, 2001). A Figura 5 ilustra uma situação em que a restauração da imagem foi prejudicada por conta da escolha equivocada na ordem de preenchimento da região $\mathrm{W}$.

A utilização dos isófotos da imagem, cal culados diretamente a partir da imagem de entrada $f$, são frequentemente utilizados em abordagens clássicas para defini $r$ a ordem de prenchimento (CHEN; ZHANG; LIU, 2007; CHENG et al., 2005; CRIMINISI; PEREZ; TOYAMA, 2004). Além disso, a orientação do processo de retoque como um todo pode ser feita pela orientação das linhas de nível da imagem fornecida diretamente pelo usuário (KWOK; WANG, 2009; SUN et al., 2005) ou inferidas diretamente a partir da imagem a ser restaurada (LI; ZHAO, 2011; CAO et al., 2011).

Ao contrário do que é fei to nos métodos clássicos, a abordagem de retoque DTAS utiliza uma imagem auxiliar contendo informações sobre os contornos da imagem para cal cular a orientação dos isófotos e a ordem de preenchimento durante o processo de reconstrução da imagem. Esta imagem auxiliar é o componente cartoon u extraído a partir de f. Afinal, esta imagem auxiliar u possui inf ormações das bordas da imagem e não contém padrões de textura, como pode ser observado na Figura 8.

É possível notar que o campo de direções na Figura 8f possui perturbações menores quando comparado com o campo cal cul ado di retamente da imagem f, apresentado na Figura 8 e.

Para extrair o componente cartoon u de f, é utilizada a equação de difusão proposta em (BARCELOS; BOAVENTURA; JR, 2003), a qual foi inicial mente modelada para tratar 


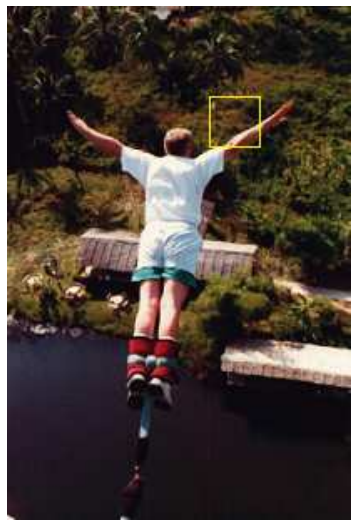

(a)

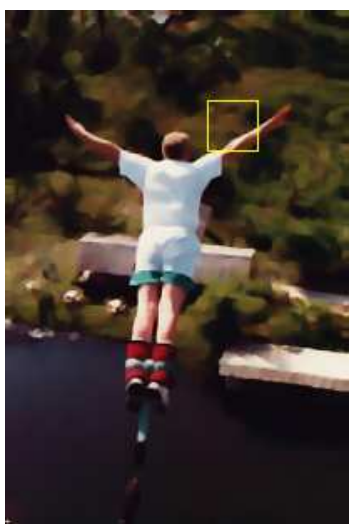

(b)

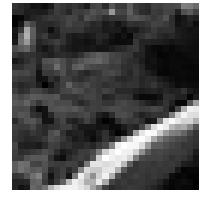

(c)

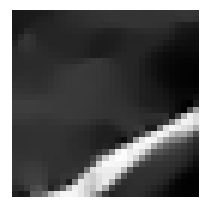

(d)

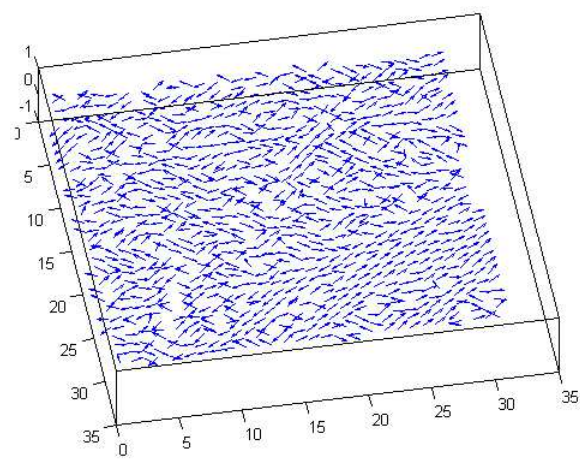

(e)

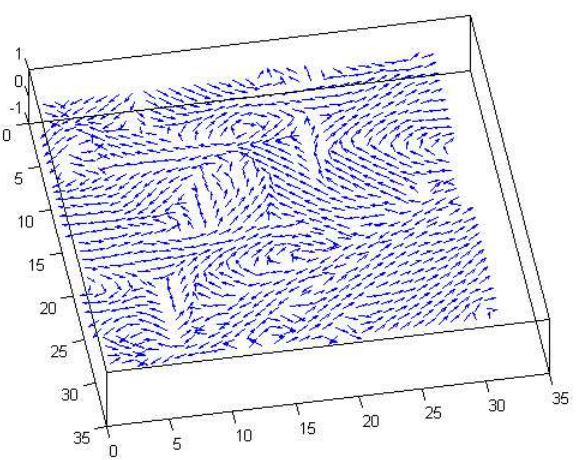

$(\mathrm{f})$

Figura 8 - Representação do campo de direções em uma imagem. (a) Imagem original f. (b) Componente cartoon u,

(c) Região destacada em (a). (d) Região destacada em (b). (e) Campo de direção normalizados de (c) usando o versor de $\perp$ f. (f) Campos de direção normal izado de (d) com o versor de $-\mathcal{\perp}$ u. Fonte: (CASACA et al., 2014).

problemas de eliminação de ruído e de suaviação de imagens. De modo semelhante a (CASACA, 2010), em que tal equação foi empregada para decompor $f$ nos componentes cartoon e textura de forma a satisfazer a Equação (2.7), obtemos u ao resolver numericamente a segui nte equação de difusão anisotrópica:

$$
\begin{gathered}
\frac{\partial f^{(t)}}{\partial t}=g\left|f^{(t)}\right| \operatorname{div} \frac{f^{(t)} !}{\mid-f^{(t) \mid}}-(1-g)\left(f^{(t)}-f\right) ; \\
f(x)^{(0)}=f(x) ; \frac{\partial f(x)^{(t)}}{\partial \vec{n}} \stackrel{M^{y}}{\partial \mathrm{D}} \times R_{+}=0 ; x \in D ; t \in R_{+} ;
\end{gathered}
$$

em que $f^{(t)}$ é a versão escalar de $f, g=g\left(\left|-G_{S}{ }^{*} f^{(t)}\right|\right)$ é uma função de detecção de bordas, $G_{S}$ representa a função gaussiana e s é um parâmetro aju ustável.

O próximo passo é atribuir um rótulo de forma iterativa para cada pixel na fronteira da região a ser preenchida de modo a estabel ecer a ordem de preenchimento da região W. $O$ componente u é utilizado para definir estes rótul os.

A medida efetiva para definir a prioridade de preenchimento é dada por

$$
P(p)=R(p) \cdot C(p) ; p \in \partial W:
$$


no qual os termos $R$ ( p) e C (p) são dados pelas Equações (2.14) e (2.16), respectivamente.

Na Equação (2.13), o medi da de relevância $R$ calcula os i sófotos da fronteira $\partial W$ com base nas ideias concebidas em (BERTALMíO et al., 2000; BORNEMANN; MäRZ, 2007):

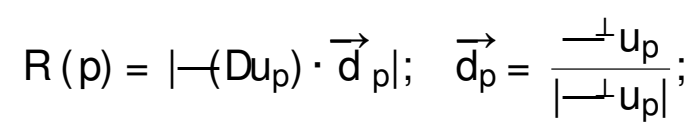

em que $\mathrm{p}$ é o pixel corrente e $\overrightarrow{\mathrm{d}_{\mathrm{p}}}$ é dado pelo vetor ortogonal ao gradiente de $\mathrm{u}$ em $\mathrm{p}$. $\mathrm{R}$ tem por objetivo quantificar o grau de rel evância das estruturas geométricas na imagem danificada. Ao contrário da expressão defini da na Equação (2.14), o campo de direção na Equação (2.10) não é normal izado. Desse modo, é razoável substituir a imagem de entrada I da Equação (2.10) pelo componente cartoon u (sem textura) a fim de al cançar uma deteção mai s refinada dos i sóf otos da imagem original $f$, a qual, a priori, poderia conter regiões com texturas. Além disso, a escolha de u em vez de f na Equação (2.14) pode ser justificada pel a regularidade do campo de di reções $\frac{\perp}{|-\mathrm{u}|}$ quando comparado com $\frac{\perp \mathrm{f}}{|-\mathrm{f}|}$ (Figura 8) e pela ausência de textura, o que permite ressal tar de modo mais adequado a geometria de interesse (i sófotos) por meio da apl icação da “medida de propagação de suavização" Du (Figura 9a-Figura9d).

A Figura9emostrauma comparação entre o termo de relevância $R$ e o termo utilizado em Criminisi et al. (CRIMINISI; PEREZ; TOYAMA, 2004). Note que, o termo clássico de Criminisi e colaboradores apresenta pi cos mais el evados no gráfico, o que induz a produção de uma curva irregular e, consequentemente, provoca a redução da precisão da ordem de prioridade de retoque. Em contraste, o termo de rel evância $R$ da Equação (2.14) apresenta um comportamento mais estável e menos sensível às al tas frequências presentes na imagem. Além disso, o termo da Equação (2.14) é mais eficaz na detecção apenas do campo de direção das linhas de nível, sendo mais eficaz em preservar a evolução das estruturas lineares da imagem.

A Equação (2.14) pode ser interpretada (exceto pelo valor absoluto) como sendo a variação da medida de suavização Du ao longo de $\overrightarrow{\mathrm{d}}$, isto é,

$$
\frac{\partial(\mathrm{Du})}{\partial \overrightarrow{\mathrm{d}}}=-(\mathrm{Du}) \cdot \overrightarrow{\mathrm{d}} \text {; o que implica em } R(p)=\overrightarrow{\partial \vec{d}_{p}}
$$

Assim, o estimador da Equação (2.15) mede a variação de Dup para o campo de isófotos $\overrightarrow{\mathrm{d}}$ : se o val or da derivada de Dup em $p$ em relação a $\vec{d}_{p}$ é alto, a relevância de p também será alta, caso contrário, o pixel p não terá al ta prioridade no processo de restauração.

Na Equação (2.13), o termo de confiança regularizado C assegura a coerência do prenchimento na imagem, isto é, faz com que a região Wda imagem seja restaurada da forma mais isotrópica possível.

Seguindo as ideias apresentadas em (CRIMINISI ; PEREZ; TOYAMA, 2004; CASACA, 2010), neste trabal ho é proposta a medida de balanceamento chamada de termo de confiança 
regularizado $C(p)$ :

$$
C(p)=C_{k}(p)=\underbrace{0}_{q \in H_{m}(p) \cap(D-w)} \frac{\hat{A}(q)^{\frac{1}{k}}{ }^{1} k}{\left|H_{m}(p)\right|}
$$

em que $\left|H_{m}(p)\right|$ denota o tamanho do bloco $H_{m}(m \times m)$ centrado no pixel p, conforme a Equação (2.6), C(q) é inicial izado com 1 e k > 0 é o parâmetro regularizador. Observe também que, parak = 1, a Equação (2.16) resul ta no mesmo termo proposto em (CRIMINISI; PEREZ; TOYAMA, 2004).

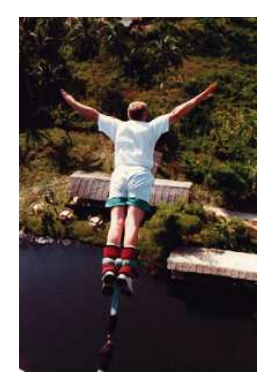

(a)

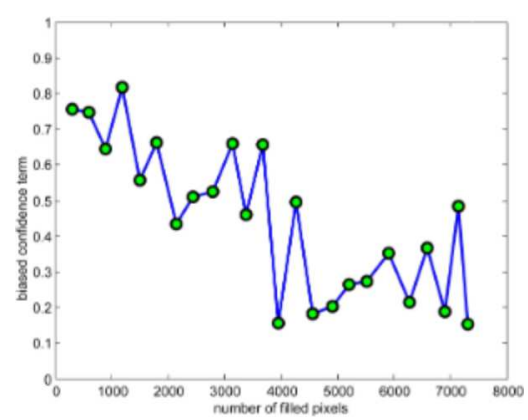

(f)

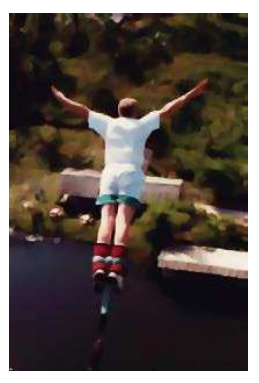

(b)
Figura 9 - (a) Imagem original . (b) Componente cartoon u. (

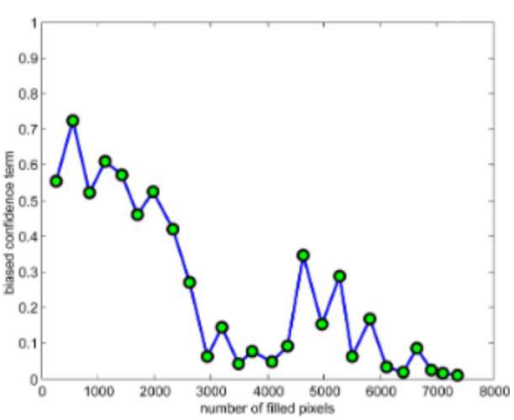

(g)

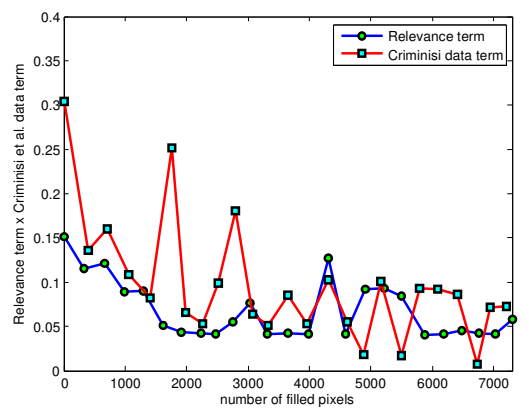

(e)

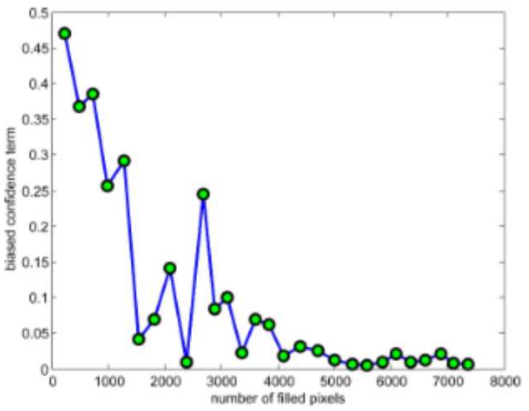

(h) na imagem original. (d) Operador Lapl aciano D aplicado no componente cartoon u. (e) Comparação entre o termo de relevância $R$ e o termo de dados de Criminisi et al. (CRIMINISI; PEREZ; TOYAMA, 2004). (f), (g) e (h) Gráfico do termo de confiabilidade proposto $C$ parak $=0: 5 ; 1: 0 ; 1: 5$, respectivamente, por número de iterações quando aplicamos o retoque na imagem (a). Fonte: (CASACA et al., 2014).

Como apontado em (CHENG et al., 2005), regularizar o termo confiança C é muito importante para garantir a qualidade do retoque. $\mathrm{A}$ medida regularizada $\mathrm{C}$ nos permite ajustar o mecanismo de prioridade do seguinte modo: se $\mathrm{k}<<1$, então $\mathrm{C}$ terá um alto impacto na Equação (2.13). Já a significância moderada ocorre quando $k \approx 1$ enquanto que, para $k>>1$, a significância é aj ustada para atuar de forma bem menos incisiva na ordenação dos pixels. As Figuras 9f-9h ilustram a contribuição de $\mathrm{C}$ quando realizamos o retoque na Figura 9a. Em todos os casos, há uma diminuição da intensidade, mas a taxa de decrescimento modifica-se significativamente a medida que $\mathrm{k}$ aumenta demasiadamente. 


\subsubsection{Amost ragem dinâmica}

Dado um domínio de retoque $W$, a região $L$ onde será feita a busca pelos pixels a serem utilizados para preencher a área danificada geralmente é definida como sendo $L=$ WC (o complementar do domínio de retoque) nas abordagens clássicas (CAO et al., 2011; CHEN; ZHANG; LIU, 2007; CHENG et al., 2005; CRIMINISI; PEREZ; TOYAMA, 2004; EFROS; LEUNG, 1999). Esta metodologia é mais sucetível ao problema de introduzir pixels incongruentes na região recuperada, pois pixels distantes podem fazer parte de um grupo de informação completamente distinto.

Para superar esta limitação, o método DTAS utiliza um mecanismo de amostragem dinâmica, ajustável para cada pixel a ser prenchido, ao invés de definir $L$ como uma região estática da imagem. Dessa forma, é possível inibir a cópia de pixels muito distantes da região de retoque e evitar a reprodução de pixels incongruentes na região a ser recuperada, como ilustra a Figura 12. Com isso, a região $L=L p$ é sel ecionada de forma iterativa para cada pixel $p \in \partial W e$ obtida com base na região válida $H_{L}(p)$, a qual corresponde a um bloco de pixels $L \times L$ centrado no pixel p:

$$
L_{p}=H_{L}(p) \cap W^{c}
$$

para cada pixel $p \in \partial W$. A Figura 10a ilustra essa construção. Outra vantagem dessa estratégia é

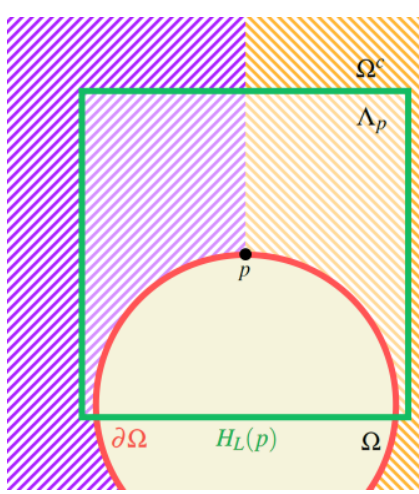

(a)

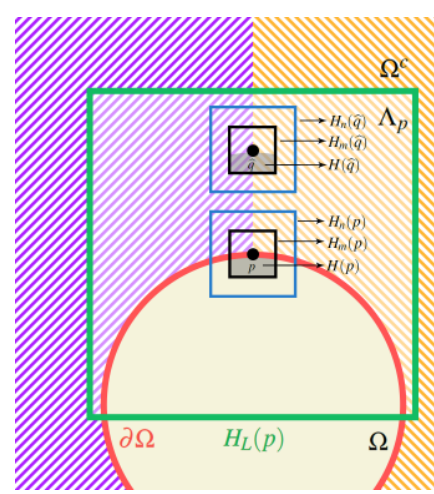

(b)

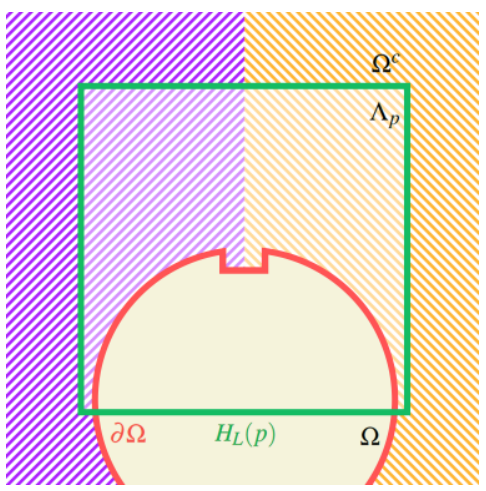

(c)

Figura 10 - Esquema para ilustrar a amostragem dinâmica e o processo de preenchimento do domínio de retoque W. (a) Os pixels candidatos em $L_{p}$ estão destacados (região mais clara) dentro da região válida, dada pela interseção de $\mathrm{H}_{\mathrm{L}}(\mathrm{p})^{1}$ (quadrado verde) e $W^{\mathcal{F}}$. (b) Comparação entre o conteúdo dos bl ocos $\mathrm{H}_{\mathrm{n}}(\mathrm{p})$ e $\mathrm{H}_{\mathrm{n}}(\mathbf{b})$ (bloco ótimo). (c) Resultado da restauração após preencher a região de interesse.

o ganho em tempo de processamento, pois el a verifica apenas a região $L_{p}$, cujas dimensões são muito menores do que as utilizadas nas abordagens tradicionais da literatura. Como $L_{p}$ é definida passo-a-passo para cada pixel p, o processo de preenchimento ocorre de forma recursiva.

As Figuras 11a 11d comparam o ganho computacional da amostragem dinâmica em comparação com as metodologias utilizadas em (CRIMINISI; PEREZ; TOYAMA, 2004) e

1 O pixel p nas imagens da Figura 10 é o centro e $H_{n}(p)$. Contudo ele não está central izado na ilustração apenas para obter uma mel hor vizualização do processo. 
(WEXLER; SHECHTMAN; IRANI, 2007) ao restaurar uma fotografia de grandes dimensões (1000 × 1300, 51k pixels danificados). O método DTAS (Figura 11) real iza o retoque em poucos minutos. Neste mesmo tempo, enquanto o método DTAS havia concluído a restauração, o al goritmo proposto em (CRIMINISI; PEREZ; TOYAMA, 2004) preencheu apenas uma pequena parte da imagem (Figura 11c) e a técnica proposta em (WEXLER; SHECHTMAN; IRANI, 2007) resultou em uma imagem numa escal a mais grossa $(325 \times 250)$ com bai xa qualidade de reconstrução (Figura 11d).

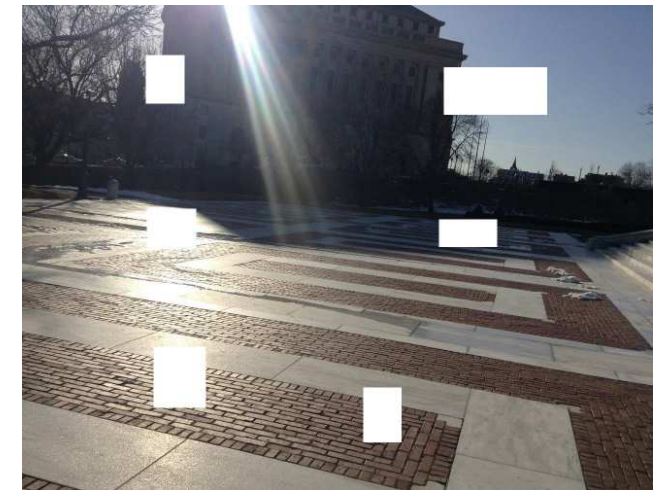

(a)

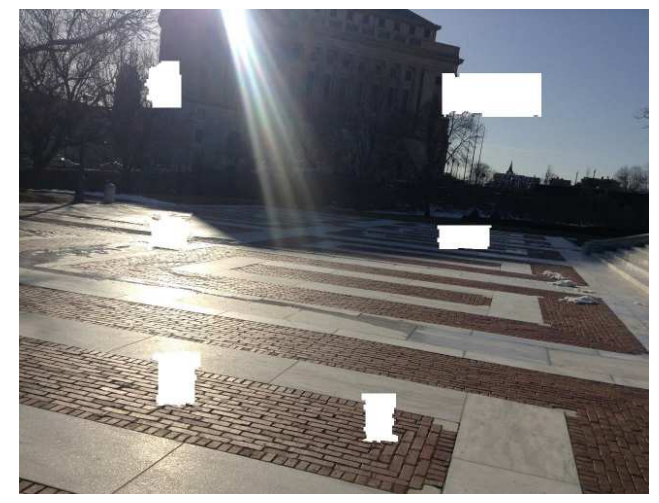

(c)

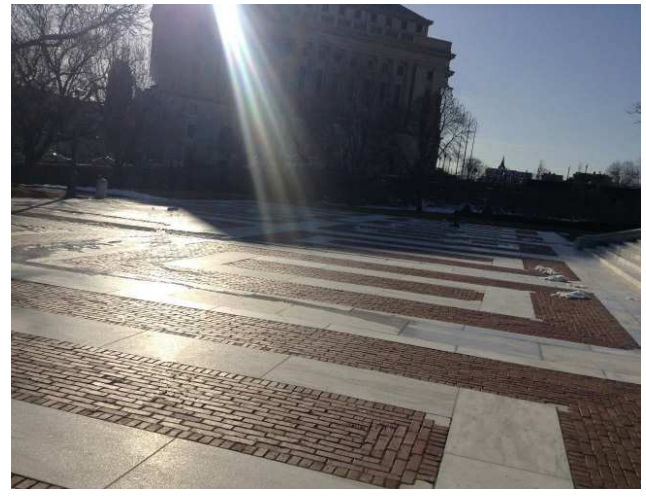

(b)

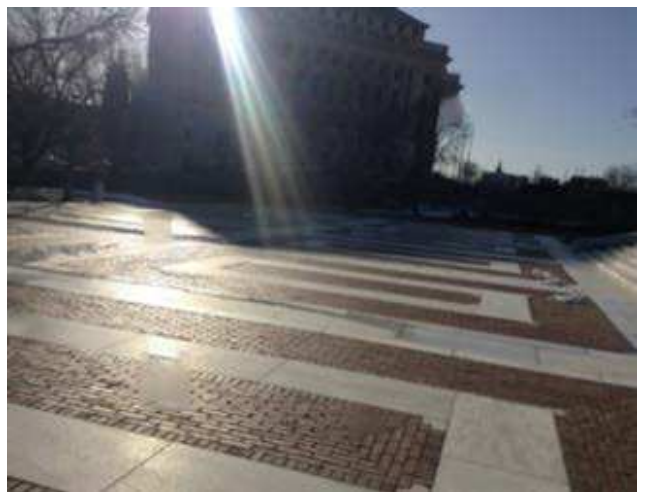

(d)

Figura 11 - Comparação entre o uso da amostragem dinâmica e os métodos (CRIMINISI; PEREZ; TOYAMA, 2004) e (WEXLER; SHECHTMAN; IRANI, 2007) na restauração de uma fotografia 1000 × 1300. O tempo de processamento é o mesmo para todos os métodos e foi considerado como o tempo gasto para o método DTAS concluir a taref a de restauração. (a) Fotogragia danificada (b) Resultado do método DTAS. (c) Imagem obtida pelo método (CRIMINISI; PEREZ; TOYAMA, 2004). (d) Restauração por meio do método (WEXLER; SHECHTMAN; IRANI, 2007). Fonte: (CASACA et al., 2014).

\subsubsection{Replicação baseada em blocos}

Para restaurar um determinado pixel em $\partial \mathrm{W}$, incial mente a Equação (2.13) determina o pixel p com mai or prioridade de preenchimento. Em seguida, a região de amostragem $L_{p}$ é obtida pela Equação (2.17). O próximo passo é local izar o bl oco de pixels dentro da região $L_{p}$ que seja o mais adequado para restaurar a vizinhança do pixel $p$.

Para real izar a tarefa de local izar o bloco de pixels dentro da região $L_{p}$ de modo que ele seja o mais adequado para restaurar a vizinhança do pixel p. Desse modo, é utilizada uma medida 
de similaridade para comparar o bloco de referência $\mathrm{H}_{n}(p)$ com todos os demais blocos de candidatos $\mathrm{H}_{n}(q)$ dentro da região $L_{p}$. O bloco ideal $H_{n}(\mathbf{q})$ é defini do ao minimizar a distância entre $H_{n}(p)$ e $H_{n}(q)$, para todo $H_{n}(q) \in L p$, com relação a uma determinada métrica. Um bloco menor $\mathrm{H}_{\mathrm{m}}(\mathbf{q})$ é sel ecionado a partir de $\mathrm{H}_{\mathrm{n}}(\mathbf{q})$ e seus pixels válidos $\mathrm{H}(\mathbf{q})$ são utilizados para preencher a vizinhança $\mathrm{H}(\mathrm{p})$ do pixel $\mathrm{p}$. As Figuras 10b e 10c apresentam uma ilustração deste processo. Esta estratégia faz com que a tarefa de busca seja mais rápida e efetiva, pois utiliza as regiões de suporte $H_{n}(q)$ em $L_{p}$ para encontrar pixels adequados para restaurar a região danificada.

A fim de cal cular a distância (ou similaridade) entre dois blocos $\mathrm{H}_{n}(\mathrm{p})$ (região a ser prenchida) e $\mathrm{H}_{n}(\mathrm{q})$ (regiões candidatas), propomos a utilização da métrica chamada di stância da raiz dos quadrados médi os normalizada (nor malized root mean-square deviation) (NRMSD). Sejam $p=\left(f_{p_{1}} ; f_{p_{2}} ; \ldots ; f_{p_{k}}\right), q=\left(f_{q_{1}} ; f_{q_{2}} ; \ldots ; f_{q_{k}}\right)$ vetores coluna em $R^{k}, k<n^{2}$, contendo as intensidades dos pixels em $H_{n}(p)$ e em $H_{n}(q)$, respectivamente. A distância entre $H_{n}(p)$ e $H_{n}(q)$ é mensurada por:

$$
d(p ; q)=q \frac{\|p-q\|_{D U}}{\|p\|_{D U}^{2}+\|q\|_{D U}^{2}} ;
$$

com

$$
\|p-q\|_{D U}=\stackrel{q}{(p-q)^{\top} D U(p-q)} ; \quad\|p\|_{D U}=\stackrel{p}{p^{\top} D U p} ; \quad\|q\|_{D U}=p \overline{q^{\top} D U q} ;
$$

em que DU é uma matriz diagonal definida pelo Laplaciano da componente cartoon u, ou seja, $\mathrm{DU}_{\mathrm{ii}}=\mathrm{Du}_{\mathrm{p}} ; \operatorname{comp}_{\mathrm{i}} \in \mathrm{H}_{\mathrm{n}}(\mathrm{p}) \cap \mathrm{L}_{\mathrm{p}}$.

A métrica da Equação (2.18) atribui pesos mais el evados para os pixels situados nas bordas do Laplaciano de u. Os pesos dos pixels na Equação (2.19) são definidos a partir do Laplaciano de u e compõem a distância para comparação de blocos.

Em termos matemáticos, a métrica da Equação (2.18) possui propriedades interessantes. O termo $\|\cdot\|_{D u}$ é uma métrica Euclidiana induzida por um produto interno, a qual codifica os dados de DU. Na verdade, podemos escrever $\|x\|_{D U}={ }^{p} \frac{}{\langle x ; x\rangle_{D U}}>0 ; \forall x=0 \in R^{k}$, de modo a garantir as seguintes propriedades matemáticas:

1. $\operatorname{det}(D U)=\mathrm{DU}_{11} \mathrm{DU}_{22} \cdots: \mathrm{DU}_{\mathrm{kk}}>0$ (a matriz $\mathrm{DU}$ é obtida a partir de uma imagem);

2. DU é simétrica (matriz diagonal).

Como $\|\cdot\|_{D U}$ é uma métrica Euclidiana, a Equação (2.18) também define uma métrica em $R^{k}$. As vantagens de empregar a métrica da Equação (2.18) reside no fato de que ela pode utilizar informações fornecidas pelo operador Laplaciano ao mesmo tempo em que mede a semel hança estrutural entre os blocos envolvidos (vide (BRUNET; VRSCAY; WANG, 2012) para mais detalhes). 


\subsection{Resultados experimentais}

A seguir são apresentados al guns resul tados obtidos com o metodol ogia DTAS e também um estudo comparativo com métodos do estado da arte. Nos experimentos, foi fixado $\mathrm{N}=50$ e s foi deixado variável na Equação (2.12). A escol ha destes parâmetros é detal hada em (BARCELOS; BOAVENTURA; JR, 2003; BARCELOS; BOAVENTURA; JR., 2005). Na Equação (2.16), foi fixado $k=0: 5$. As dimensões m e $n$ da Equação (2.18) são parâmetros livres, enquanto $L$ na Equação (2.17) foi definido em função de $n: L=L(n)=4 n+1$ (escolha feita após a realização exaustiva de testes), exceto na Figura 24, onde $L=71$. Os experimentos foram desenvolvidos por meio do simulador MATLAB em um AMD 1.80GHz com 8GB de RAM sem qual quer esquema de otimização MATLAB-MEX (interface com a linguagem $C$ ).

\subsubsection{Transferência de padrões e contribuições de C;R e P}

A Figura 12 mostra al guns resultados de retoque para uma fotografia real. Sem utilizar o esquema de amostragem di nâmica, é possível notar que partes da região destacada em verde na imagem da Figura 12a foram transferidas para o domínio restaurado (destacado em vermelho na Figura 12b). Embora seja visual mente agradável, o resultado não é real ista em relaçao à vegetação em volta desses padrões. Além disso, o custo computacional foi bastante elevado (seis vezes mai or do que a metodol ogia usando a amostragem dinâmica). Nas Figuras 12c-12f, é possível ver os resultados ao consi derar: 12c apenas a medida proposta $\mathrm{C}$ da Equação (2.16), $12 d$ apenas a medida $R$ da Equação (2.14) e, 12 e o mecani smo para ordem de preenchimento $P$ da Equação (2.13) para cal cular a prioridade de retoque após um número fixo de iterações. Final mente, a imagem restaurada ( $s=40, m=7, n=15$ ) é apresentada na Figura 12f. Em todos os casos, é possível notar a contribuição individual de cada termo no processo de restauração.

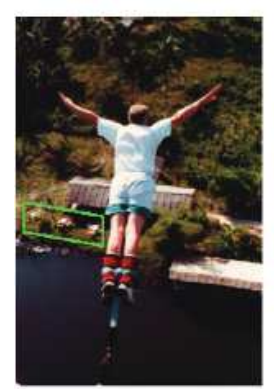

(a)

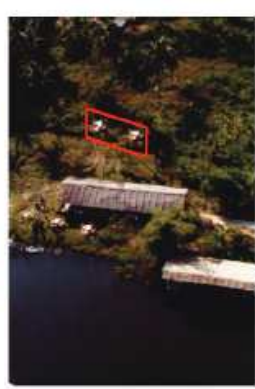

(b)

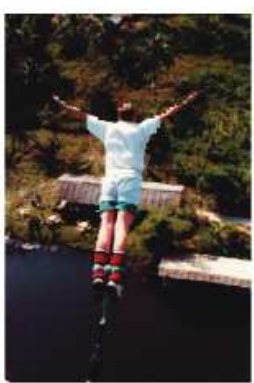

(c)

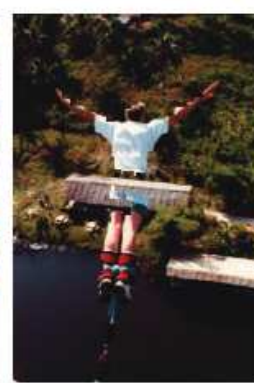

(d)

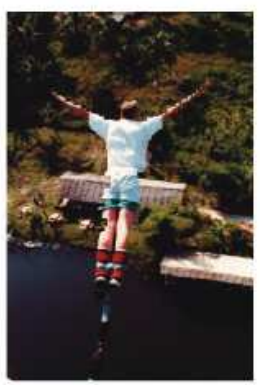

(e)

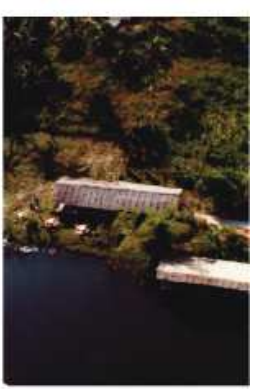

(f)

Figura 12 - Características do método DTAS: transf erência indevida de padrões e contribuição individual de cada termo $C ; R$ eP . Fonte: (CASACA et al., 2014).

\subsubsection{Preenchimento guiado por cartoon}

O passo-apasso do método DTAS está ilustrado na Figura 13, quando aplicado a uma imagem tanto com texturas quanto com regiões homogêneas, as quais foram danificadas intenci- 
onal mente (Figura 13a). Como mostram as Figuras 13c e 13d, as regiões destacadas em verde e vermelho foram reconstituídas primeiro devido ao mecanismo de prioridade, calculado a partir do componente cartoon (Figura 13b). Além disso, a textura foi totalmente reconstruída e os detal hes daimagem foram bem preservados, como mostrado na reconstrução final (Figura 13e, $s=30, m=9, N=9)$. Note que os isófotos são priorizados no processo de restauração.

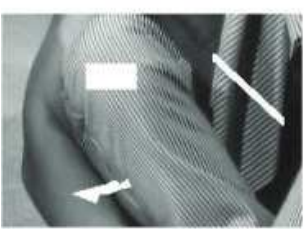

(a)

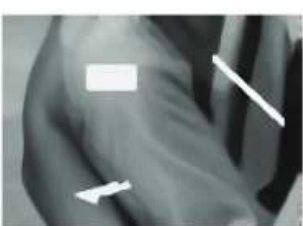

(b)

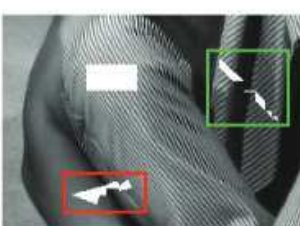

(c)

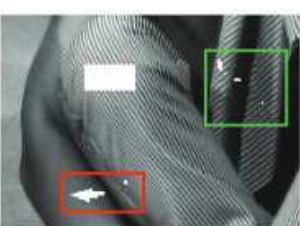

(d)

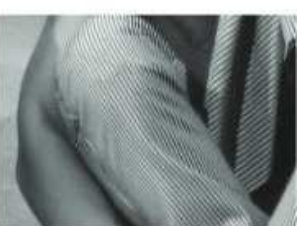

(e)

Figura 13 - Características do método DTAS: passo-a-passo do método e ef etividade do esquema de ordem de preenchimento. Fonte: (CASACA et al., 2014).

\subsection{3 retoque de texturas detalhadas}

Um exemplo de remoção de objetos é apresentado a seguir, no qual o objeto-al vo está local izado em uma área que contém padrões de texturas regulares. A imagem da Figura 14a mostra a fotografia original ao passo que a Figura 14b ilustra o objeto a ser removido (destacado em branco). A Figura 14c apresenta o resultado obtido com o método DTAS ( $s=15, m=9$, $\mathrm{n}=11$ ) e na Figura 14d é mostrado uma ampliação da região restaurada. Podemos verificar que a imagem foi restaurada de modo muito sati sfatório. Além disso, o mecanismo de amostragem dinâmica contribuiu na obtenção de um bom resultado, uma vez que apenas os pixels nas proximidades do domínio de retoque foram usados no processo de preenchimento.

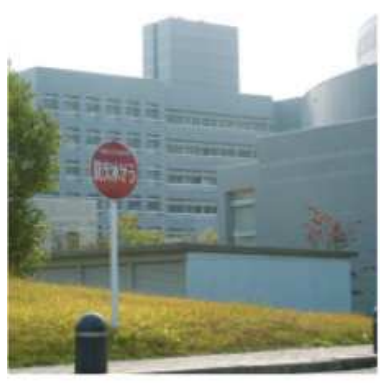

(a)

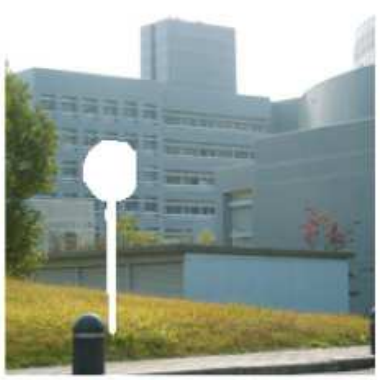

(b)

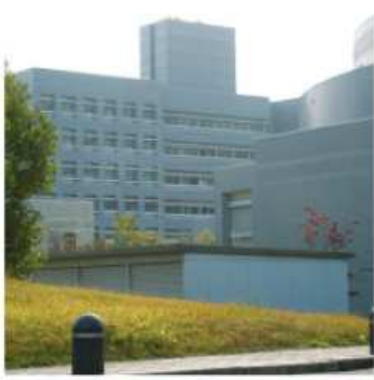

(c)

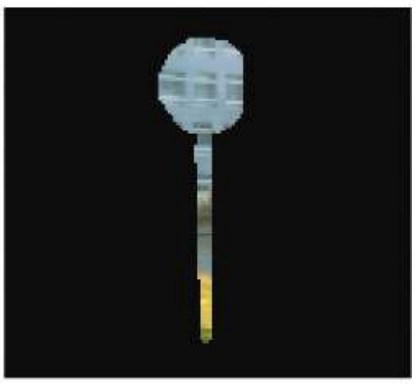

(d)

Figura 14 - Características do método DTAS: explorando uma imagem com texturas ricas em detal hes. Fonte: (CASACA et al., 2014).

\subsubsection{Robust ez à variação de parâmetros}

A robustez da técnica DTAS quanto à variação do parâmetro de janelamento é apresenta a seguir. O parâmetro de janelamento desempenha um papel primordial nos demais al goritmos 
do estado-da-arte em retoque.

Para abordar este aspecto, é consi derada uma imagem de teste e o parâmetro de janelamento para a metodologia DTAS é livre para variar, tal como também para a técnica clássica de replicação de blocos (CRIMINISI; PEREZ; TOYAMA, 2004). Conforme apresentado na Figura 15, é possível notar que a técnica DTAS não apresenta variações bruscas na qual idade visual das imagens ao variar o val or do parâmetro de janelamento. Tal conclusão não pode ser constatada na técnica clássica de Crimini si et al. (CRIMINISI; PEREZ; TOYAMA, 2004), uma vez que vários padrões não foram replicados com sucesso (observe o "pote" próximo ao monge).

\subsubsection{Resultados comparativos}

Esta seção sumariza os resultados experimentais obtidos pelo uso da técnica DTAS quando comparada com as demais metodologias do estado-daarte em retoque digital. Em particular, foram realizados testes experimentais com o emprego dos seguintes métodos de retoque:

· SPT : Síntese Pura de Textura² (EFROS; LEUNG, 1999);

- MSE: retoque via Equação de Difusão de Mumford-Shah-Euler ${ }^{3}$ (ESEDOGLU; SHEN, 2002; SCHöNLIEB, 2015);

· RE: retoque via Replicação de Blocos $^{4}$ (CRIMINISI; PEREZ; TOYAMA, 2004);

- EPM : Inpaiting baseado em blocos com Prioridade Remodelada ${ }^{5}$ (L.J.; T.Z.; X.L., 2015); e

Adobe CAW: Adobe Photoshop CS 2016 (Content-Aware Fill) (WEXLER; SHECHTMAN; IRANI, 2007; BARNES et al., 2009).

Nas comparações apresentadas, os parâmetros utilizados em cada um dos métodos listados acima foram ajustados a partir das implementações originais disponibilizadas pelos autores em seus sites pessoais de pesqui sa, ou ainda tomando como base os val ores indicados em seus trabal hos científicos. As imagens utilizadas para os testes experimentais foram adqui ridas do clássico repositório público de imagens de Berkeley UCLA, a qual foi descrita em (ARBELAEZ et al., 2011).

É válido ressal tar que na avaliação experimental realizada foi adotado o uso de recursos profissi onais de restauração de imagens, tal como a ferramenta Content-Aware Fill, ideal izada

tamanho da janela: $(3 ; 5 ; 3 ; 5 ; 3 ; 3 ; 3 ; 3)$

3 parâmetros de passo, difusividade, entre outros tal como sugerido em (SCHöNLIEB, 2015).

4 tamanho dajanela: 9.

5 tamanho da janela: 9. 


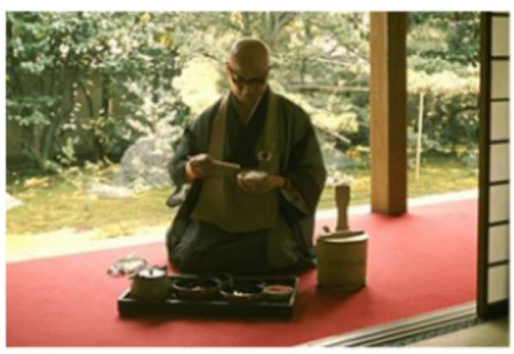

(a)

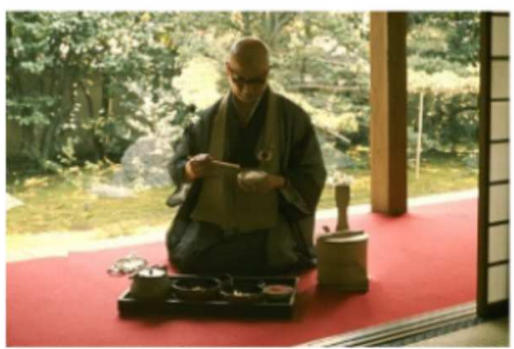

(d)

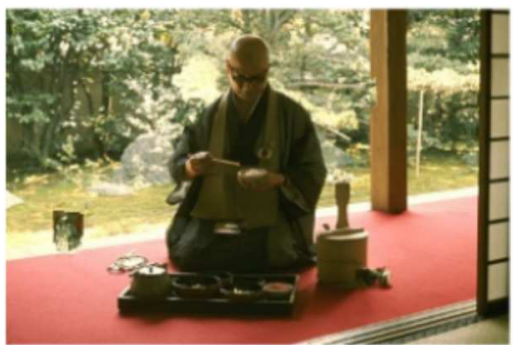

(g)

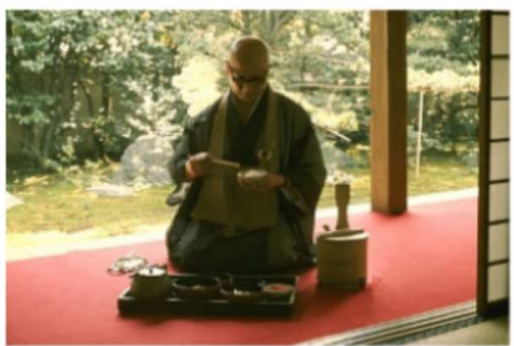

(j)

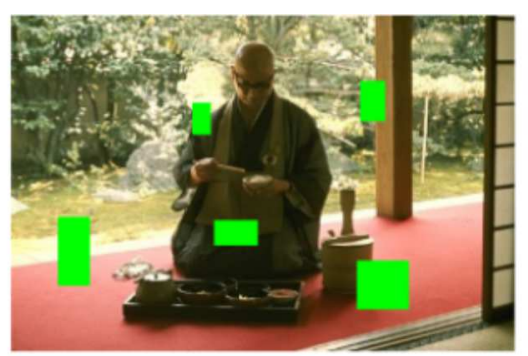

(b)

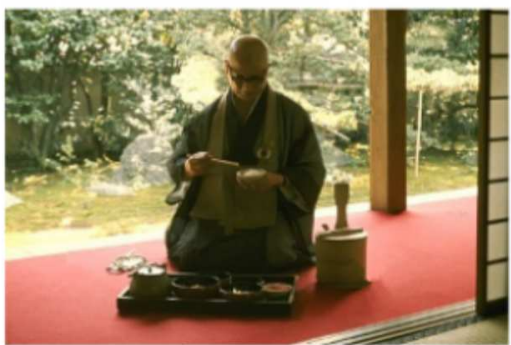

(e)

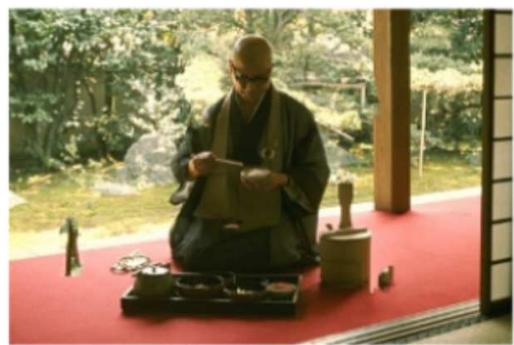

(h)

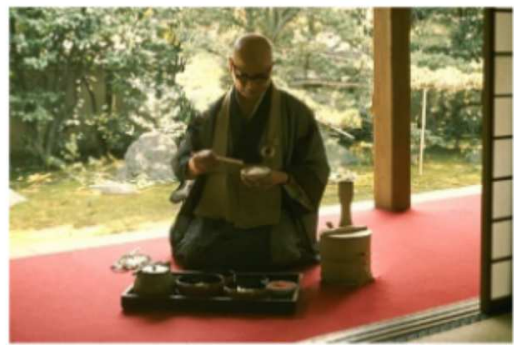

(k)

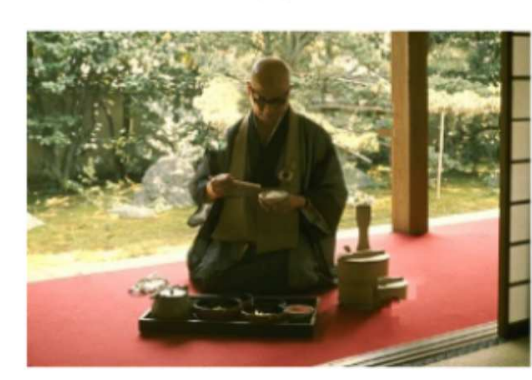

(m)

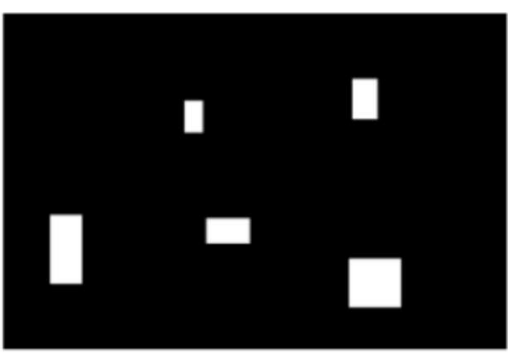

(c)

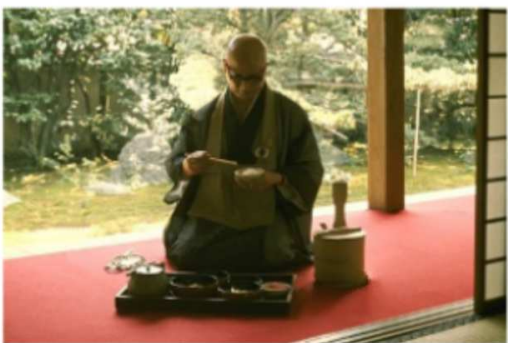

(f)

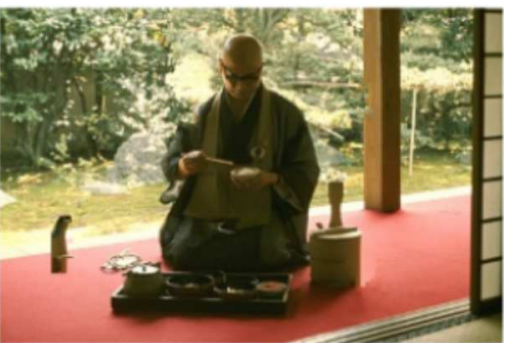

(i)

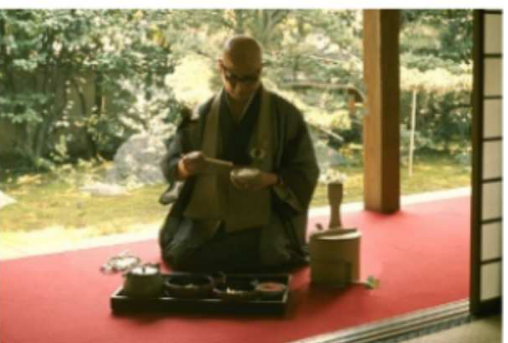

(I)

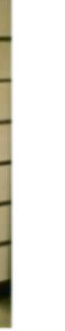

Figura 15 - Efeito da variação do parâmetro de janelamento da técnica DTASx (CRIMINISI; PEREZ; TOYAMA, 2004). Segunda linha, método DTAS com: (d) janelamento de 3; (e) janelamento de 5; (f) janelamento de 7. Terceiralinha, (CRIMINISI; PEREZ; TOYAMA, 2004) com os níveis de: (g) janelamento de 3; (h) janelamento de 5; (i) janelamento de 7. Quarta linha, método DTAS com: (j) janelamento de 9; (k) janelamento de 11. Quarta e quinta linha, (CRIMINISI; PEREZ; TOYAMA, 2004) com os níveis de: (I) janelamento de 9; $(\mathrm{m})$ janelamento de 11. 
como componente de edição do tradicional software profissional Adobe Photoshop (versão 2016).

A seguir são apresentados os resultados obtidos por meio das técnicas previamente indicadas, no sentido de avaliar os métodos a partir de diferentes tipos de imagens, no contexto tanto de remoção de objetos quanto de restauração de imagens sintéticas. As análises experimentais são divididas em duas partes: avaliações qualitativas e avaliações quantitativas, conforme relacionado a seguir.

\section{Comparações qualit at ivas}

Vários experimentos práticos utilizando imagens digitais constituídas por diferentes tipos de texturas e/ou regiões de natureza homogênea (bordas, contornos e estruturas) são apresentados na sequência. O objeto é aval iar de modo qual itativo a performance da técnica de retoque DTAS com as modificações propostas juntamente com o desempenho dos métodos do estado-daarte indicados anteriormente, isto é, o resultado visual final da reconstituição é considerado nesta aval iação.

No primeiro experimento (Figura 16), a fotografia de umaigrejaémostradanaFigura 16a, a qual foi danificada sinteticamente conforme ilustrado na imagem Figura 16b. Assim, a imagem foi af etada em regiões homogêneas e também em regiões estruturais, como em partes onde preval ece forte presença de texturas. Asimagens das Figuras 16c até $16 \mathrm{~h}$ apresentam os resultados obtidos pelas segui ntes técnicas de retoque: Síntese Pura de Texturas (EFROS; LEUNG, 1999), Mumford-Shad (SCHöNLIEB, 2015), Replicação por Blocos (CRIMINISI; PEREZ; TOYAMA, 2004), Blocos com prioridade remodel ada (L.J.; T.Z.; X.L., 2015) e pela abordagem DTAS. Nos resul tados obtidos nas Figuras 16c e 16e as imagens foram preenchidas com conteúdo irregular nas regiões de textura (região da "escada"), enquanto que a imagem da Figura 16d apresentou uma suavização excessiva (efeito de borramento). Por outro lado, os resultados das Figuras $16 f$ até $16 \mathrm{~h}$ evidenciam resul tados mais consistentes em termos de síntese da informação perdidae de preenchimento das estruturas da imagem (reconstrução linear das "quinas").

As Figuras 17a e 17b mostram a imagem original e sua versão danificada artificial mente pel a introdução de diversos retângul os posi cionados em regiões contendo padrões e/ou partes estruturais. As Figuras 17c até 17h concentram, nesta ordem, os resultados obtidos pel as técnicas SPT, MSE, RE, EPR, Adobe e pel a metodologia DTAS. Em todos os casos, é possível verificar que a "coluna de madeira" presente na imagem não foi reconstruída de modo adequado, com exceção do resultado gerado pelo método DTAS. Além disso, apenas nas imagens das Figuras 17c e 17h houve um preenchimento adequado do item "pote", situado à esquerda do monge. Por fim, é importante notar que a única técnica capaz de reconstruír a roupa do monge integral mente, isto é, sem a presença de artefatos indesejáveis em toda a sua extensão, foi a metodol ogia DTAS.

O terceiro experimento trata-se de uma aplicação de remoção de objetos, conforme 


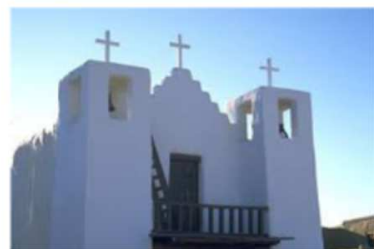

(a)

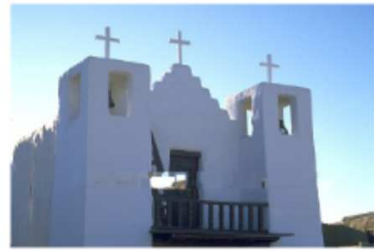

(e)

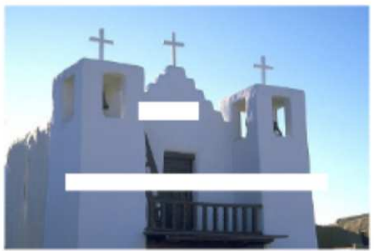

(b)

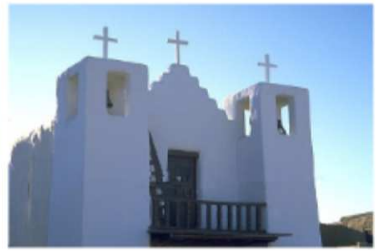

(f)

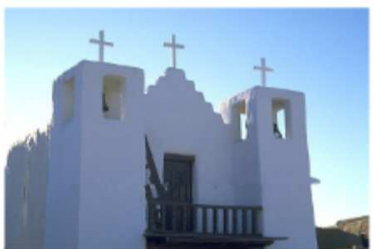

(c)

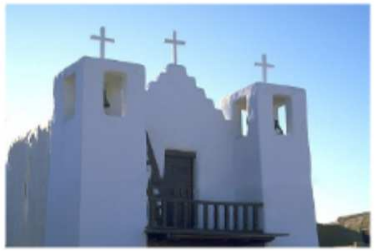

(g)

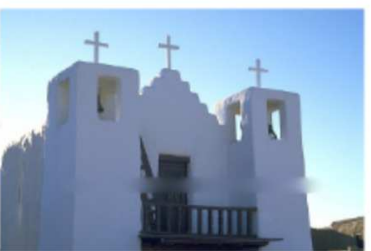

(d)

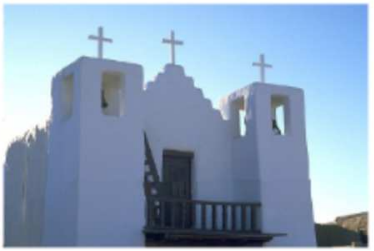

(h)

Figura 16 - Comparação com métodos do estado-da-arte considerando-se uma fotografia digital contendo texturae regiões homogêneas, a qual foi danificada artificial mente. (a) Imagem original. (b) Imagem danificada. (c) Síntese pura de textura (EFROS; LEUNG, 1999). (d) Mumford-Shad (SCHöNLIEB, 2015). (e) Replicação por blocos (CRIMINISI; PEREZ; TOYAMA, 2004). (f) Blocos com prioridade remodeIada (L.J.; T.Z.; X.L., 2015). (g) Adobe CAW (WEXLER; SHECHTMAN; IRANI, 2007; BARNES et al., 2009). (h) Método DTAS.

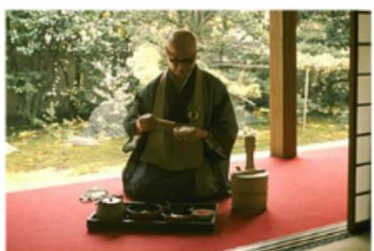

(a)

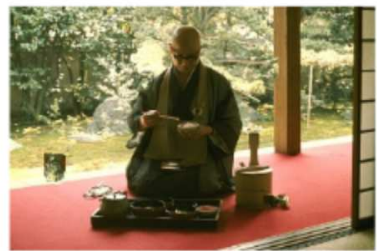

(e)

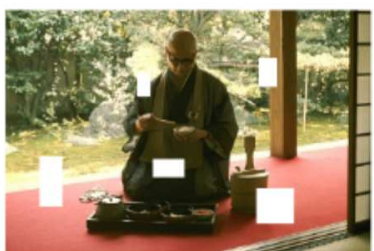

(b)

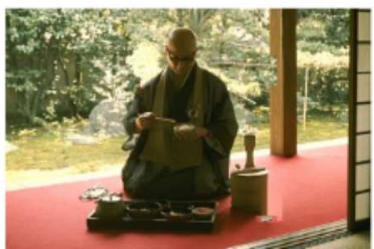

(f)

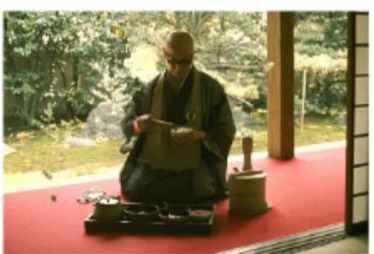

(c)

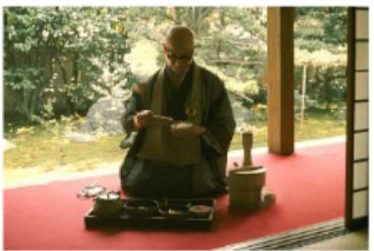

(g)

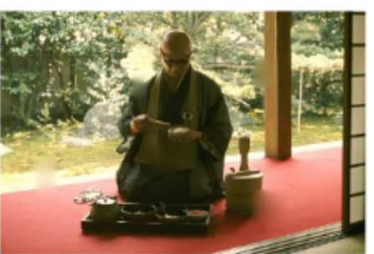

(d)

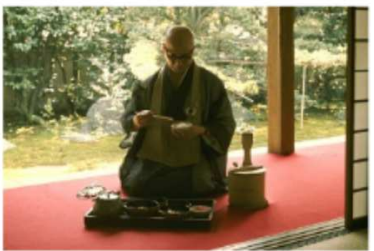

(h)

Figura 17 - Comparações qual itativas em imagens danificadas artificial mente. (a) Imagem original . (b) Imagem danificada (c) Síntese pura de textura (EFROS; LEUNG, 1999). (d) Mumford-Shad (SCHöNLIEB, 2015). (e) Replicação por blocos (CRIMINISI; PEREZ; TOYAMA, 2004). (f) Blocos com prioridade remodelada (L.J.; T.Z.; X.L., 2015). (g) Adobe CAW (WEXLER; SHECHTMAN; IRANI, 2007; BARNES et al., 2009). (h) Técnica DTAS.

ilustrado pelo par de imagens das Figuras 18a 18b. Os resultados obtidos pelo uso das técnicas SPT, MSE, RE, EPR, Adobe e pela abordagem DTAS são mostrados nas Figuras 18c até 18h, respectivamente. Conforme apresentado nas Figuras18c e 18f, as técnicas SPT e EPR preencheram a imagem de entrada com texturas irregulares. O método SPT produziu o efeito de borramento devido a sua model agem ser mais ef etiva para tratar regiões homogêneas ao invés de fragmentos texturizados. Finalmente, as técnicas RE, Adobe CAW e a metodologia DTAS produzi ram resultados consistentes para um observador humano, reproduzindo adequadamente 
as regi ões ricas em texturas.

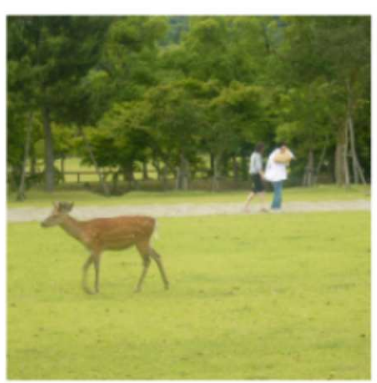

(a)

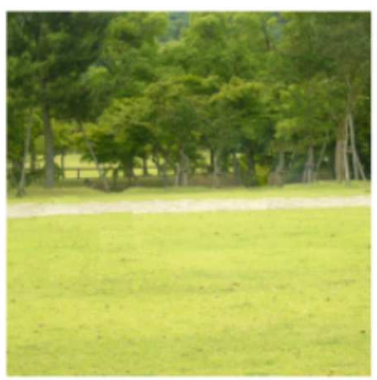

(e)

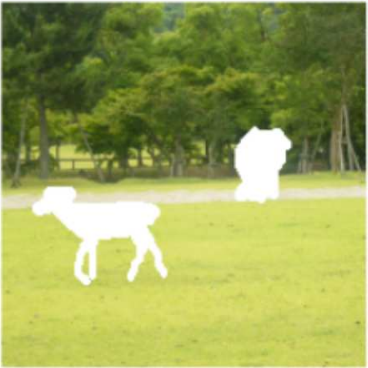

(b)

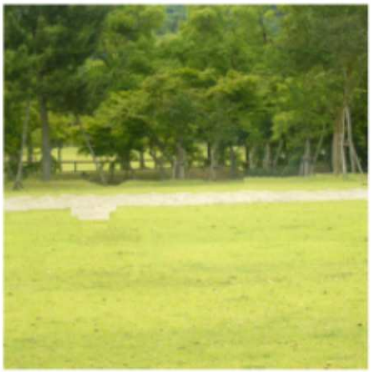

(f)

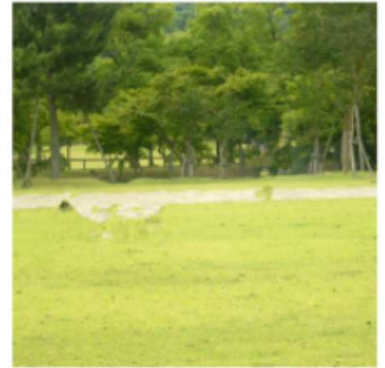

(c)

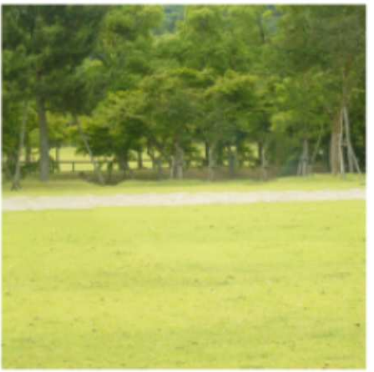

(g)

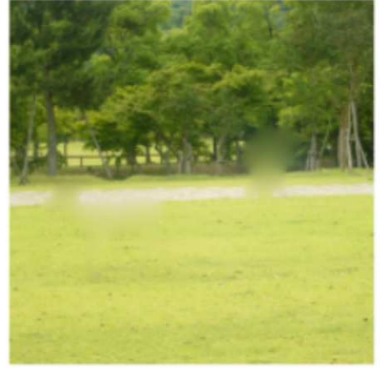

(d)

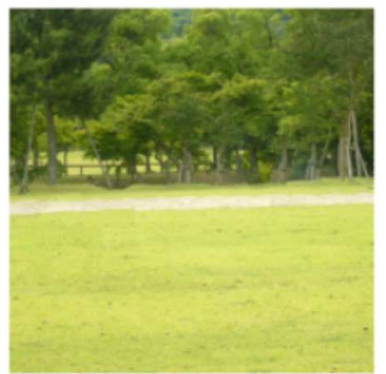

(h)

Figura 18 - Comparações qual itativas visando a aplicação de remoção de objetos em imagens digitais. (a) Imagem original. (b) Imagem contendo os objetos delineados. (c) Síntese pura de textura (EFROS; LEUNG, 1999). (d) Mumford-Shad (SCHöNLIEB, 2015). (e) Replicação por blocos (CRIMINISI; PEREZ; TOYAMA, 2004). (f) Blocos com prioridade remodelada (L.J.; T.Z.; X.L., 2015). (g) Adobe CAW (WEXLER; SHECHTMAN; IRANI, 2007; BARNES et al., 2009). (e) Técnica DTAS.

O experimento descrito pela Figura 19 comtempla novamente a tarefa de remoção de objetos em uma imagem digital. Tal como ilustrado pelas imagens original (Figura 19a) e sua versão a ser processada (Figura 19b), o objeto encontra-se em uma região com padrões complexos, como degraus da escada e cal çada. Conforme observado nas imagens resultantes, os resul tados visuais obti dos nas Figuras 19c até 19h evidenciam a geração de muitos padrões artificiais na região processada, de modo que o ef eito visual final parace bastante incongruente à percepção visual humana. Além disso, em todos os casos a escada no fundo da foto não foi restaurada corretamente. Entretanto, a técnica DTAS produziu um resultado visual bastante equilibrado em termos de reconstrução de padrões, onde a região da escada foi reconstruída com sucesso inteiramente.

O experimento da Figura 20 tem por objetivo reconstruír uma grande área da imagem inserida em uma região dotada de textura regular, conforme ilustrado nas Figuras 20a e 20b. Com base nas imagens reconstruídas ilustradas nas Figuras 20c até 20h, é possível observar que, com exceção dos métodos DTAS e EPR (L.J.; T.Z.; X.L., 2015), as técnicas do estado-da arte anal isadas fal ham na tarefa de replicar a textura da parede na lacuna, gerando resultados significativamente não naturais. Ainda sobre os resultados visuais, quando comparado com EPR, a técnica DTAS obtém um resul tado superior em termos de recomposi ção visual, uma vez que as texturas preenchidas são menores e apresentam mai or si milaridade com o restante da imagem. 


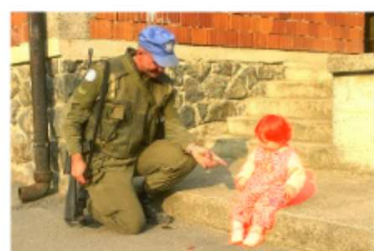

(a)

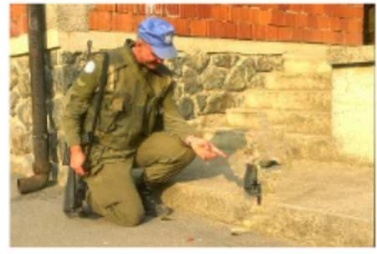

(e)

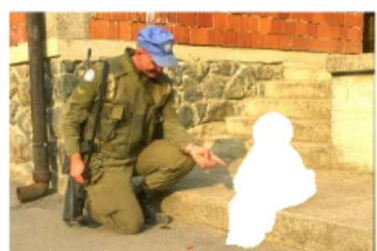

(b)

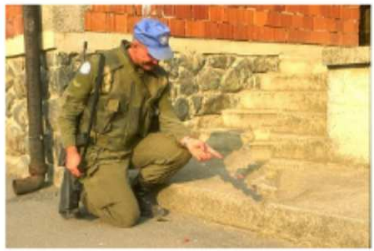

(f)

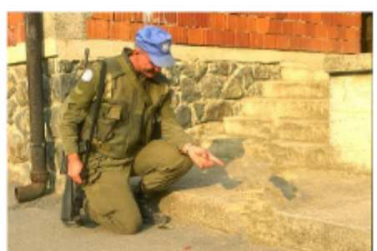

(c)

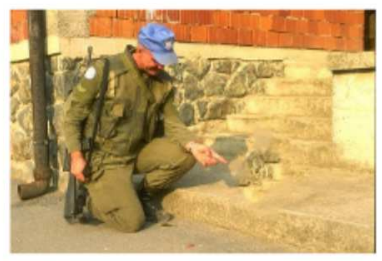

(g)

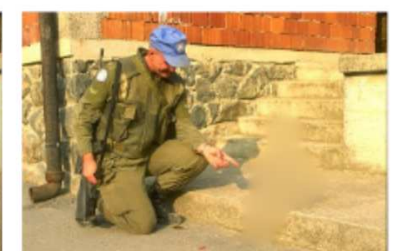

(d)

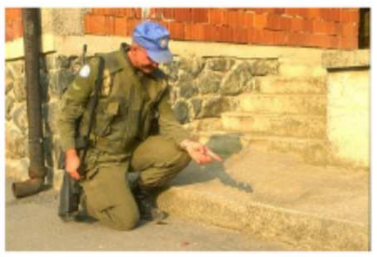

(h)

Figura 19 - Comparações qual itativas visando a aplicação de remoção de objetos em imagens digitais. (a) Imagem original. (b) Imagem contendo o objeto delineado (criança). (c) Síntese pura de textura (EFROS; LEUNG, 1999). (d) Mumford-Shad (SCHöNLIEB, 2015). (e) Replicação por blocos (CRIMINISI; PEREZ; TOYAMA, 2004). (f) Blocos com prioridade remodel ada (L.J.; T.Z.; X.L., 2015). (g) Adobe CAW (WEXLER; SHECHTMAN; IRANI, 2007; BARNES et al., 2009). (h) Técnica DTAS.

A Figura 21 aborda novamente o caso de remoção de objetos onde tem-se uma grande área a ser removida em meio a uma região al tamente texturizada. Entretanto, a textura deste caso apresenta um padrão mais amplo do que a do caso anterior. As Figuras21a e 21b apresentam as imagens original e de entrada, enquanto que as Figuras $21 \mathrm{c}$ até $21 \mathrm{~h}$ remetem aos resultados produzidos pelas técnicas avaliadas, a saber: SPT, MSE, RE, EPR, Adobe CAW e pela metodologia DTAS. De acordo com as imagens resultantes obtidas pel os métodos citados anteriormente, é possível visualizar que o úni co caso em que as linhas de textura foram adequadamente interligadas foi na Figura $21 \mathrm{~h}$ (método DTAS). Outro ponto importante acerca dos resultados é o aspecto visual final. Nesse quesito, a técnica DTAS obteve novamente um desempenho satisfatório quando comparada com as demais metodologias.

Conforme ilustrado na Figura 22, o seguinte experimento visa avaliar cada uma das técnicas quando o objeto a ser removido encontra-se inserido em uma região de fronteira entre tipos variados de texturas e estruturas homogêneas. As Figuras 22c até Figura 22h mostram, na sequência, os resul tados obtidos pelas técni cas el encadas anteriormente em nossa bateria de testes. É possível visualizar nas Figuras 22c até $22 f$ que, ou a técnica utilizada não reconstrói a estrutura no fundo da fotografia ("região da janela") ou ela prolonga erroneamente essas estruturas para regiões indevidas (Figura 22e). Por outro lado, tanto as Figuras $22 \mathrm{~g}$ e $22 \mathrm{~h}$ reproduzem corretamente as informações fal tantes na imagem de entrada. Além disso, quando compara-se as Figuras $22 \mathrm{~g}$ e 22h, nota-se que apenas a Figura $22 \mathrm{~h}$ preserva adequadamente a espessura da janela.

Final mente, em nosso úl timo experimento submetemos cada uma das técncias anal isadas à compl exa tarefa de reconstrução quando uma grande porção daimagem está danificada em meio a um cenário bastante rico em detal hes visuai s de textura, conforme ilustrado pelas Figuras 23a 


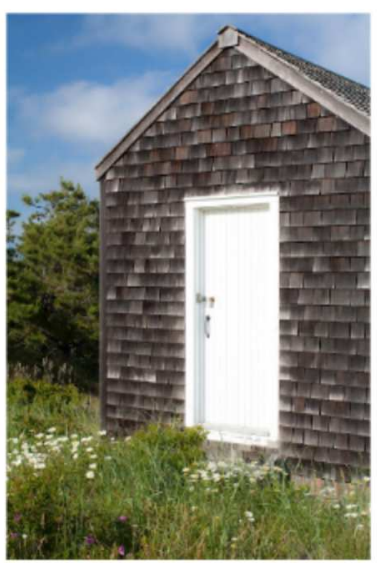

(a)

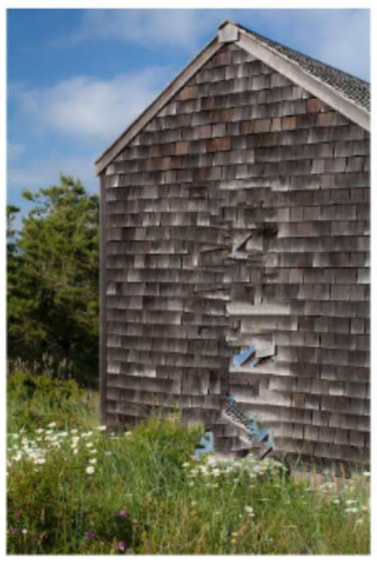

(e)

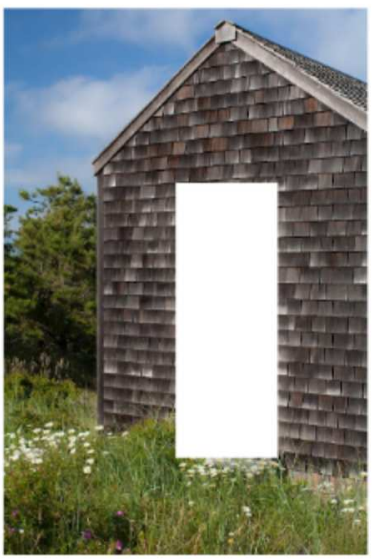

(b)

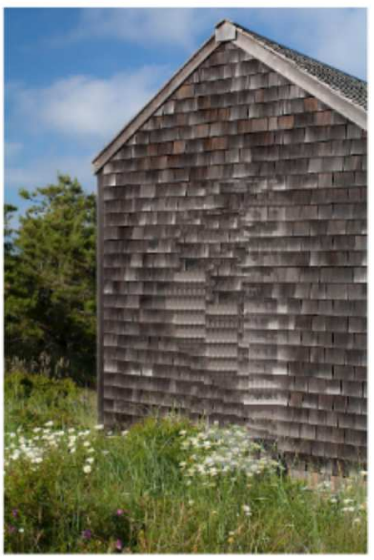

(f)

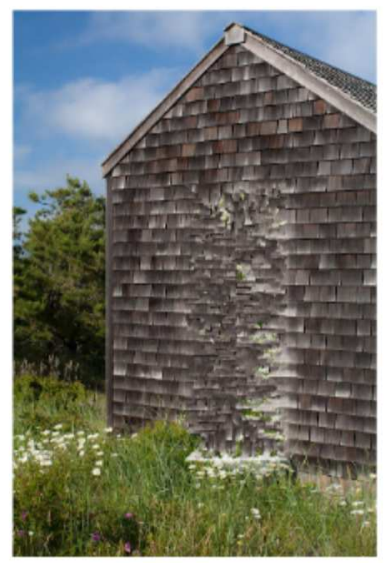

(c)

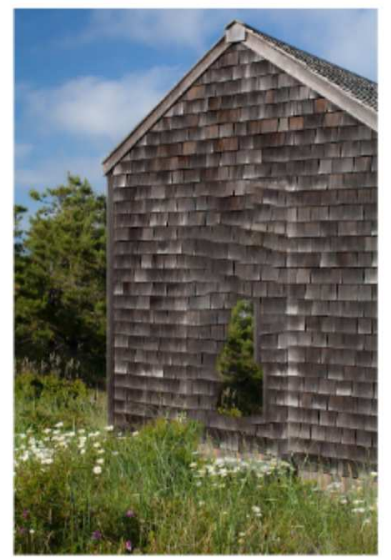

(g)

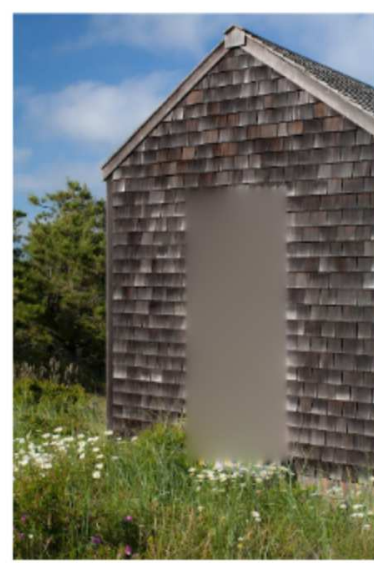

(d)

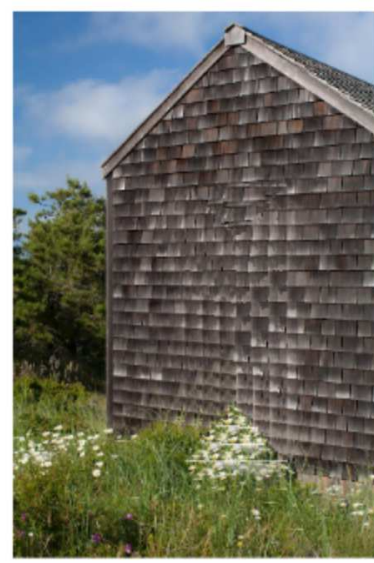

(h)

Figura 20 - Comparações qualitativas acerca da tarefa de remoção de objetos em imagens digitais. (a) Imagem original. (b) Imagem contendo o objeto delineado (porta). (c) Síntese pura de textura (EFROS; LEUNG, 1999). (d) Mumford-Shad (SCHöNLIEB, 2015). (e) Replicação por blocos (CRIMINISI; PEREZ; TOYAMA, 2004). (f) Blocos com prioridade remodelada (L.J.; T.Z.; X.L., 2015). (g) Adobe CAW (WEXLER; SHECHTMAN; IRANI, 2007; BARNES et al., 2009). (h) Técnica DTAS.

e 23b (por exemplo, veja o "telhado do chalé" e suas "janelas"). Dentre os resultados visuais obti dos por cada uma das técni cas (Figuras 23c até 23h), os resultados das Figuras23c, 23d e 23e não reproduzem devidamente os padrões de textura presentes na imagem, de modo a produzir um ef ei to visual indesejável. Por outro lado, as imagens das Figuras $23 f$ até $23 \mathrm{~h}$ produzem resultados sati sf atórios. Entretanto, é possível averiguar que na Figura 23h, que tanto o telhado quanto a região das janelas do chal é foram reconstruídas com mais qual idade em comparação com as demais metodologias em termos de preservação de detal hes finos.

\section{Comparações quant it ativas}

A performance da técnica DTAS quando comparada numericamente com os demais métodos do estado-da-arte em retoque é apresentada a seguir. Os métodos empregados nas comparações são: SPT (EFROS; LEUNG, 1999), MSE (SCHöNLIEB, 2015), RE (CRIMINISI; PEREZ; TOYAMA, 2004), EPM (L.J.; T.Z.; X.L., 2015) e Adobe Photoshop Content-Aware 


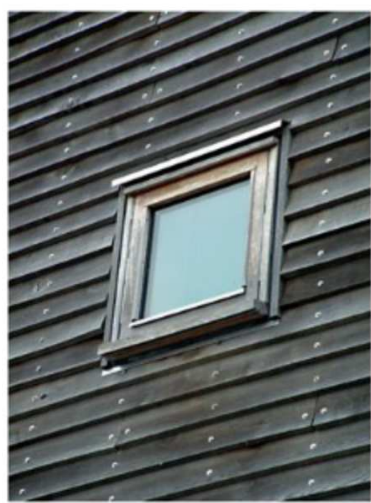

(a)

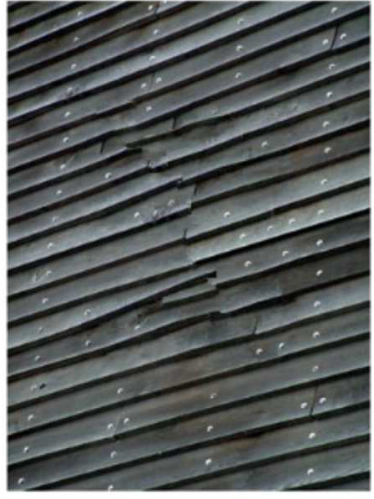

(e)

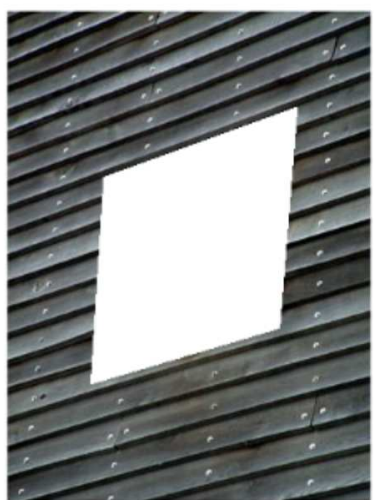

(b)

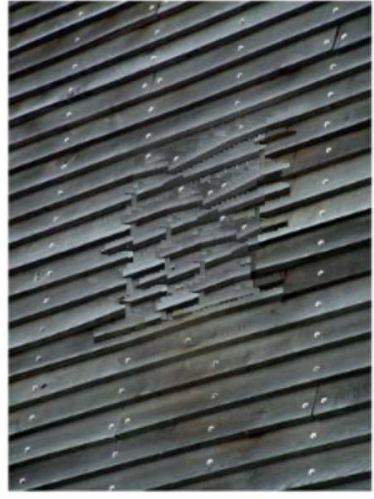

(f)

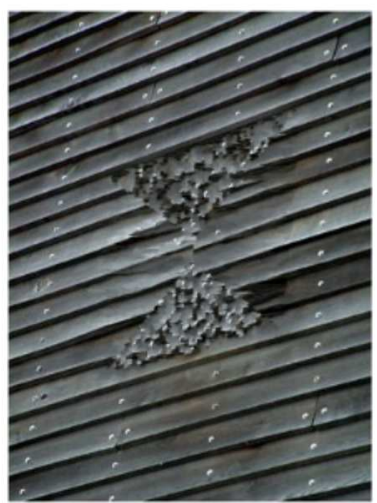

(c)

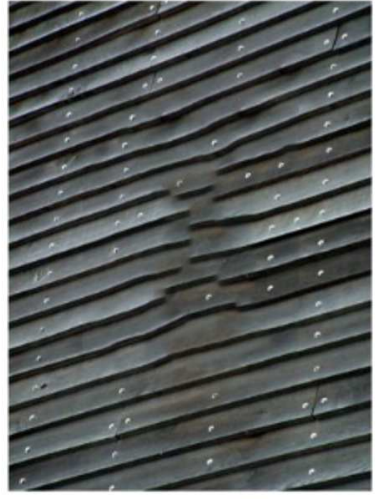

(g)

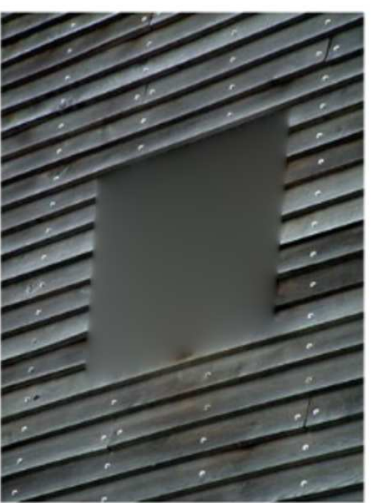

(d)

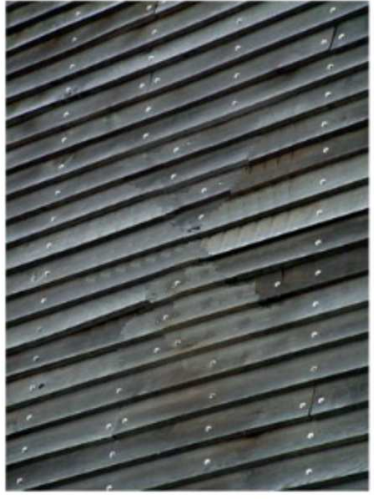

(h)

Figura 21 - Comparações qual itativas para a tarefa remoção de objetos em uma fotografia texturizada. (a) Imagem original. (b) Imagem contendo o objeto del ineado (janela). (c) Síntese pura de textura (EFROS; LEUNG, 1999). (d) Mumford-Shad (SCHöNLIEB, 2015). (e) Replicação por blocos (CRIMINISI; PEREZ; TOYAMA, 2004). (f) Blocos com prioridade remodelada (L.J.; T.Z.; X.L., 2015). (g) Adobe CAW (WEXLER; SHECHTMAN; IRANI, 2007; BARNES et al., 2009). (h) Técnica DTAS.

Fill.

Para aval iar quantitativamente o impacto de cada técnica, adotamos duas métricas comumente utilizadas pela comunidade de Ciências da Informação e Visão Computacional, a saber: PSNR (Peak Signal-to-Noise Ratio) e SSIM (Structural Similarity Index) (WANG et al., 2004).

A primeira métrica considera o maior val or atingido pel os sinais aval iados (em nosso caso, as imagens) e o erro médio quadrático entre os mesmos. Já a métrica SSIM tem sido utilizada para predição da qual idade percebi da por tel espectadores no ramo de tel evisão digital e filmes de cinema ${ }^{6}$. Ela leva em consideração a percepção visual humana, comparando as imagens não em termos de val ores absol utos da diferença entre as imagens, mas sim aval iando-se a similaridade entre as estruturas das imagens anal isadas.

Neste contexto, é importante salientar que não é possível mensurar a qualidade de reconstrução no caso da apl icação de remoção de objetos, uma vez que não há uma imagem de referência ("ground truth") para a utilização das métricas. Com isso, foram anal isadas apenas as

6 <https://en.wikipedia.org/wiki/Structural_similarity> 


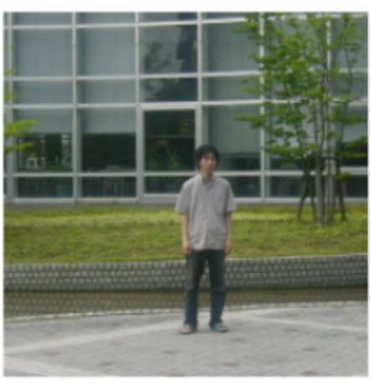

(a)

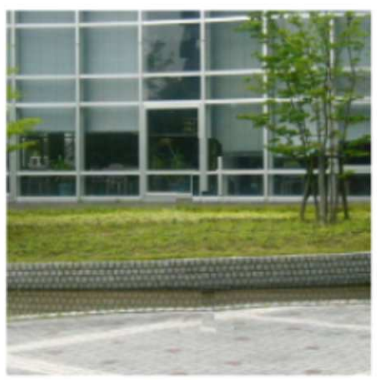

(e)

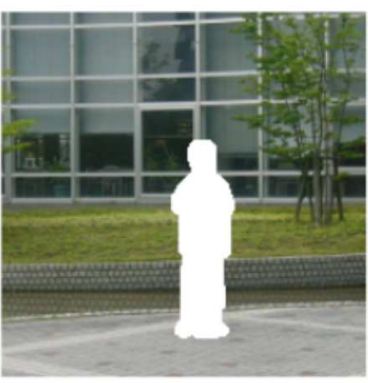

(b)

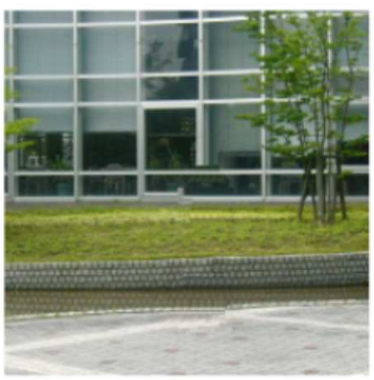

(f)

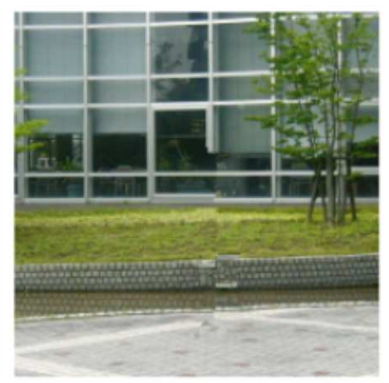

(c)

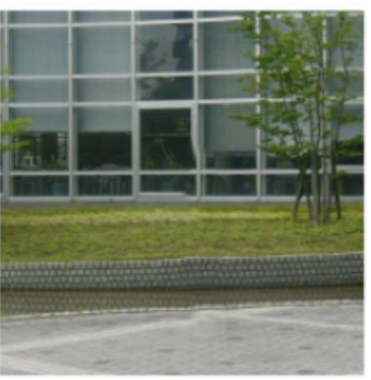

(g)

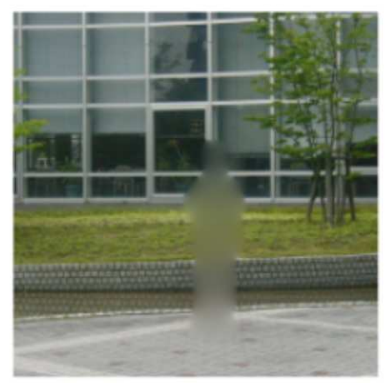

(d)

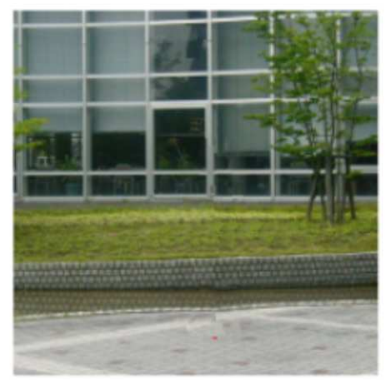

(h)

Figura 22 - Comparações qual itativas levando-se em conta a remoção de um objeto em meio a diversas classes de texturas. (a) Imagem original. (b) Imagem contendo o objeto delineado (pessoa). (c) Síntese pura de textura (EFROS; LEUNG, 1999). (d) Mumford-Shad (SCHöNLIEB, 2015). (e) Replicação por blocos (CRIMINISI; PEREZ; TOYAMA, 2004). (f) Blocos com prioridade remodelada (L.J.; T.Z.; X.L., 2015). (g) Adobe CAW (WEXLER; SHECHTMAN; IRANI, 2007; BARNES et al., 2009). (h) Técnica DTAS.

imagens identificadas como danificadas artificial mente, pois tais imagens possuem uma versão original.

A Tabela 1 reúne os resultados para a métrica PSNR quando avaliada nas imagens danificadas artificialmente da seção anterior. Conforme sumarizado pela tabela abaixo, a técnica DTAS obteve o mel hor score para todos os casos dentre os métodos aval iados. Essa concl usão também pode ser obtida quando comparamos as médias de cada técnica, situação em que a metodol ogia DTAS obteve um score de 21:24 seguido pel o método EPM (L.J.; T.Z.; X.L., 2015) com um score de 19:91.

Tabela 1 - Avaliação quantitativa usando PSNR (em dB) para os resul tados si ntéticos apresentados na seção anterior.

\begin{tabular}{lcccccc}
\hline Imagem & STP $^{7}$ & MSE $^{8}$ & RE $^{9}$ & EPM $^{10}$ & Adobe CAW & Método DTAS \\
\hline Curch & $26: 04$ & $26: 17$ & $14: 10$ & $29: 23$ & $28: 80$ & $31: 46$ \\
\hline Monge & $17: 25$ & $19: 00$ & $11: 01$ & $18: 90$ & $16: 59$ & $19: 37$ \\
\hline Snow & $11: 02$ & $12: 20$ & $11: 66$ & $11: 61$ & $12: 17$ & $12: 88$ \\
\hline Média & 18.10 & 19.12 & 12.26 & 19.91 & 19.19 & 21.24 \\
\hline \hline
\end{tabular}

O resul tado da utilização da métrica SSIM nas imagens restauradas pelas técnicas em questão para as imagens dani ficadas sinteticamente pode ser visual izado na Tabela 2. De modo 


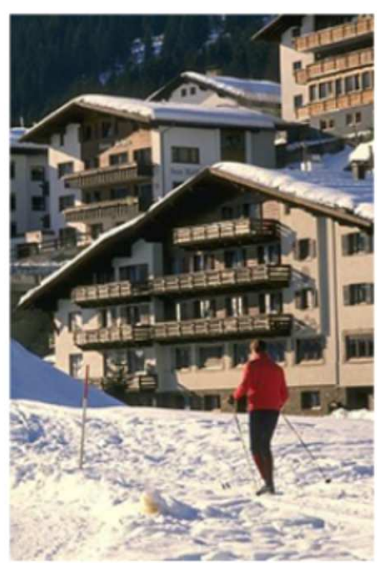

(a)

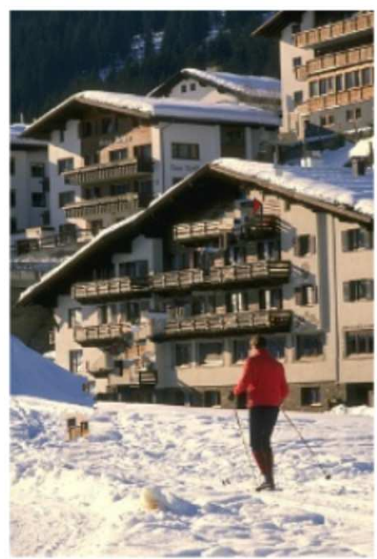

(e)

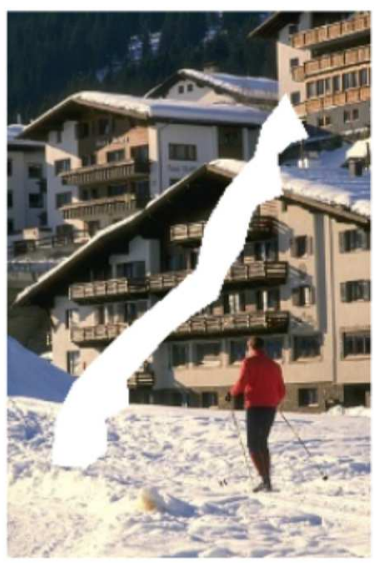

(b)

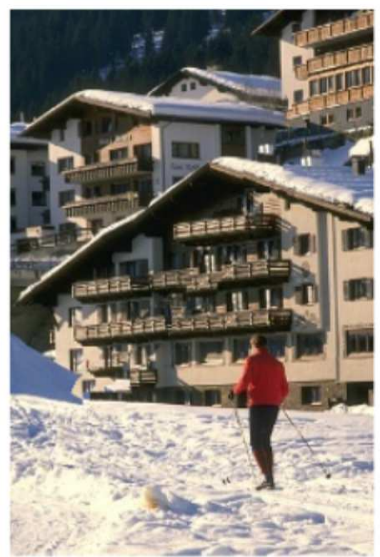

(f)

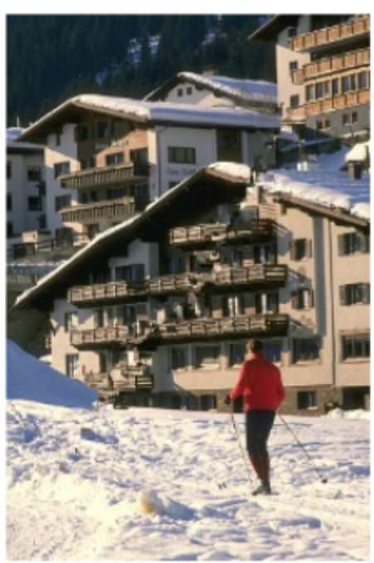

(c)

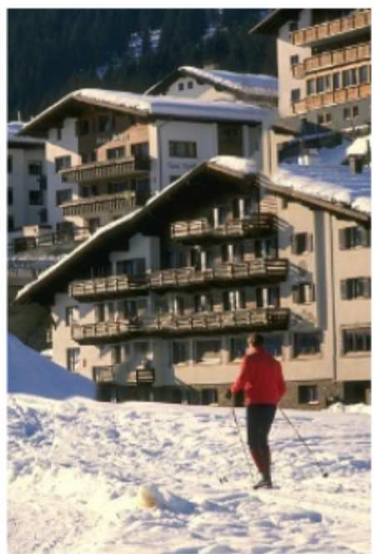

(g)

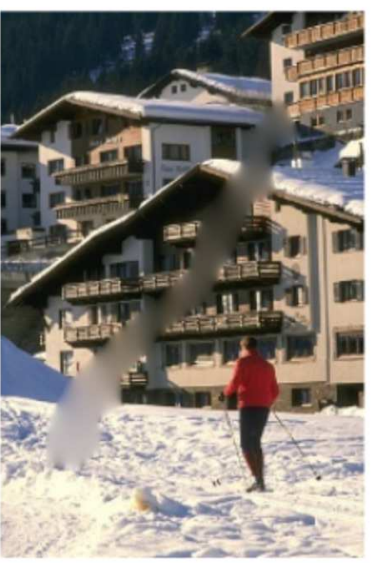

(d)

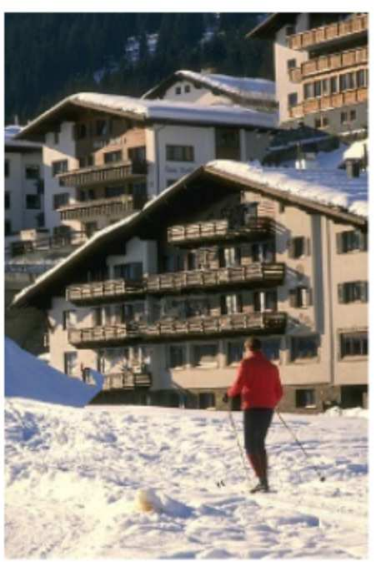

(h)

Figura 23 - Comparações qual itativas considerando-se uma imagem contendo diversas regiões de textura (a) Imagem original. (b) Imagem contendo região a ser restaurada. (c) Síntese pura de textura (EFROS; LEUNG, 1999). (d) Mumford-Shad (SCHöNLIEB, 2015). (e) Replicação por blocos (CRIMINISI; PEREZ; TOYAMA, 2004). (f) Blocos com prioridade remodel ada (L.J.; T.Z.; X.L., 2015). (g) Adobe CAW (WEXLER; SHECHTMAN; IRANI, 2007; BARNES et al., 2009). (h) Técnica DTAS.

similar ao caso anterior, a técnica DTAS obteve um resultado bastante satisfatório quando comparado com as demais técnicas anal isadas. Nesse sentido, a metodol ogia DTAS obteve um score 0:9149, seguido pelo Adobe Photoshop CAW (score 0:9100) e EPM (score 0:9088).

Tabela 2 - Avaliação quantitativa usando SSIM (Structural Similarity Metric) para os resultados sintéticos apresentados na seção anterior.

\begin{tabular}{lcccccc}
\hline Imagem & STP $^{11}$ & MSE $^{12}$ & RE $^{13}$ & EPM $^{14}$ & Adobe CAW & Método DTAS \\
\hline Curch & $0: 9312$ & $0: 9291$ & $0: 9210$ & $0: 9325$ & $0: 9339$ & $0: 9348$ \\
\hline Monge & $0: 9276$ & $0: 9328$ & $0: 9177$ & $0: 9282$ & $0: 9280$ & $0: 9335$ \\
\hline Snow & $0: 8610$ & $0: 8633$ & $0: 8686$ & $0: 8656$ & $0: 8680$ & $0: 8764$ \\
\hline Média & 0.9066 & 0.9084 & 0.9024 & 0.9088 & 0.9100 & 0.9149 \\
\hline \hline
\end{tabular}


Comparações quantitativas utilizando técnicas de representação esparsa

A avaliação comparativa apresentada na sequência consiste na restauração de blocos degenerados na imagem. Foi real izada uma comparação qual itativa e também quantitativa com métodos que fazem uso de propriedades de esparsidade das imagens. Da esquerda para a direita, na Figura 24, são ilustradas: 24a as imagens de entrada, e na sequência os resultados produzidos pelos métodos de 24b Guleryuz ul eryuz ${ }^{15}$ (GULERYUZ, 2006), 24c El ad et al. ${ }^{16}$ (ELAD et al., 2005), 24d Fadili et al. ${ }^{17}$ (FADILI; STARCK; MURTAGH, 2009), 24e Xu e Sun ${ }^{18}$ (XU; SUN, 2010) e $24 \mathrm{f} \mathrm{Li}^{19}$ (LI, 2011). $24 \mathrm{~g}$ os resul tados com o método DTA $S^{20}$. Final mente, $24 \mathrm{~h}$ ilustram a imagem original ("ground truth").

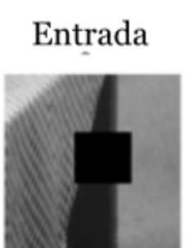

Guleryuz
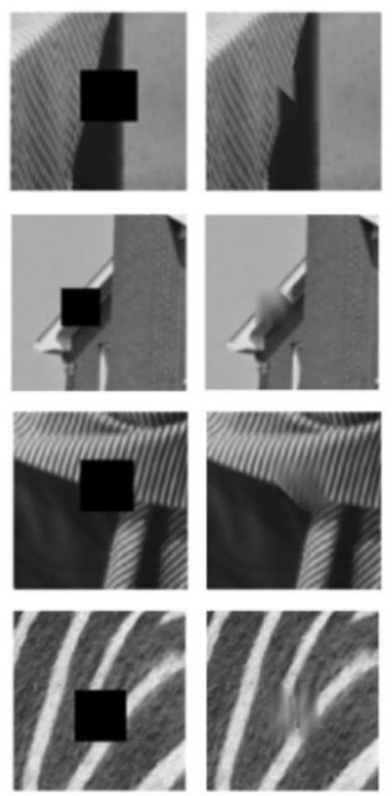

(a)
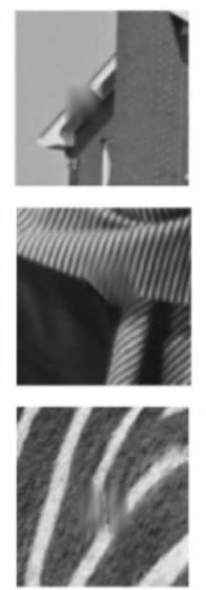

(b)
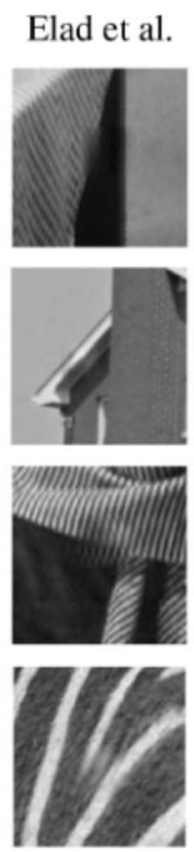

(c)
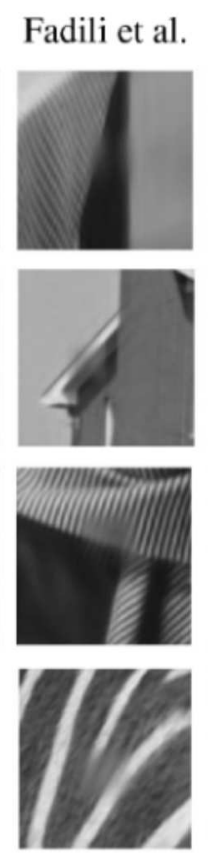

(d)
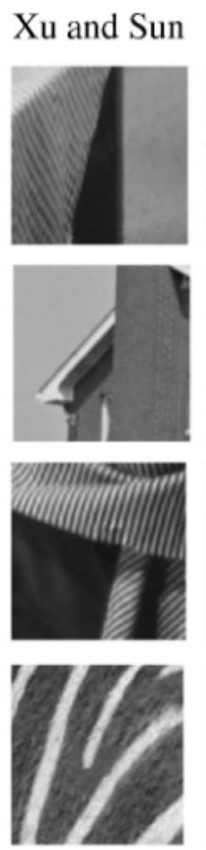

(e)
$\mathrm{Li}$
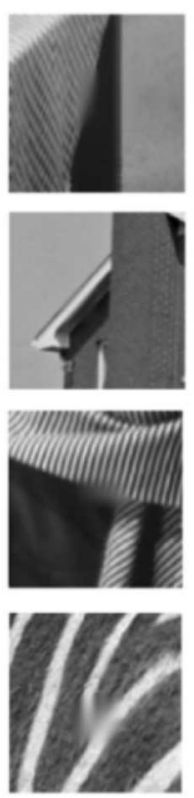

(f)
DTAS
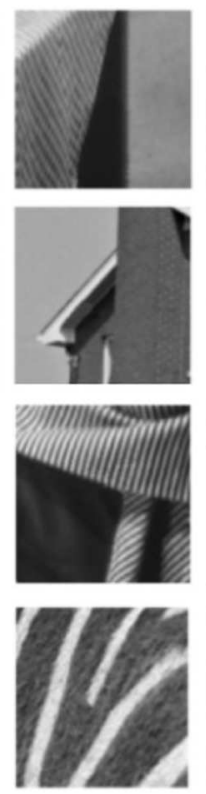

(g)
Original
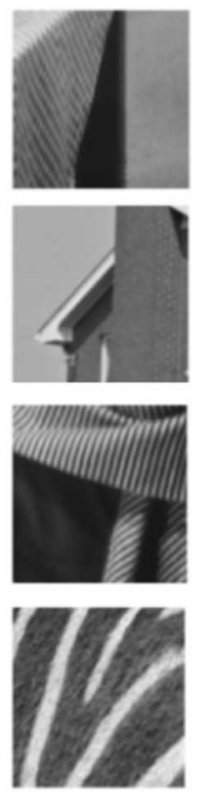

(h)

Figura 24 - Comparação com métodos de retoque baseados em representação esparsa. (a) Imagens de entrada ("Tissue", "Eaves", "parte da Barbara" e "Fur"). (b) Guleryuz (GULERYUZ, 2006). (c) Elad et al. (ELAD et al., 2005). (d) Fadili et al. (FADILI; STARCK; MURTAGH, 2009). (e) Xu e Sun (XU; SUN, 2010). (f) Li (LI, 2011). (g) Método DTAS. (h) Imagem original. Fonte: (CASACA et al., 2014).

Os exemplos são difíceis de manusear devido à predominância de estruturas e texturas em torno da região a ser preenchida. Observe que os algoritmos de Guleryuz e Fadili et al. produziram um ef ei to de desfoque sobre as imagens, enquanto o método de El ad et al. introduziu al guns artef atos nas imagens. Os resultados obtidos com os métodos de Xu e Sun e de Li são visual mente mel hores do que os apresentados por Gul eryuz e Fadili et al., mas eles ainda sofrem

\footnotetext{
15 com DCT de $32 \times 32$

16 com dicionário de textura/camadas de cartoon usando DCT de $32 \times 32$

17 transformada curvelet com 5-resolution (CANDèS et al., 2006)

18 com tamanho de pache de $7 \times 7, \mathrm{~N}(\mathrm{p})$ tamanho de $51 \times 51 \mathrm{ee}=\mathrm{N}=25$

$19 \mathrm{~B}=31, \mathrm{k}=30, \mathrm{~d}=4, \mathrm{n}_{\max }=50, \mathrm{~N}_{\max }=3$

$20 \quad(s ; m ; n)=(15 ; 13 ; 15),(10 ; 3 ; 7),(15 ; 7 ; 11),(15 ; 5 ; 7)$, de cima para baixo
} 
com o efeito de suavização excessiva. A técnica DTAS restaurou as imagens sem causar o ef eito de desfoque e recuperou com precisão as isófotas e regiões contendo apenas textura, produzindo resultados mais próximos das imagens "ground truth".

Para ef eito de comparação quantitativa, a medida PSNR (Peak Signal-to-Noise Ratio) foi cal cul ada entre as imagens restauradas e as originais da Figura 24, conforme apresentado na Tabela 3. Ao observar o PSNR médio, naúltimalinha da Tabela 3, verificamos que a abordagem DTAS apresenta um desempenho superior aos dos demais métodos.

Tabela 3 - Aval iação quantitativa usando PSNR (em dB) para todas as comparações com as imagens da Figura 24.

\begin{tabular}{lcccrcc}
\hline Imagem & Guleryuz $^{21}$ & Elad et al. $^{22}$ & Fadili et al. $^{23}$ & Xu and Sun & Li & Método DTAS \\
\hline Tecido & $20: 41$ & $22: 43$ & $22: 16$ & $23: 53$ & $22: 21$ & $25: 02$ \\
\hline Beiral & $16: 15$ & $22: 85$ & $17: 86$ & $28: 45$ & $26: 77$ & $29: 30$ \\
\hline Parte da Barbara & $18: 39$ & $19: 20$ & $17: 85$ & $23: 07$ & $23: 61$ & $24: 43$ \\
\hline Pele & $16: 46$ & $19: 49$ & $20: 67$ & $20: 87$ & $18: 43$ & $21: 55$ \\
\hline Média & 17.85 & 20.99 & 19.64 & 23.98 & 22.75 & 25.08 \\
\hline \hline
\end{tabular}

\subsection{Discussões e limit ações}

A ordem de preenchimento guiada pelo componente cartoon e o mecanismo de amostragem dinâmica mostraram-se bastante eficientes na tarefa de restaurar/recompor uma imagem. Além disso, o termo proposto utilizado na métrica baseada em cartoon para cal cular a prioridade na ordem de preenchimento e a métrica proposta para avaliar a similaridade entre os bl ocos de pixels apresentaram resul tados sati sfatórios, superando as métricas baseadas puramente na representação da imagem de entrada. As comparações apresentadas na Seção 2.4 atestam a eficácia da abordagem apresentada em termos de qual idade de reconstrução. $O$ bom desempenho ao lidar com imagens texturizadas ricas em detal hes mostram a flexibilidade e a robustez do método apresentado.

Apesar dos bons resultados e propriedades de restauração, o método DTAS com as métricas propostas também tem limitações. Por exemplo, el e exige o ajuste al guns parâmetros para serem ef etivos. Otimizar os parâmetros é uma questão que será investigada em trabalhos futuros. Além disso, resul tados insatisf atórios podem ser produzidos quando real izamos retoque em imagens não texturizadas com el evada variação de cor, sendo esta outra limitação do método DTAS.

eliminação de ruído 



\section{ELIMINAÇÃO DE RUÍDOS}

\subsection{Int rodução}

A área de eliminação de ruído (denoising) é um assunto bastante rel evante no campo de processamento de imagens. A ideia fundamental das técni cas de eli minação de ruídos é recuperar detal hes perdidos em uma imagem contaminada por ruído. Procura-se, deste modo, reconstituir as informações original mente presentes na imagem, mas que foram degradadas por meio de al gum processo de interferência ou deterioração. Neste contexto, a noção de ruído pode ser entendi da como uma al teração da intensidade ou da cor dos pixels que estão dispersos por toda a imagem, de acordo com uma lei de formação matemática específica.

A Figura 25 mostra como o ruído pode af etar as informações em uma imagem. A Figura 25a mostra a imagem original e sem ruído. Nas Figuras 25b e 25c são apresentadas as imagens obtidas após aplicar ruído gaussi ano com diferentes intensi dades na imagem original . As imagens das Figuras 25d, e e f ilustram seus respectivos contornos, identificados por meio da variação do módul o do gradiente das imagens correspondentes (mapa de contornos).

O ruído modifica a aparência da imagem, reduzindo ou até mesmo removendo partes da informação visual inicial mente presente na mesma. A plicações que utilizam métodos de remoção de ruídos nos processos de transmissão, aquisição e processamento de imagens vêm sendo empregados cada vez mais em problemas práticos de visão por computador. Alguns exemplos desses problemas são aqueles que abrangem fotografias, imagens forenses e médicas, si stemas de gravação de segurança, dentre outros. De fato, pode-se afirmar que a situação ideal, de trabal har com imagens sem a presença de ruído, raramente ocorre em situações reais.

As principais fontes de contaminação de ruído em imagens são, em geral , decorrentes das etapas de aqui si ção e transmi ssão em um si stema de visão por computador. De fato, quase todos os di spositivos de aquição e manipul ação de imagem estão suj eitos à limitações técnicas ou ambientais. Por exemplo, o problema de contami nação por ruído devido aos ef ei tos de campos 


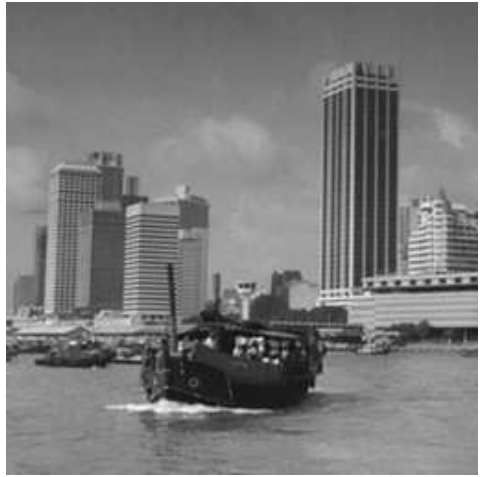

(a)

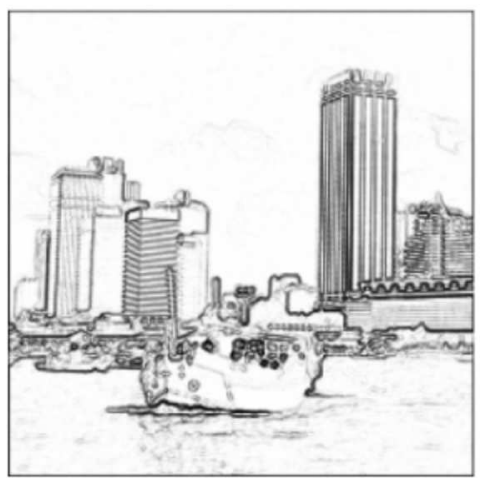

(d)

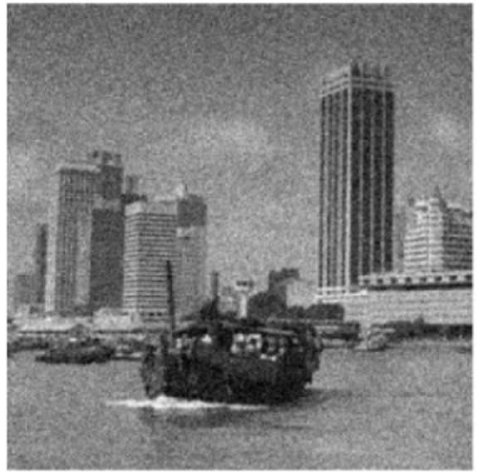

(b)

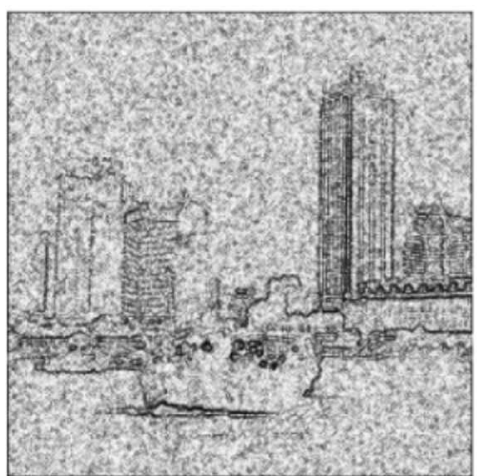

(e)

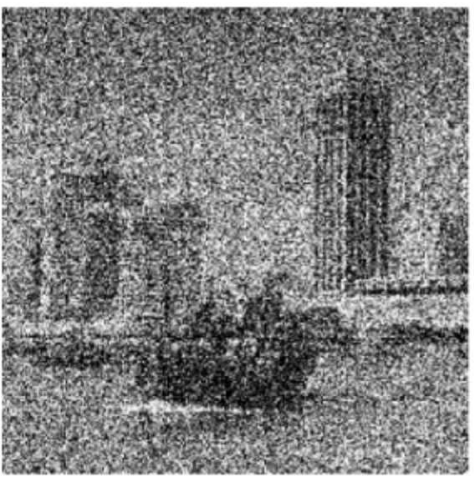

(c)

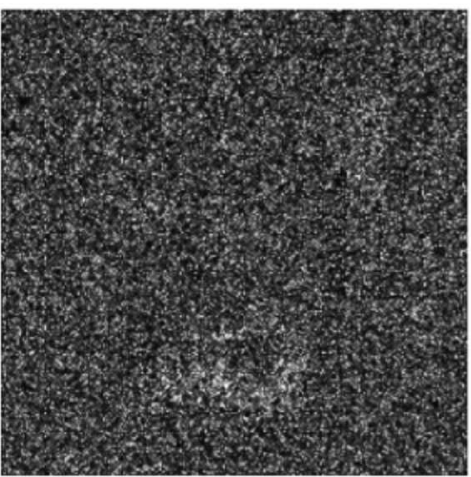

(f)

Figura 25 - Imagens com diferentes níveis de ruído e seus respectivos contornos.

magnéticos quando um tel escópio no espaço captura imagens e as envia para a Terra é um exempl o clássi co das restrições ambientais. Já a contami nação por ruído produzi da durante a aqui sição de uma imagem de nanotecnologia é, por sua vez, um exemplo clássico de limitações de ordem tecnológica. Ainda sobre o problema, também não é incomum a captura de fotografias com ruído por dispositíveis móveis atuai s como celulares, smartphones, tablets, etc. Por exemplo, a Figura 26 apresenta uma fotografia recentemente tirada por meio de um celular (smartphone) em um ambiente escuro, a qual contém uma grande incidencia de ruído.

Grande parte dos tipos de degradações por ruído em imagens digitais podem ser formulados por meio de um model o si mples de degeneração aditiva (GONZALEZ; WOODS, 2007):

$$
\mathrm{I}(\mathrm{x} ; \mathrm{y})=\mathrm{u}(\mathrm{x} ; \mathrm{y})+\mathrm{n}(\mathrm{x} ; \mathrm{y})
$$

no qual $\mathrm{u}(\mathrm{x} ; \mathrm{y})$ indica a imagem original (sem ruído), $\mathrm{n}(\mathrm{x} ; \mathrm{y})$ descreve os efeitos do ruído e l $(\mathrm{x} ; \mathrm{y})$ representa a imagem dani ficada pelo ruído. Devido à existência de diferentes classes de ruídos, a função $n(x ; y)$ geralmente é definida numericamente como sendo uma variável al eatória, de modo semel hante às abordagens encontradas em aplicações estatísti cas. Assim, podemos usar funções densidade de probabilidade (CASELLA; BERGER, 2002) para estimar e descrever os efeitos do ruído na qualidade da imagem.

A função de distribuição de probabilidade Gaussiana (Normal) pode ser empregada para 


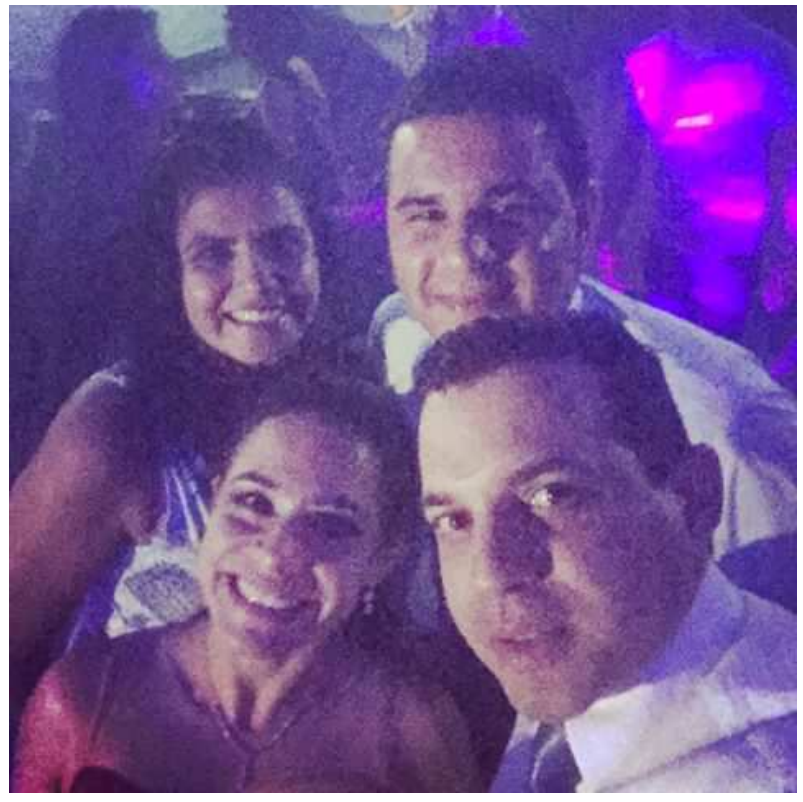

Figura 26 - Exemplo de fotografia capturada com rúido.

modelar os efeitos do ruído gaussiano enquanto a distribuição de Bernoulli é aplicada para estimar o ruído impulsivo (do tipo "sal e pimenta") (ALMEIDA; BOAVENTURA, 2009). O ruído gaussiano geral mente se mani festa em imagens geradas a partir de câmeras, microscópios e telescópi os especiais, af etando todos os pixels da imagem. Os erros que podem acontecer em operações de transmi ssão e digital ização de dados são fontes de geração de ruído impul sivo. De modo geral, podemos consi derar que estes são os tipos de ruídos mais pesqui sados na literatura, pois ocorrem frequentemente em situações práticas (ALMEIDA; BOAVENTURA, 2010).

Na Figura 27 podemos visual izar o comportamento e o impacto dos dois tipos de ruído (gaussiano e impul sivo) em uma fotografia A imagem sem ruído é apresentada na Figura 27a e a Figura 27b mostra sua representação em um espaço de cor RGB. Na Figura 27c podemos observar a imagem após ser danificada pelo ruído gaussiano. Ao observar a representação desta imagem no espaço RGB (Figura 27d) podemos notar que todos os pixels da imagem sofreram al terações em suas tonal idades. Ao contrário do que ocorre ao degradar a imagem com ruído gaussiano, a al teração provocada pelo ruído impul sivo af eta apenas al guns pixels da imagem, fato ilustrado nas Figuras 27e e $27 \mathrm{f}$.

A distinção contemplando tais tipos de ruído implica na utilização direta de abordagens específicas para eliminar, ou amenizar, a presença de ruído em uma imagem. Desse modo, o problema de eliminação de ruído com foco no ruído gaussiano é abordado neste capítulo, uma vez que este é um dos tipos de ruído que aparece com mai or frequência nas aplicações.

Este capítulo está organizado da seguinte maneira: na Seção 3.1.2 são apresentados al guns model os do estado-da-arte em el iminação de ruído desti nados às imagens com texturas; o método para tratar imagens com ruído gaussiano baseado na EDP não-linear ani sotrópica regularizada e sua val idação teórica são abordados na Seção 3.2; a implementação numérica 


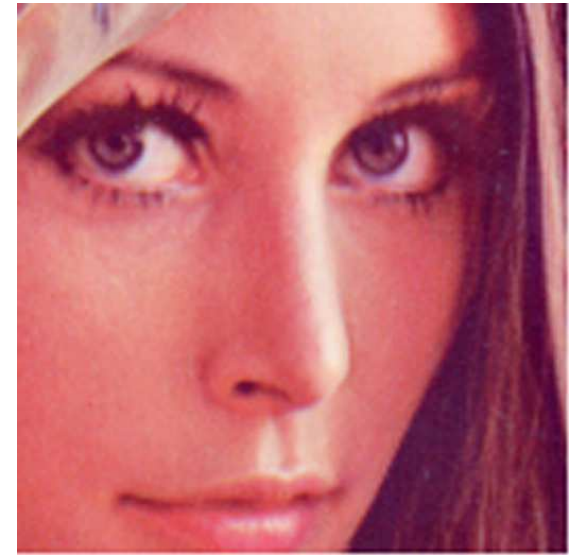

(a)

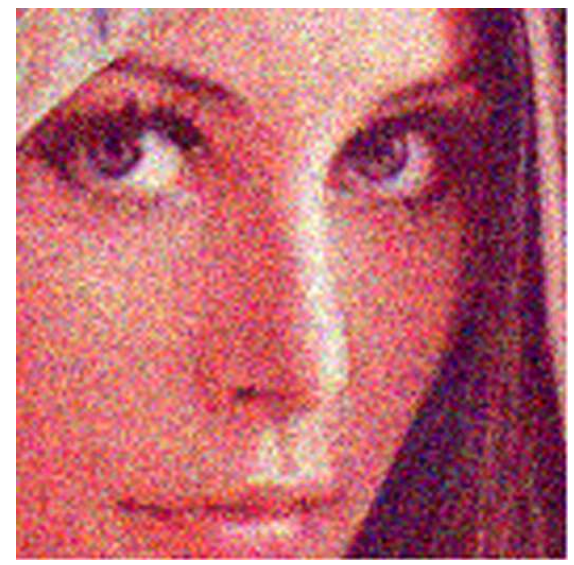

(c)

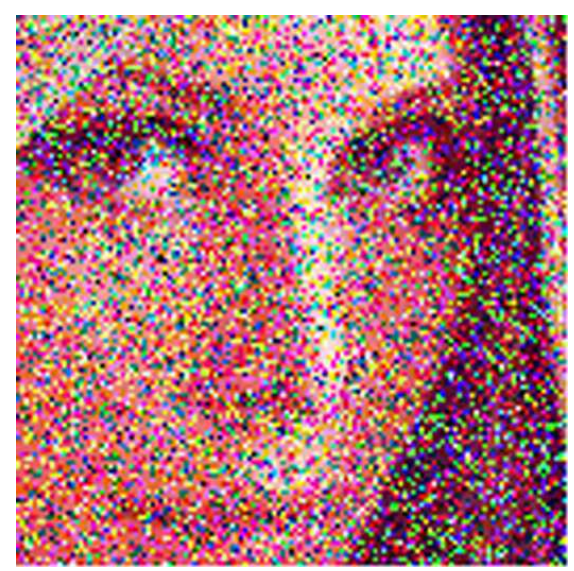

(e)

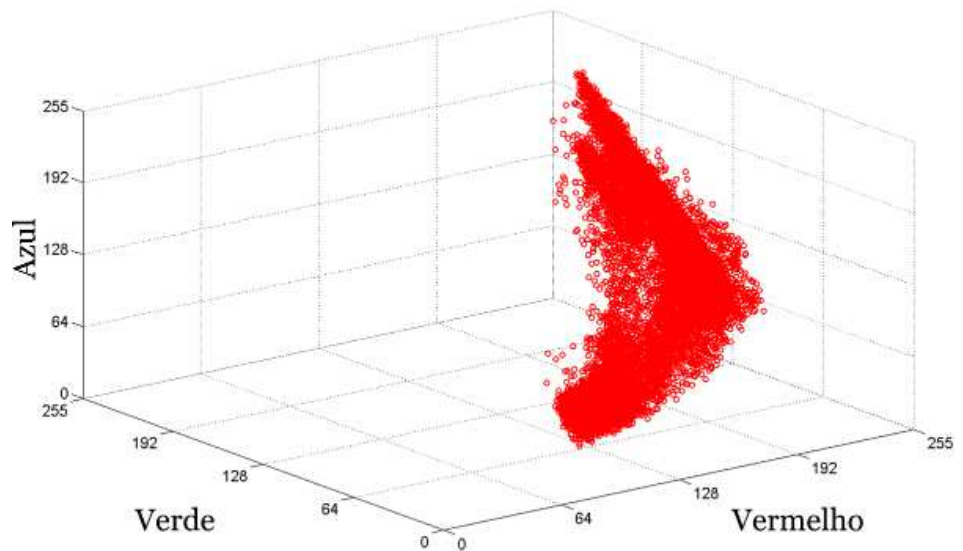

(b)

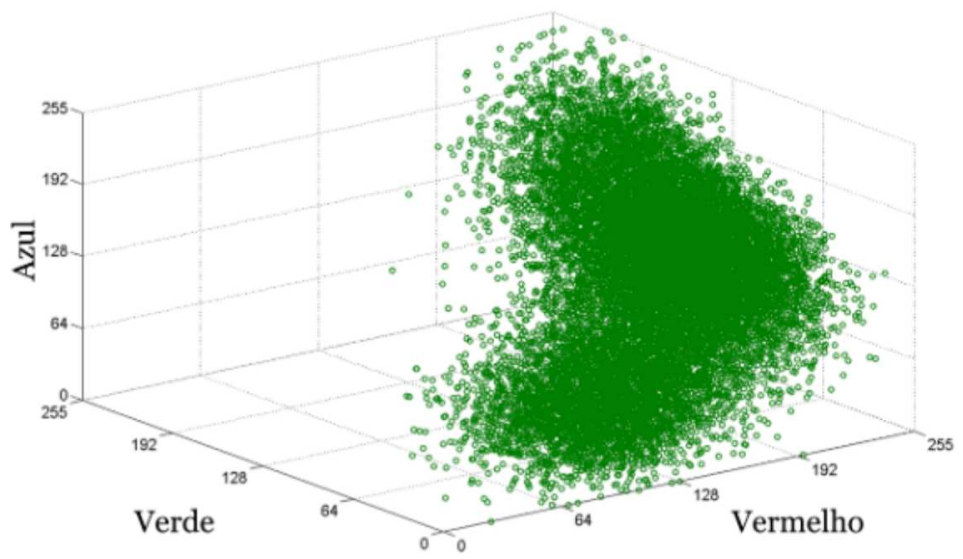

(d)

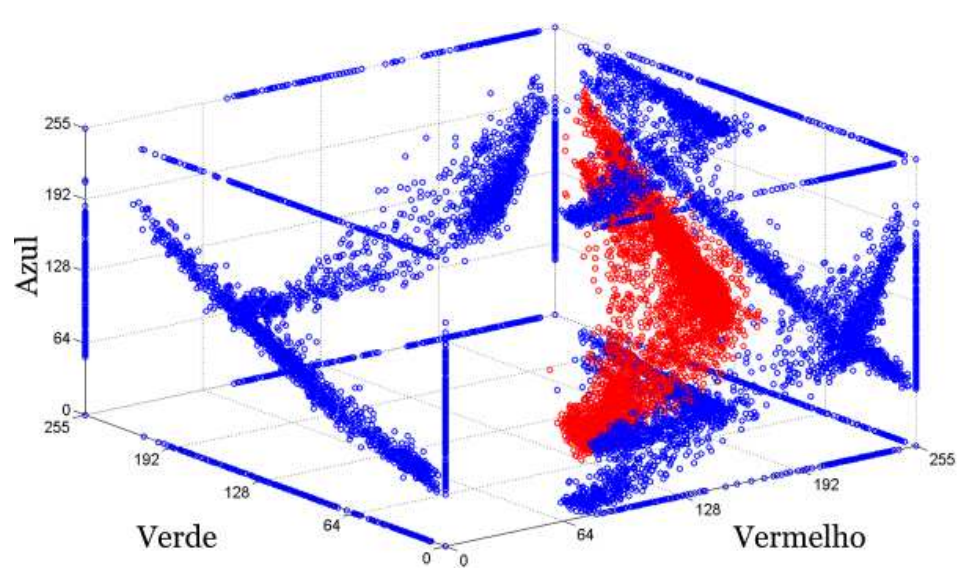

(f)

Figura 27 - Alterações geradas em uma determinada imagem pela ação dos ruídos gaussiano e impul sivo. (a) Imagem original. (b) Representação no espaço RGB da imagem original com círcul os vermelhos. (c) Imagem af etada pel o ruído gaussiano. (d) Visual ização no espaço RGB da imagem com ruído gaussiano em círculos verdes. (e) Imagem deteriorada pelo ruído impulsivo. (f) Gráfico em coordenadas RGB da imagem com ruído impulsivo indicado por círcul os azuis. Fonte: (ALMEIDA; BOAVENTURA, 2010) 
da EDP é descrita na Seção 3.3; a anál ise dos parâmetros, resul tados experimentais, análise do desempenho e a comparação com outras técnicas de el iminação de ruído são apresentadas na Seção 3.4; e, por fim, na Seção 3.5 são descritas as consi derações finais sobre o trabal ho na área de eliminação de ruído.

\subsubsection{Motivação}

Em termos da formul ação matemática, várias técnicas de el iminação de ruído consideram que a imagem de entrada é uma função com variação limitada (bounded variation) sem a presença de qualquer tipo de textura/oscilações, enquanto que a imagem desejada é suave por seções. Além disso, o ruído é, de modo geral, caracterizado por uma função de oscilação de alta frequência. Assim, um bom modelo de eliminação de ruído deve ser capaz de recuperar uma imagem danificada e também preservar suas principais características visuais tais como bordas, contornos e contraste.

Na literatura sobre o tema há diversas variações de técnicas destinadas ao tratamento do problema, em especial aquel as baseadas em formulações não-lineares tais como, Difusão Anisotrópica (PERONA; MALIK, 1990; NORDSTROM, 1991; ALVAREZ; LIONS; MOREL, 1992; WANG et al., 2013), Métodos Variacionais (RUDIN; OSHER; FATEMI, 1992; CHAN; OSHER; SHEN, 2001), Regularização Iterativa (OSHER et al., 2005) e Espaços de Escala Inversos (BURGER et al., 2006). De fato, tais abordagens não são plenamente adequadas para tratar imagens com elevada concentração de texturas, pois as imagens podem apresentar um nível consi derável de informações contrastantes como regiões de alta oscil lação na escal a de cinza da imagem, áreas detal hadas ou ainda padrões complexos (CASACA; ALMEIDA; BOAVENTURA, 2013). Estas informações de natureza oscilatória estão incorporadas em meio ao ruído também presente na imagem. Dessa forma, é desejado que essas características sejam distinguidas durante o processo de restauração.

Para i lustrar estas características, a Figura 28a apresenta uma imagem clássica de processamento de imagens contendo vários tipos de informações visuais relevantes da imagem (texturas, áreas com detal hes e padrões complexos) enquanto que a Figura 28b apresenta sua versão degradada por ruído gaussiano.

Com o intui to de tratar de forma unificada várias classes de imagens, cada qual contendo características bastante específicas a serem preservadas como texturas, existem estudos direcionados à combi nação das abordagens anteriormente mencionadas com técnicas amparadas pela teoria moderna de anál ise harmônica tais como Wavel ets, Curvel ets e Wave atoms (ANSARI; BUDHHIRAJU, 2016; ANSARI; BUDDHIRAJU, 2015; DEMANET; YING, 2007a; DEMANET; YING, 2007b; STARCK; CANDèS; DONOHO, 2002). Em particular, diversos métodos de eliminação de ruído tem sido propostos visando integrar difusão anisotrópica, modelagem variacional, curvel ets e wave atoms, naintenção de se produzir filtros regularizados para remoção de ruídos (MA; PLONKA, 2007; PLONKA; MA, 2008; LIU; FENG; BAI, 2008; LIU, 2011). 


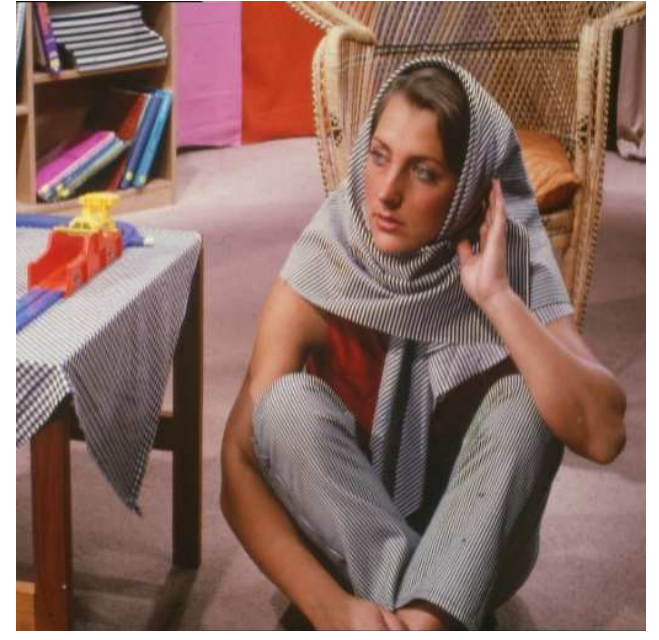

(a)

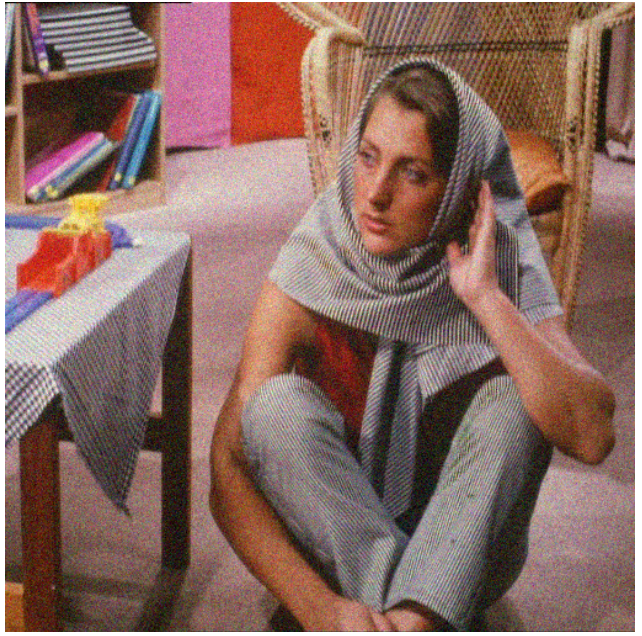

(b)

Figura 28 - Exemplo clássico de imagem contendo informações geométricas e texturas complexas. (a) mostra a imagem original. (b) apresenta a imagem com ruído gaussiano.

Embora robustas do ponto de vista da formulação teórica, na prática o uso destas abordagens tendem a suavizar significativamente a imagem e seus detal hes finos.

Para tratar as limitações sobre a suavização excessiva da imagem, apresentamos neste capítulo uma EDP (Equação Diferencial Parcial) não-linear anisotrópica regularizada, proposta em (CASACA; BOAVENTURA, 2009; CASACA, 2010). Dada uma imagem contendo regiões texturizadas e que foi al terada pela presença de ruído, a EDP não-linear ani sotrópica regularizada (EDP-NAR) visa restaurar as informações presentes na imagem de modo a preservar suas principais características visuais, tais como arestas, bordas, estruturas geométricas, texturas. A EDP foi proposta ao combinar conceitos matemáticos sobre análise harmônica (descritos em (NORDSTROM, 1991; ALVAREZ; LIONS; MOREL, 1992; BARCELOS; BOAVENTURA; JR, 2003)) com ferramentas sobre Wave atoms, como em (DEMANET; YING, 2007b; DEMANET; YING, 2007a), de modo a definir um método híbrido e regularizado por um termo de difusão sensível abordas e texturas.

A EDP foi apresentada com embasamento empírico, de acordo com al guns resultados experimentais iniciais e sem embasamento matemático rigoroso. Com o objetivo de validar matematicamente a EDP não-linear ani sotrópica regul arizada, nesta pesqui sa foi realizado um estudo teórico mais detal hado para garantir a parabol icidade daEDP etambém provar a existência e a unicidade de sol uções para a mesma. Além disso, neste trabal ho são real izados um novo estudo experimental, mais completo e detal hado, para atestar o bom desempenho do método baseado na EDP-NA R quando aplicado ao problema de eliminação de ruído em imagens digitais com textura, e também uma nova abordagem de ajuste paramétrico do método de eliminação de ruído. Os resultados decorrentes deste neste trabal ho foram apresentados em (CASACA; ALMEIDA; BOAVENTURA, 2013), de modo a complementar e extender o trabal ho apresentado inicial mente a cerca da EDP-NAR. 


\subsubsection{Trabalhos relacionados em eliminação de ruído usando EDPs}

Nas últimas décadas, diversas técnicas formuladas a partir de EDPs foram propostas com o obj etivo de remover o nível de ruído presente em imagens nos mais variados cenários de aplicação. Grande parte destas técnicas têm si do modeladas por meio de adaptações das segui ntes abordagens clássi cas da literatura:

- Introdução de uma equação de difusão evolucionária, tal como a clássi ca EDP ani sotrópica original mente proposta por Perona-Malik (PERONA; MALIK, 1990), ou

- Formulação de um problema de minimização de funcional de energia (por exemplo, o tradicional método da Variação Total proposto por Rudin-Osher-Fatemi (RUDIN; OSHER; FATEMI, 1992)), cuja resolução numérica, na maioria dos casos, está também associada a uma equação diferencial.

Em ambos os casos a ideia é recuperar a imagem danificada de modo a mi ni mizar a perda das informações básicas da mesma, em especial seus contornos e bordas. Assim, a restauração, quando gui ada por uma equação diferencial, pode ser considerada matematicamente como uma representação em um espaço de escala (TEIXEIRA, 2001), onde o principal objetivo é evitar o decrescimento monótono das estruturas bási cas da imagem enquanto a escala aumenta.

\section{Eliminação de ruído gaussiano não-sensível a texturas}

A partir de trabal hos sobre a detecção de bordas e a suavização de imagens no início da década de 1980, surgi ram os primei ros trabal hos destinados a eliminação de ruído via EDP. Inicialmente, Marr e Hildreth (MARR; HILDRETH, 1980) desenvolveram um modelo para detecção de bordas em imagens, baseado no produto de convolução de uma imagem com o laplaciano de uma função gaussiana, a partir da equação

$$
\frac{\partial u}{\partial t}=D G^{*} u:
$$

Alguns anos depois, foi apresentado em (KOENDERINK, 1984) uma forma de utilizar a equação do calor para identificar detal hes estruturais de uma imagem.

$$
\frac{\partial u}{\partial t}=D u:
$$

As técnicas dadas pelas equações (3.2) e (3.3), bem como combinações das mesmas, foram importantes para o desenvolvimento de técnicas baseadas em EDPs para restauração de imagens.

No final da década de 1980, uma importante contribuição para a mudança de paradigma na área de eliminação de ruído foi apresentada em (PERONA; MALIK, 1990), na qual o problema de remoção de ruído em uma imagem foi tratado com o objetivo de remover o ruído e, 
simul taneamente, preservar as características elementares da imagem. Isto ocorreu a partir da proposta da seguinte equação diferencial não-linear:

$$
\frac{\partial u}{\partial t}=\operatorname{div}(g(|-u|)-u)
$$

em que $\mathrm{g}=\mathrm{g}(\mathrm{s})$ é uma função decrescente não negativa satisfazendo $\mathrm{g}(\mathrm{s}) \rightarrow 0$ quando $\mathrm{s} \rightarrow++^{\bullet}$ e $\mathrm{g}(0)=1$. Um exemplo clássico para este tipo de função é dado por $\mathrm{g}(\mathrm{s})=\mathrm{e}^{-\mathrm{t}^{2} \mathrm{~s}}$, em que $\mathrm{t}$ é uma constante. O objetivo de usar a Equação (3.4) (de Perona-Malik) é aplicar uma difusão orientada durante o processo de remoção de ruído, trocando o coeficiente de condutividade constante presente na equação do cal or $(g(s)=1$ por uma função do tipo $g(|-u|)$ satisfazendo as propriedades descritas previamente.

Esta EDP pode ser vista como um balanceamento sel etivo entre o processo de difusão nas direções ortogonal e tangencial em rel ação às bordas e contornos da imagem. Matematicamente, tem-se que

$$
\frac{\partial u}{\partial t}=g(|-u|) \frac{\partial^{2} u}{\partial \vec{x}^{2}}+b(|-u|) \frac{\partial^{2} u}{\partial \vec{h}^{2}}
$$

com $b(|-u|)=g(|-u|)+2|-u|^{2} \frac{d}{d s} g(|-u|)$ e $\vec{x}$ e $\vec{h}$ representam, respectivamente, os vetores tangencial e ortogonal com relação aos contornos de u, conforme ilustra a Figura 29.

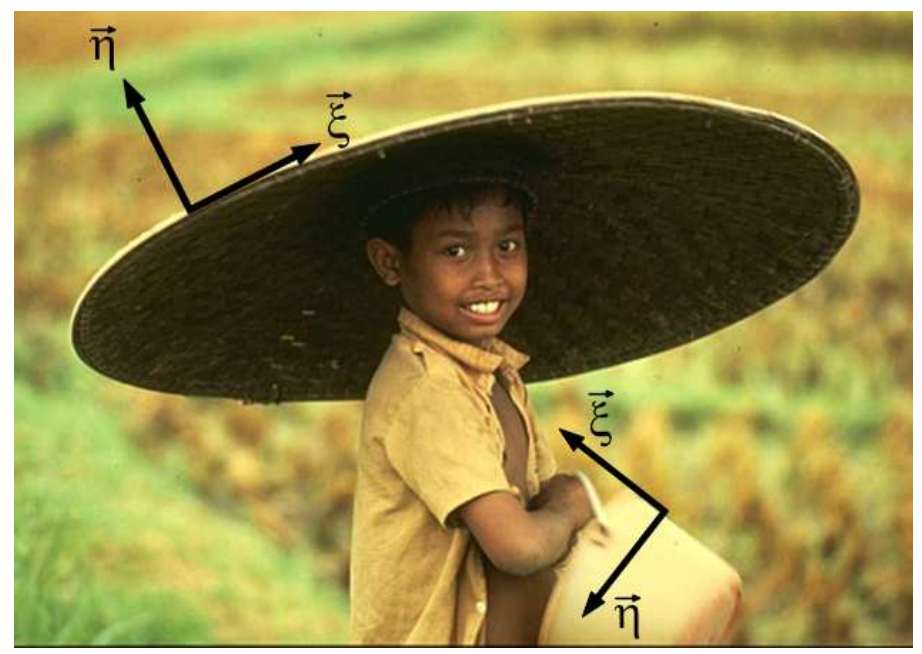

Figura 29 - Representação dos vetores tangencial e ortogonal em uma determinada imagem. Fonte: (CASACA; ALMEIDA; BOAVENTURA, 2013)

A equação do cal or também pode ser descrita em termos de derivadas de segunda ordem com coeficientes unitários, isto é,

$$
\frac{\partial u}{\partial t}=\operatorname{div}(-u)=\frac{\partial^{2} u}{\partial x^{2}}+\frac{\partial^{2} u}{\partial y^{2}}=\frac{\partial^{2} u}{\partial \overrightarrow{x^{2}}}+\frac{\partial^{2} u}{\partial \vec{h}^{2}}:
$$

É possível verificar que a equação de PeronaMal ik realiza uma competição tendenciosa entre difusão tangencial e normal, a qual depende do gradiente de u e da expressão matemática da função de condutividade g, como mostrado na Equação (3.5). 
Embora este model o expresse uma importante contribuição em termos de suavização com sel etividade, el e apresenta dificuldades práticas e teóricas, pois sua formul ação é consi derada um problema mal -posto. Quando aplicado em imagens com al ta concentração de ruído, o espaço de escal a originado pela Equação (3.4) tende a produzir al tos val ores para o gradiente, o que resulta em $g \approx 0$ e, consequentemente, implica na incapacidade de eliminar o ruído durante o processo de restauração.

Para converter o problema mal-posto de Perona-Malik em uma formulação mais estável, foi introduzido em (CATTé et al., 1992) um termo de regularização na equação-base. Os autores modificaram o coeficiente de condutividade $g$ al terando o detector de borda clássico, baseado em $-u$, por um termo suave pré-processado $-\left(G_{s}{ }^{*} u\right)$, em que * indica o operador de convolução e $\mathrm{G}_{\mathrm{S}}$ é um núcleo gaussiano (o qual é conhecido/dado). Com base nessa premissa, os autores propuseram o seguinte modelo regularizado:

$$
\frac{\partial u}{\partial t}=\operatorname{div}\left(g\left(\left|-\left(G_{s}^{*} u\right)\right|\right)-u\right) ;
$$

com condições de contorno do tipo Neumann es sendo o desvio padrão do ruído presente na imagem.

O método ajusta, do ponto de vista teórico, aformul ação original de Perona-Malik, a qual também emprega uma redução preliminar do ruído, realizada pel o filtro gaussiano. Além disso, o resultado dessa regularização em g torna a EDP da Equação (3.6) um problema bem-posto, no sentido da existência, unicidade e estabilidade das soluções (CATTé et al., 1992). Entretanto, é importante notar que a regularização gaussiana introduzida pode desf ocar arestas e danificar os padrões de texturas presentes na imagem.

No contexto de estratégias de regularização, várias técnicas de difusão regularizadas foram propostas para remover ruídos, sendo ainda muitas del as técni cas das quais baseiam-se em conceitos geométricos. Um exemplo bastante significativo e que define um processo de difusão com uma perspectiva geométrica pode ser encontrado em (ALVAREZ; LIONS; MOREL, 1992). Os autores consideraram o primeiro termo da Equação (3.5), o qual é responsável por realizar a suavização ortogonal com relação às bordas, combinado com um fator multiplicativo, dado pela função de ajuste $\left.\mathrm{g}\left(\mid-\mathrm{G}_{\mathrm{s}}{ }^{*} \mathrm{u}\right) \mid\right)$, proposta em (CATTé et al., 1992). Além disso, técni cas de regularização baseadas em concei tos geométricos possuem um desempenho superior quando comparadas com as técnicas anteriormente descritas. Tais técnicas, porém, continuam a apresentar o comportamento de danificar arestas finas e cantos agudos, inclusive regiões de texturas.

Outra forma interessante de mel horar a qual idade da suavização e, simul taneamente, preservar as estruturas originais da imagem é a combi nação de difusão sel etiva com funções de força/reação. O model o proposto em (NORDSTROM, 1991) é um dos principais expoentes deste tipo de modelagem. O principal objetivo é resolver um problema de minimização para um funcional de energi a específico. Dessa forma, é possível derivar um método com base em uma 
EDP anisotrópica A equação é constituída pelo modelo de Perona-Malik dado pela Equação (3.4) com o acréscimo de um termo de força $(u-1)$ em sua formulação, isto é,

$$
\frac{\partial u}{\partial t}=\operatorname{div}(g(k|-u|)-u)+(u-I):
$$

Neste caso, são utilizadas condições de contorno do tipo Neumann, com k constante, e a função de difusão $g=g(s) \in(0 ; 1]$ dada por

$$
g(s)=\frac{1}{1+s^{2}}:
$$

O termo de força $(u-I)$ visa manter a escal a da imagem u perto da imagem de entrada I, uma vez que isso preserva as estruturas naturais da imagem. Além disso, a EDP da Equação (3.7) tem a propriedade de possuir um estado estacionário não trivial. Desse modo, não há necessidade de um critério de parada temporal. De acordo com (NORDSTROM, 1991), foi provado que o acréscimo do termo de força $(u-I)$ não al tera os resultados teóricos já al cançados para a Equação (3.4).

A equação parabólica ani sotrópica a seguir foi proposta em (BARCELOS; BOAVENTURA; JR, 2003) a partir das ideias apresentadas em (NORDSTROM, 1991; PERONA; MALIK, 1990; ALVAREZ; LIONS; MOREL, 1992), com a intenção de manter a integridade as bordas e as frontei ras da imagem durante o processo de eliminação de ruído:

$$
\frac{\partial \mathrm{u}}{\partial \mathrm{t}}=\mathrm{g}|-\mathrm{u}| \operatorname{div} \frac{-\mathrm{u}}{|-\mathrm{u}|}+\mathrm{a}(1-\mathrm{g})(\mathrm{I}-\mathrm{u})
$$

em que a é um parâmetro de ajuste e as condições de contorno para este problema são do tipo Neumann. A função $g=g(s)$ é dada pela Equação (3.8), com $s=\sqrt{k}\left|-\left(G_{s}{ }^{*} u\right)\right|$, em que $G_{s}$ é o núcl eo gaussiano, s denota o desvio padrão da imagem l e k é uma constante.

A função g é usada para detectar bordas e controlar local mente o grau de incidência de difusão, de modo similar ao modelo anterior. Dessa forma, se - u tem um val or médio pequeno na vizinhança de um ponto x (médi a cal culada pel o produto de convolução $G_{s}{ }^{*} u$ ), então x é consi derado um ponto interior e a difusão aplicada pela Equação (3.9) será intensa. Por outro lado, se o val or médio na vizinhança de x é grande, então x é consi derado um ponto de fronteira e a di fusão será mais suave. Dessa forma, o fil tro ani sotrópi co da Equação (3.9) possui a capaci dade de suavizar partes mais homogêneas e preservar as bordas e contornos da imagem.

Embora o modelo da Equação (3.9) produza resul tados visuais bastante satisf atórios, tal formulação não al cança uma boa performance quando aplicado em imagens com texturas, pois o termo de difusão g atua local mente em um ponto x (com base no cál culo do "val or médio" entre seus pontos vizinhos). De fato, pontos contidos nas regiões de textura possuem oscil ações bruscas de valor, mesmo em pequenas vizinhanças, e tal premissa pode interferir na obtenção desta média.

Ao contrário do model o anterior, que consi dera apenas o aspecto da detecção local de bordas para eliminar o ruído, em (MISHRA et al., 2010) uma nova abordagem (não-local) para 
eliminação de ruídos foi apresentada, na qual é resolvido um probl ema bayesi ano de estimação por mínimos quadrados. Neste caso, a principal vantagem é o uso de uma perspectiva estocástica não-local para detectar e manter as estruturas fundamentais da imagem. Isto se deve ao fato do processo de remoção de ruído ser real izado com base na geração de um espaço de escal a com a capacidade de manter tais estruturas. Um model o de esti mação de densidade quase-al eatório é definido a fim de cal cular a distribuição a posteriori por meio de passos sucessivos no espaço de escal a Para controlar a velocidade da suavização, os autores utilizaram um conjunto de três funções objetivo: intensi dade, gradiente e localização para mini mizar a perda de resolução em cada nível da decomposição no espaço de escala.

Embora a formulação de (MISHRA et al., 2010) não seja ef etivamente uma EDP, ela apresenta um comportamento semel hante ao de uma EDP, já que apresenta a utilização da teoria de espaço de escal as quase-al eatório para representar os diferentes níveis da escal a da imagem durante o processo de suavização, ou seja, um espaço de escal a é criado do mesmo modo como ocorre nos métodos baseados em EDPs. Devido ao aspecto global construído pela model agem estocástica e as três funções de penal ização mencionadas anteriormente, esta abordagem funciona de forma satisf atória para imagens com presença moderada de texturas, porém, ela ainda tende a introduzir alguns artefatos quando a imagem possui grande concentração de texturas.

\section{Eliminação de ruído gaussiano sensível à texturas}

Visando abordar o problema de remover ruídos em imagens com texturas, em (MA; PLONKA, 2007) os autores desenvolveram uma técnica baseada na EDP

$$
\left.\frac{\partial \mathrm{u}}{\partial \mathrm{t}}=\operatorname{div}(\mathrm{g}-\mathrm{Pu})\right)
$$

com condições de contorno de Neumann, $g=g(|-(P u)|)$ dada pelo termo de difusividade apresentado na Equação (3.8), e P representando uma função de projeção definida pelo operador de análise harmônica curvelet, proposto em (CANDèS; DONOHO, 2004; CANDèS et al., 2006).

Este modelo pode ser visto como uma difusão do tipo TV (RUDIN; OSHER; FATEMI, 1992) direcionada pelo termo de regularização $\mathrm{Pu}$, o qual identifica a textura em u. A detecção de bordas fornecida por g na Equação (3.10) tende a ser mais sensível do que as apresentadas nas formul ações anteriores, uma vez que esta se baseia em um termo de difusividade focado na identificação de texturas, devido ao emprego da transformada curvelet. A ideia dos autores foi utilizar o processo de difusão para mini mizar os artefatos oriundos do fenômeno de "Gibbs" originados pelo uso direto do operador curvel ets.

Uma variante da Equação (3.10) foi proposta pel os mesmos autores em (PLONKA; MA, 2008) um ano depois, na qual modificaram o filtro de difusão dado pela Equação (3.10) com o acréscimo do termo de reação ( $\mathrm{Sl}-\mathrm{u}$ ), com a intenção de manter e mel horar os dados rotulados como textura. Neste caso, Sé um operador de preservação de textura o qual pode ser definido em termos de uma transformada do tipo wavelet, curvelet ou ainda wave atoms (PLONKA; 
MA, 2008). Ainda nesta mesma di reção, outras técnicas guiadas por transformadas de análise harmônica a fim de preservar e mel horar as características de uma imagem também podem ser encontradas em (LIU; FENG; BAI, 2008) e (LIU, 2011).

O modelo concebido por (GILBOA; SOCHEN; ZEEVI, 2006) é inspirado no comportamento de adaptabilidade local e baseado na abordagem clássica de Rudin-Osher-Fatemi (Variação Total) (RUDIN; OSHER; FATEMI, 1992):

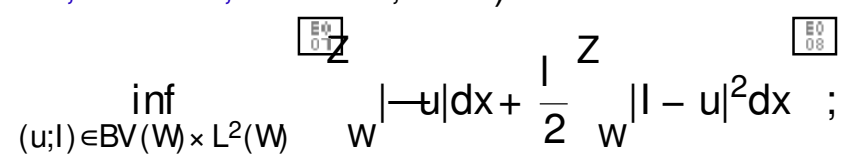

em que BV (W) denota o espaço das funções com variação limitada, Wo domínio da imagem e I é eum parâmetro a ser escolhido. O primeiro termo na Equação (3.11) representa a Variação Total de u ao passo que o segundo termo é procura manter a fidelidade dos dados, no sentido de manter u próxima da imagem original $\mathrm{I}$.

Ao deixar de utilizar I constante na Equação (3.11), os autores apresentaram em (GILBOA; SOCHEN; ZEEVI, 2006) uma versão com a capacidade de preservar texturas durante o processo de difusão. Dessa forma, $I=I_{I}(x)$ variável em todo We possui a capacidade de representar propriedades locais da imagem, tais como contrastes e texturas. Com isso, a EDP obtida em (GILBOA; SOCHEN; ZEEVI, 2006) baseia-se em uma versão modi ficada da Equação (3.11), a qual é dada pela seguinte EDP regul arizada

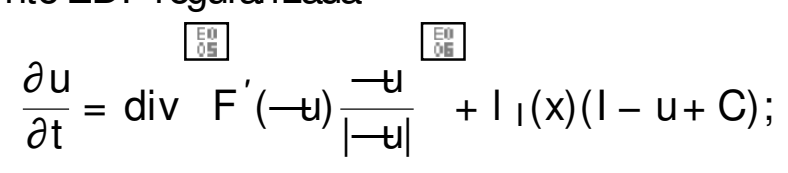

em que $C$ é uma constante e $F$ é uma função de regularização para $-u$. O fator div $F^{\prime}(\cdot) \frac{-u}{|-t|}$ representa o processo de difusão adaptativo e $I_{I}(x)(I-U+C)$ é o termo de reação local mente ponderado por $I$. Portanto, o coeficientel contribui para preservar a textura de $u$. Existem ainda outros model os de denoising nessa linha que preservam texturas e que são derivados das ideias de (GILBOA; SOCHEN; ZEEVI, 2006) tais como (GILLES, 2007) e (LI et al., 2009).

\subsection{Eliminação de rúidos via EDP não-linear anisot rópica regularizada}

Vamos discutir nesta seção a equação anisotrópica regul arizada proposta inicial mente em (CASACA; BOAVENTURA, 2009). A contribuição desta pesqui sa consiste na val idação experimental e matemática da equação anisotrópica regularizada, conforme apresentado em (CASACA; ALMEIDA; BOAVENTURA, 2013). Dessa forma, al gumas de suas propriedades matemáticas fundamentais, como a regularização, a estratégia de reação-difusão, a preservação da textura e detecção de borda e a existência e unicidade de soluções são descritas e investigadas neste trabal ho. 
Equação anisot rópica não-linear regularizada

Seja $u=u(x ; t)$ umaimagem em escal a de cinzas variando no tempo el $=I(x)$ aimagem observada (contaminada por ruído), respectivamente representadas por funções reais

$$
\mathrm{u}(\cdot ; \mathrm{t}): \mathrm{W} \times[0 ;+\cdot \cdot] \rightarrow \mathrm{R} \quad \text { e } \quad \mathrm{I}: \mathrm{W} \rightarrow \mathrm{R}:
$$

Considere que o domínio Wé uma região retangular de $\mathrm{R}^{2}$ e que a degradação devida à presença do ruído na imagem I seja do tipo aditiva, conforme a Equação (3.1), onde n representa a função de ruído modelada por uma distribuição normal com média 0 e variância s ${ }^{2}$.

Além disso, também vamos supor que a imagem variável no tempo u contenha padrões oscilatórios tais como texturas, detal hes finos e informações de al ta frequência. O objetivo do problema de eliminação de ruído é reduzir a intensidade do ruído na imagem inicial I, ou seja, a interferência do ruído $\mathrm{n}(\mathrm{x})$ deve ser mínima na imagem de saída, tornando-a visual mente mais próxima da imagem origi nal, sem a presença de ruído, de modo a preservar bordas, texturas e outras características significativas da imagem.

Seguindo as ideias de (BARCELOS; BOAVENTURA; JR, 2003; GILBOA; SOCHEN; ZEEVI, 2006; PLONKA; MA, 2008), um novo filtro de difusão ani sotrópico regularizado foi proposto recentemente em (CASACA; BOAVENTURA, 2009; CASACA, 2010; CASACA; ALMEIDA; BOAVENTURA, 2013) para o problema de eliminação de ruído em imagens com texturas. Esta abordagem combi na difusão orientada, regularização, estratégia de ponderação orientada e um esquema baseado em reação-di fusão a fim de formar a seguinte EDP:

$$
\begin{gathered}
\frac{\partial u}{\partial t}=h|-u| d i v \frac{-u}{|-t|}+a(1-h)(I-u)+b(1-h)(S I-u) ; x \in W ; t>0 ; \\
u(x ; 0)=I(x) ; x \in W ; \quad \frac{\partial u}{\partial \vec{n}}=0 ; x \in \partial W ; t>0 ;
\end{gathered}
$$

em que h éo termo de difusividade, Sé um operador baseado em um descritor de textura ea e b são parâmetros de ajuste. Como observado na Equação (3.13), as condições de fronteira são do tipo Neumann e a condição inicial para a EDP (quando $t=0$ ) é a imagem com ruído I. A Figura 30 apresenta um exemplo ilustrativo obtido com base na aplicação da Equação (3.13) em uma imagem contendo textura.

A EDP da Equação (3.13) foi regul arizada pelo emprego de um termo de penalização $h$ (Figura 30d) o qual garante um bom equilíbrio entre eliminação de ruído e preservação de textura Além disso, a utilização de tal termo tende a gerar resultados bastante satisfatórios em termos de manutenção de padrões de inf ormação, os quais são natural mente observados em imagens reais.

1 Fotografia por lan Sane <https://www.flickr.com/photos/31246066@N04/30801757755/in/datetaken/>. 


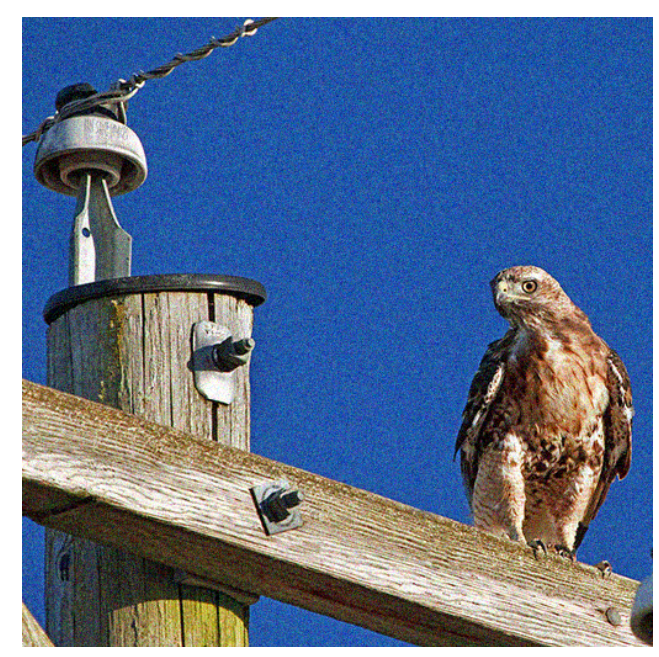

(a)

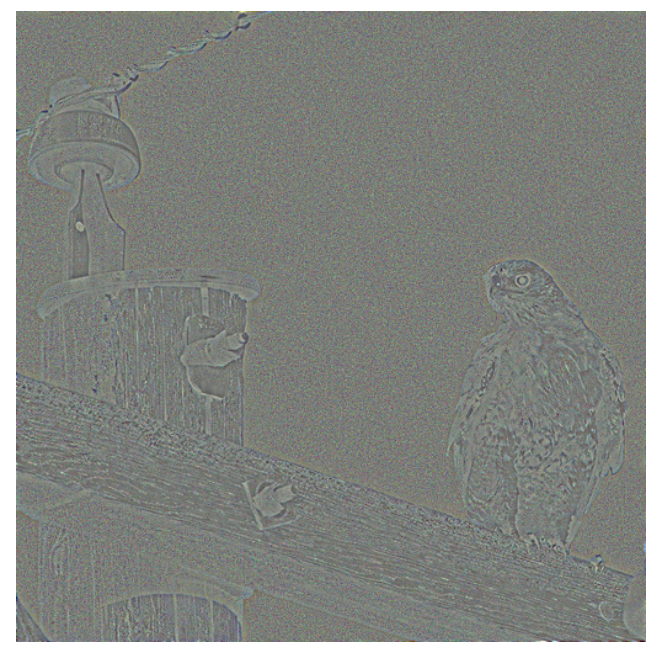

(c)

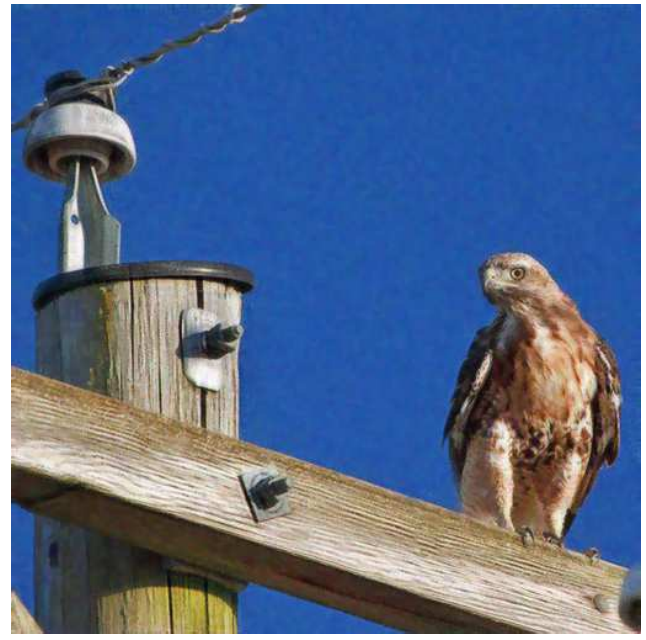

(b)

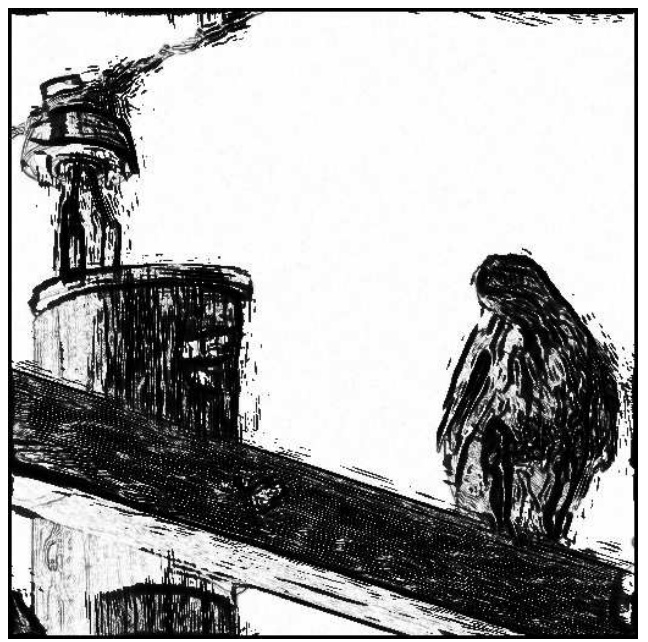

(d)

Figura 30 - Exemplo de eliminação de ruído utilizando a abordagem EDP-NAR. (a) Fotografia' com ruído; (b) imagem restaurada; (c) imagem residual (diferença entre a e b); e (d) representação gráfica do termo de h.

\section{Cont ribuição da difusão}

Consi dere as curvas de nível rel ativas a u na escal at, $S_{e}(t):=\{x \in W: u(x ; t)=e\} . O$ primeiro componente não regul arizado na Equação (3.13),

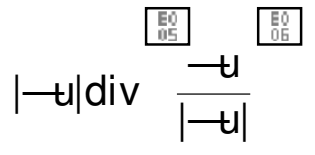

emprega um processo de difusão na direção tangencial ao nível $S_{e}(t)$. Esta declaração pode ser verificada ao considerar as direções do nível $\vec{x}=\frac{-1}{|-u|}$, uma vez que o gradiente $-u$ é sempre normal às curvas de nível, e também ao se cal cular a derivada de segunda ordem de u em rel ação 
à direção especificada

$$
\begin{aligned}
& \frac{\partial^{2} u}{\partial \vec{x}^{2}}=\vec{x} H \overrightarrow{u x} \vec{x}^{\top}
\end{aligned}
$$

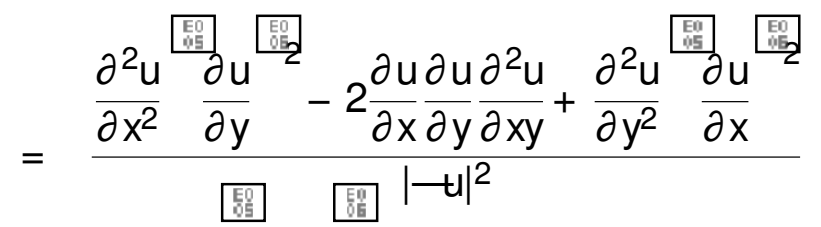

$$
\begin{aligned}
& =|-u| \operatorname{div} \frac{-t}{|-t|} \text {; }
\end{aligned}
$$

em que $\mathrm{H}$ representa a matriz hessiana.

Como o fator

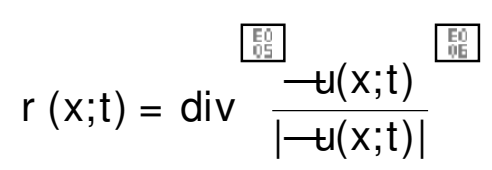

representa a curvatura para a curva de nível $S_{e}(t)$, no ponto $x$, no tempo $t$, o divergente da Equação (3.14) realiza uma suavização orientada pela curvatura da imagem. Em termos de nomenclatura, a expressão da Equação (3.14) é frequentemente mencionada na literatura por Mean Curvature Flow (MCF), a qual é responsável pela etapa de difusão associada à EDP da Equação (3.13). De acordo com a interpretação geométrica fornecida pela Equação (3.15), o MCF difunde u na direção ortogonal ao seu gradiente -u (não dif undindo em qual quer outra direção a não ser esta).

\section{Regularização}

Os termos regul arizadores t s e t u são utilizados para controlar e balancear a atuação da difusão durante o processo de eliminação de ruído:

$$
t_{s}=g\left({ }^{\sqrt{d}}-S u(x ; t) \mid\right) \quad \text { e } \quad t_{u}=g\left({ }^{\sqrt{ }} \bar{k}|-t(x ; t)|\right) ;
$$

nos quais g é dada pel a expressão da Equação (3.8), d e k são parâmetros para ajustar a ação dos operadores empregados em cada termo.

Com isso, o fator de regularização

$$
h_{m}(x)=t_{S} C_{D_{m}}+t_{u} C_{D_{m}^{c}}^{c}
$$

é responsável por controlar a força da difusão no processo de eliminação de ruído, $\operatorname{com} \mathrm{D}_{\mathrm{m}}=$ $\left\{x \in W: t_{S} \leq m\right\} ; D_{m}^{c}$ o complementar de $D_{m}$, sendo mum valor de limiar fixado e definido de modo apropriado.

Na Equação (3.15), o termo de difusão é ponderado por $h=h_{m}(x)$ e o termo que detecta informações sobre textura é ponderado por $(1-h)$. Dessa forma, é interessante obter val ores $\mathrm{h} \approx 0$ em regiões contendo textura, para que a difusão seja menos intensa nestes pontos, e $\mathrm{h} \approx 1$

2 Fotografia por lan Sane <http://www.flickr.com/photos/31246066@N04/29200712396>. 


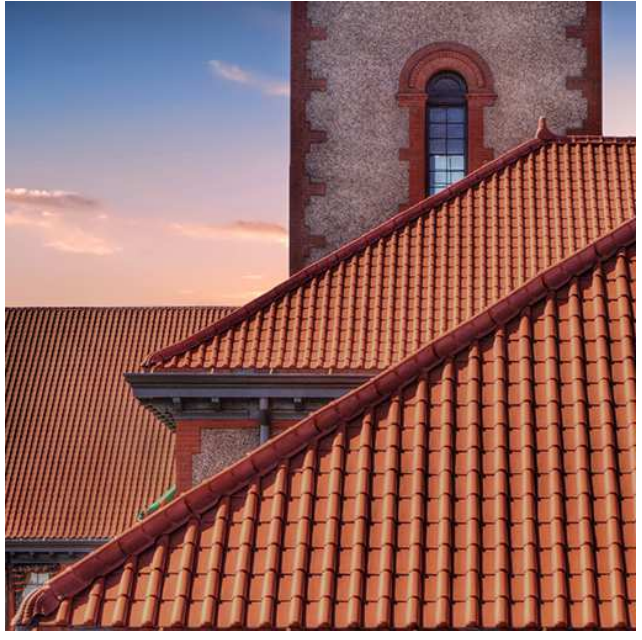

(a)

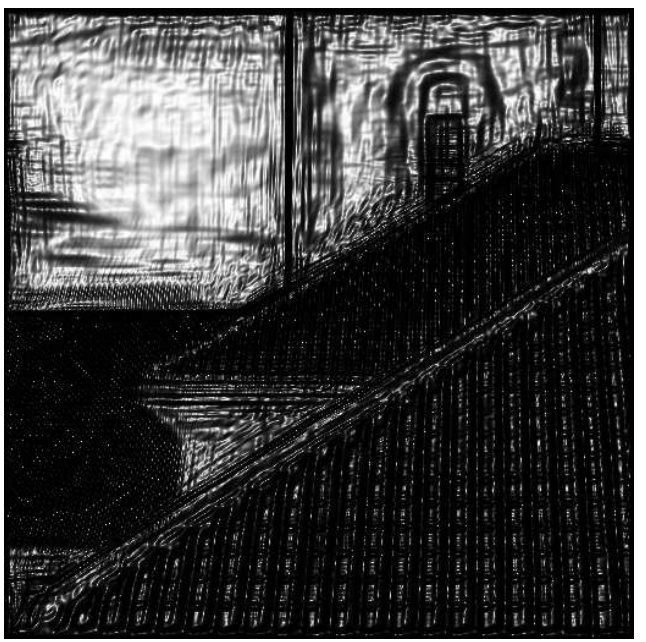

(c)

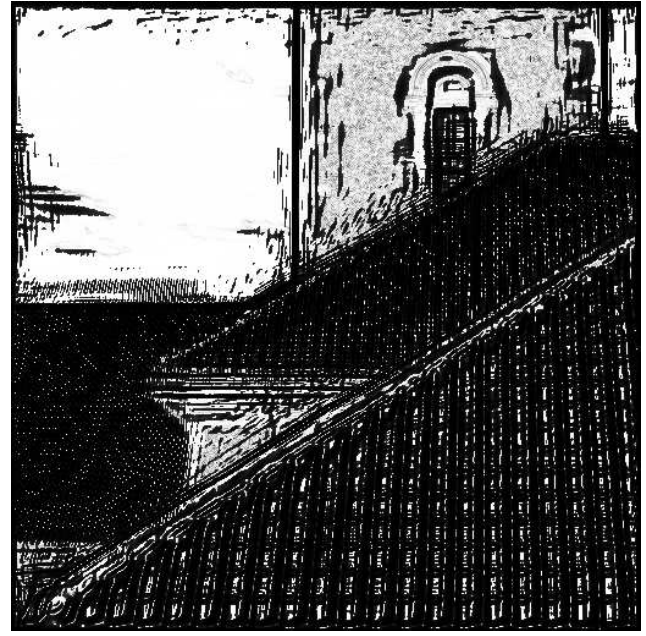

(b)

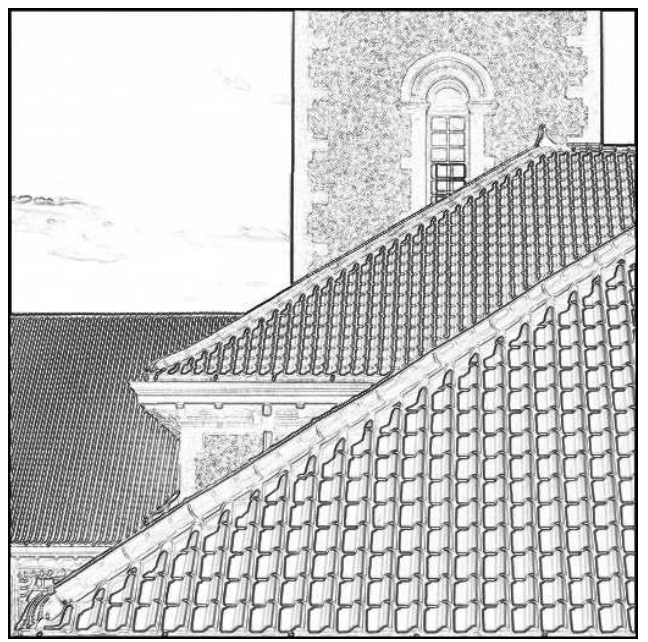

(d)

Figura 31 - Il ustração do termo $h$. O mapeamento define a cor preta para val ores próximos de zero e branco para o val or 1. (a) Fotografia ${ }^{2}$ com texturas e regiões homogêneas. (b) Fator regularizador $h=h_{m}(x)$. (c) Termo ts. (d) Termo tu.

em regiões homogêneas da imagem, para que o termo de difusão seja mais ef etivo nestes pontos. A Figura 31 ilustra o processo de regularização. A imagem da Figura 31a foi utilizada para exemplificar a função do fator de regularização h, cuja representação está indicada na Figura 31b.

O termo t s possui a capacidade de identificar pontos com padrão de textura na imagem, nestes pontos tem-se $\mathrm{t} s \approx 0$ e indica que a ação da difusão deve ser menos intensa nestas regiões. Além disso, $\left(1-t_{s}\right) \approx 1$ e faz com que o termo contendo informações sobre a textura tenha um peso mai or na restauração desses pontos do que o termo de difusão, conforme descrito na Equação (3.15).

O efeito da difusão deve ser mais intenso nas regiões homogêneas da imagem. Entretanto, t $\mathrm{s}$ também apresenta val ores próximos de zero nestas regiões e faz com que a difusão seja menos intensa do que o necessário. Com isso, a utilização apenas do termo t s no processo de restauração não é eficiente. A Figura 31c ilustra o comportamento do termo t s. 
Por outro lado, $\mathrm{t}_{\mathrm{u}} \approx 1$ para regiões mais homogêneas e produz uma ação mais ef etiva do processo de difusão nestas regiões. No entanto, $t$ u não é eficaz para detectar regiões com detal hes importantes e texturas na imagem. Dessa forma, o comportamento mapeado apenas por $t_{u}$ não é suficiente para obter um resul tado satisfatório no processo de restauração. Podemos vizualizar o mapeamento obtido por meio do termo $t_{u}$ na Figura $31 d$.

Para tornar o processo de restauração mais eficiente, o termo regul arizador $h$ equilibra a ação de $t$ s e t u para permitir uma mel hor identificação tanto de regiões com bordas e texturas quanto de regiões mais homogêneas. O termo h real iza uma ponderação na Equação (3.13) para não anular total mente as contribuições do termo de difusão e dos termos de reação, o que poderia criar descontinuidades inesperadas na imagem.

\section{Termos de força/ reação}

O termo regularizador h é responsável pelo controle do processo de difusão para que a remoção de ruídos possa ser real izada levando em consi deração a presença de informações relevantes na imagem. A manutenção das informações a respeito de bordas e texturas na Equação (3.13) é controlada pelo termo $(1-h)$ e real izada por meio da atuação dos termos de força $(I-u)$ e de reação $(S I-u)$.

A regularização por parte do termo $\mathrm{h}$, conforme descrita anteriormente, atua de forma intensa nas regiões mais homogêneas, ou seja, nas regiões da imagem com menos padrões de textura. Como a Equação de MCF (3.14) é ponderada pelo termo h na primeira parte da Equação (3.13), ela atua de modo a empregar uma suavização significativa nas regiões mais homogêneas da imagem. Além disso, o termo ( 1 - h) possui val ores próximos de zero e diminui significativamente a ação dos termos de força/reação nas regiões com menos bordas e texturas, inibindo a ação da Equação de MCF nesta regiões para evitar uma suavização excessiva de tais informações.

Nas regiões da imagem contendo bordas e texturas, o termo $\mathrm{h}$ atua de forma mais amena, com val ores próximos de zero. Isto faz com que valores mais significativos sejam atribuídos ao termo $(1-h)$. Assim, o termo de força $(I-u)$ tende a preservar bordas e fronteiras com base na imagem ruidosa I ao passo que o termo de reação $(\mathrm{SI}-\mathrm{u}$ ) procura preservar e restaurar texturas e outros detal hes oscilatórios da imagem. Dessa forma, o processo de difusão é realizado de modo que bordas, frontei ras e detal hes oscilatórios sejam preservados pela ação dos termos de força/reação $(I-u)$ e $(S I-u)$.

Portanto, o termo h atua na Equação (3.13) para viabilizar o balanceamento entre o processo de difusão, que atua para amenizar a presença de ruído na imagem, e os termos de reação, que visam preservar e recuperar detal hes importantes da imagem. 


\section{Identi咸ação de padrões e texturas}

O operador Spresente em um dos termos de reação na Equação (3.13) possui a tarefa de identificar e computar informações sobre regiões definidas por padrões de texturas. Para executar tal tarefa, o operador Sé baseado em wave atoms (DEMANET; YING, 2007a; DEMANET; YING, 2007b). Wave atom é uma técnica de anál ise harmônica, derivada de wavel et, proposta para mel horar a representação esparsa de determinados padrões oscilatórios. A modelagem por wave atoms apresenta, em geral, uma representação esparsa mais significativa para texturas orientadas, uma vez que tais características podem ser mapeadas por funções oscilatórias "com distorções" quando comparada com outras wavel ets "puras", tal como Gabor atoms ou curvelets (DEMANET; YING, 2007b). Além disso, os elementos utilizados na composição de wave atoms são ani sotrópi cos e sensívei às di reções presentes em padrões oscilatórios, dessa forma é interessante utilizar tais ferramentas para identificar detal hes oscilatórios e texturas em imagens.

Apesar de serem ferramentas importantes e versáteis na área de processamento de imagens, para o problema de eliminação de ruídos é recomendável utilizar wave atoms em conjunto com um operador de contração:

$$
u_{c}=\underset{m}{\hat{A}} Q\left(c_{m}^{(1)}(u)\right) j_{m}^{(1)}+Q\left(c_{m}^{(2)}(u)\right) j_{m}^{(2)}
$$

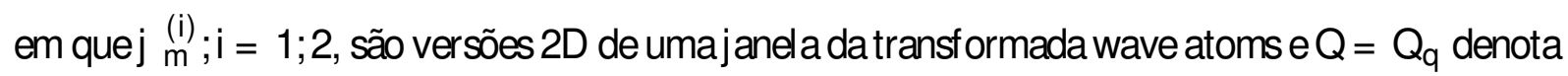
uma função de limiarização do tipo

$$
Q_{q}(x)=\quad \begin{aligned}
& x ;|x| \geq q \\
& 0 ; \quad|x|<q
\end{aligned}
$$

em que q é um val or de limiar. Mais detal hes são descritos em (DEMANET; YING, 2007b; CASACA, 2010).

\section{Validação teórica da EDP anisotrópica não-linear}

Com o intuito de validar a EDP da Equação (3.13) em termos teóricos, é necessário examinar inicialmente a parabolicidade da Equação (3.13) para uma função pré-definida $h$ respeitando al gumas restrições e, posteriormente, provar a existência e unici dade de sol uções. Para averiguar a primeira suposição, o objetivo é escrever a equação atual por meio da fórmula geral da EDP de segunda ordem:

$$
\frac{\partial u}{\partial t}=\underset{i ; j=1}{2} a_{i j} \frac{\partial^{2} u}{\partial x_{i} \partial x_{j}}+\underset{j=1}{2} b_{j} \frac{\partial u}{\partial x_{j}}+c u+f ;
$$

em que $a_{i j}, b_{j}$ e c representam funções coeficientes (que dependem das variáveis incorporadas à EDP) e $f=f(\cdot ; t)$. Na sequencia, a parabolicidade da expressão (3.13) pode ser analisada com base na seguinte definição (EVANS, 2010): 
Definição 1. Dado os coeficientes $a_{i j}, b_{j}, c,(i ; j=1 ; 2)$ da $\operatorname{EDP~(3.20),~ela~é~dita~parabólica~se,~}$ e somente se, a matriz dos coeficientes $A=\left(a_{i j}\right)$ é positiva definida para o domínio do problema Em outras palavras,

$$
\overbrace{i ; j=1}^{2} a_{i j} r_{i} r_{j}>0 \quad \forall(x ; t) \in W \times(0 ;+\cdot) ;-u l=(0 ; 0) \text { and } r=\left(r_{1} ; r_{2}\right) \in R^{2}
$$

Manipulando a Equação (3.13) de modo conveniente e usando a relação da Equação (3.15), obtemos

$$
\begin{aligned}
& \frac{\partial u}{\partial t}=h \frac{\partial u^{\text {圈 }}}{\partial y} \frac{\partial^{2} u}{\partial x^{2}}-2 h \frac{\partial u}{\partial x} \frac{\partial u}{\partial y} \frac{\partial^{2} u}{\partial x \partial y}+h \frac{\partial u^{\text {圈 }}}{\partial x} \frac{\partial^{2} u}{\partial y^{2}} \\
& +(h-1)(a+b) u+a(1-h) I+b(1-h) S \\
& =a_{11} \frac{\partial^{2} u}{\partial x^{2}}+2 a_{12} \frac{\partial^{2} u}{\partial x \partial y}+a_{22} \frac{\partial^{2} u}{\partial y^{2}}+c u+f \text {; }
\end{aligned}
$$

em que $a_{11}=h \frac{\partial u}{\partial y}, a_{12}=-h \frac{\partial u}{\partial x} \frac{\partial u}{\partial y}, a_{22}=h \frac{\partial u}{\partial x}^{\text {關 }}, c=(1-h)(a+b)$ e $f=a(1-$ $h) I+b(1-h) S I$.

De acordo com a Definição 1 de parabolicidade, devemos observar o que segue, para todo $r \in R^{2}$

$$
\overbrace{i ; j=1}^{2} a_{i j} r_{i} r_{j}=h\langle-\perp+r ;\rangle^{2} \geq 0 ; \quad \text { se } h>0
$$

Assim, podemos concl uir que a EDP (3.13) é parabólica com possibilidades de degeneração, já que o somatório aci ma mostra que $\left(a_{i j}\right)$ é positivo semi-definido, uma vez que a função de $g$ definida em $h$ é estritamente positiva para todos os $(x ; t) \in W \times(0 ;+\bullet)$.

A existência e unicidade de sol uções para a Equação não-linear parabólica (3.13) pode ser verificada no contexto das sol uções de viscosidade (CRANDALL; ISHII; LIONS, 1992), seguindo as ideias de (ALVAREZ; LIONS; MOREL, 1992; BARCELOS; BOAVENTURA; JR, 2003). A teoria de soluções de viscosidade é, essencial mente, baseada no estudo do Princípio do Máximo e pode ser aplicada com sucesso para resolver EDPs lineares ou não-lineares de qual quer ordem. Parainvestigar a solução da equação atual no sentido da teoria de viscosidade, em primeiro lugar considerase que as condições de fronteira são do tipo Neumann. Assim, é possível obter uma expressão equival ente a partir da formul ação original dada pela Equação (3.13). Sem perda de generalidade, podemos tomar $\mathrm{m}=\mathrm{d}=\mathrm{k}=1 \mathrm{em} \mathrm{h}$ e $\mathrm{a}=\mathrm{b}=\frac{1}{2}$ na Equação (3.13) de modo 
que

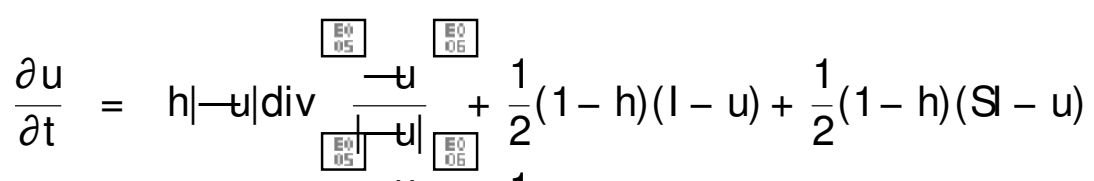

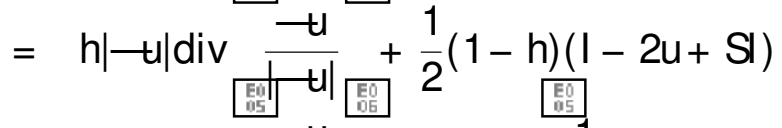

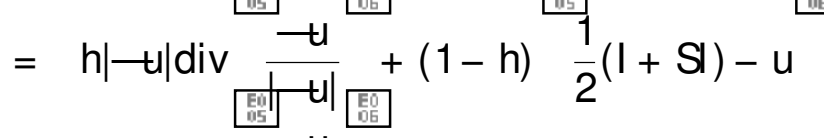

$$
\begin{aligned}
& =h|-u| \operatorname{div} \frac{-u}{|-u|}+(1-h)(P-u) \text {; }
\end{aligned}
$$

em que $\mathrm{P}=\frac{1}{2}(\mathrm{I}+\mathrm{SI})$ é a média entre a imagem com ruído I e a imagem transformada SI. Desse modo, Pé constante e não varia enquanto t varia

A Equação (3.21) pode ser vista como uma variante da EDP parabólica da Equação (3.9). Como a wave atom de contração embuti da em $\mathrm{h}$ funciona como um núcleo de suavização, o qual aparece no coeficiente de difusi vidade da Equação (3.9), tanto a existência quanto a uni cidade podem ser rigorosamente anal isadas no sentido de soluções de viscosi dade, seguindo as mesmas ideias desenvol vidas em (BARCELOS; BOAVENTURA; JR, 2003): construir um problema de Cauchy e explorar as propriedades de sub-solução e super-solução de viscosi dade, considerando a verificação do Princípio do Máximo.

\subsection{Discretização numérica}

Nesta seção, apresenta-se a resol ução numérica da Equação (3.13). Uma imagem digital pode ser representadas por uma matriz $\left(u_{i j}\right)_{m \times n}$, de modo que cada elemento $u_{i j}$ indica o val or da intensidade do brilho da imagem u no ponto $\left(x_{i} ; y_{j}\right)$, em rel ação ao sinal contínuo $u(x ; y)$, com $x_{i}=i D x$ e $y_{j}=j$ Dy. Para simplificar a notação considerase $D x=D y=1$. Desse modo, indica-se a intensidade do brilho da imagem $u$ em um determinado ponto $\left(x_{i} ; y_{j} ; t_{n}\right)$ por

$$
u_{i j}^{n}=u\left(x_{i} ; y_{j} ; t_{n}\right)
$$

em que $t_{n}=n D t$ corresponde à discretização da variável temporal t, Dt é o passo da discretização da variável t e $n=1 ; 2 ; \ldots ; ;$, de modo que $\mathrm{N}$ indica o número de iterações associado ao processo di screto de se obter uma solução numérica para a EDP da Equação (3.13).

\section{Aproximação numérica}

As derivadas da Equação (3.13) são aproxi madas numericamente por técnicas de diferenças finitas.

A derivada temporal $\frac{\partial u}{\partial t}$ é cal culada no ponto $\left(x_{i} ; y_{i} ; t_{n}\right)$ por diferença avançada, isto é,

$$
\frac{\partial u}{\partial t} \approx \frac{u_{i j}^{n+1}-u_{i j}^{n}}{D t} \quad \Rightarrow \quad u_{i j}^{n+1} \approx u_{i j}^{n}+D t \frac{\partial u}{\partial t}:
$$


Para cal cular numericamente a expressão de difusão MCF

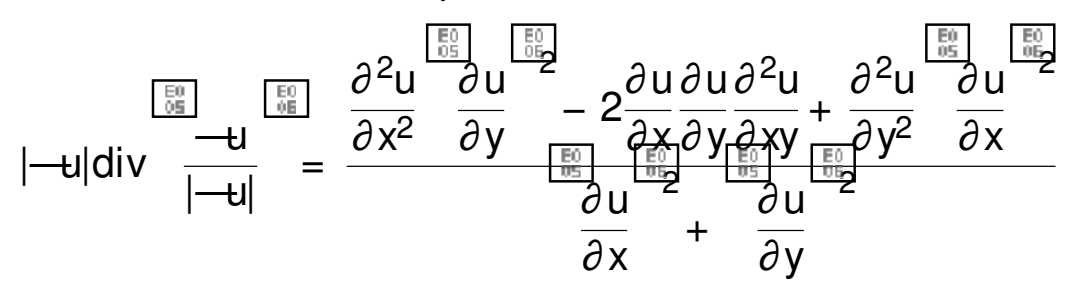

emprega-se diferenças centradas de segunda ordem, conforme segue:

$$
\begin{gathered}
\frac{\partial u}{\partial x} \approx \frac{u_{i+1 j}^{n}-u_{i-1 j}^{n}}{2 D x} ; \quad \frac{\partial u}{\partial y} \approx \frac{u_{i j+1}^{n}-u_{i j-1}^{n}}{2 D y} ; \\
\frac{\partial^{2} u}{\partial x^{2}} \approx \frac{u_{i+1 j}^{n}-2 u_{i j}^{n}+u_{i-1 j}^{n}}{D x} ; \quad \frac{\partial^{2} u}{\partial y^{2}} \approx \frac{u_{i j+1}^{n}-2 u_{i j}^{n}+u_{i j+1}^{n}}{D y} ; \\
\frac{\partial^{2} u}{\partial x y} \approx \frac{u_{i+1 j+1}^{n}-u_{i-1 j+1}^{n}-u_{i+1 j-1}^{n}+u_{i-1 j-1}^{n}}{4 D x D y}:
\end{gathered}
$$

A norma euclidiana é utilizada para cal ular tanto $|-t|$ quanto $\mid-$ Su| na Equação (3.16). Para fins de impl ementação da transf ormada wave atoms e sua inversa, empregamos a discretização proposta em (DEMANET; YING, 2007b), na qual os autores fazem uso da transformada rápi da de Fouri er integrada a uma ferramenta públ ica chamada Wave atom Lab packet, a qual pode ser encontrada no site www.waveatom. $\operatorname{org}^{3}$ para fins de avaliação (não comercial). Foi utilizada a seguinte transformada baseada em wave atoms:

$$
S f=(W A)^{-1} Q_{q}(W A)(f):
$$

Neste caso, tanto u quanto I podem ser utilizadas como sendo o sinal f. A transformada wave atom originada da Equação (3.18) é denotada por (WA) e sua transformada inversa associada é denotada por (WA) ${ }^{-1}$ (DEMANET; YING, 2007b). Além disso, $Q_{q}$ é a função de limiarização definida pela Equação (3.19).

O processo iterativo para cal cular $u_{i j}^{n+1}$ é dado pela Equação (3.3), condição de contorno do tipo Neumann, para $n=0 ; 1 ; 2 ; \ldots ; \mathrm{N}-1$. Desse modo, a fórmula discreta associada à Equação (3.13) é dada por

$$
u_{i j}^{n+1}=u_{i j}^{n}+D t L\left(u_{i j}^{n}\right) ; \quad \forall\left(x_{i} ; y_{j}\right) \in W ;
$$

em que $u_{i j}^{0}=I\left(x_{i} ; y_{j}\right)$, e $L\left(u_{i j}^{n}\right)$ representa a discretização dos termos que aparecem no lado di reito da Equação (3.13), exceto pelo do termo h, que é previamente cal cul ado para cada iteração da Equação (3.23).

O al goritmo completo, conforme descrito em (CASACA; ALMEIDA; BOAVENTURA, 2013), é apresentado a seguir.

3 Último acesso em 01/04/2016 
Algoritmo (Aproximação numérica da Equação (3.13))

Entrada: I (imagem com ruído), Dt (passo temporal), N (número de iterações), a eb (pesos da EDP),

d ek (pesos do mapeamento do termo h), m(limiar de h) eq (parâmetros da wave atom).

Saída: $\mathbf{e}$ (image restaurada).

1. Calcular $\mathrm{SI}$ usando a Equação (3.22) e definir $v^{0}=\mathrm{S}$

2. Para $\mathrm{n}=0: \mathrm{N}-1$ faça

- Atualizar pixels da fronteira de $u$ aplicando condições de contorno de Neumann

- Calcular $\mathrm{O}_{1}(\mathrm{i} ; \mathrm{j})=\overline{\mathrm{d}}\left|-\vartheta_{i j}^{n}\right|, \mathrm{O}_{2}(\mathrm{i} ; \mathrm{j})=\sqrt{\mathrm{k}}\left|-\mathrm{u}_{\mathrm{ij}}^{n}\right| \mathrm{e}=\mathrm{h}_{\mathrm{ij}}$ de acordo com a Equação (3.17), $\forall(\mathrm{i} ; \mathrm{j}) \in \mathrm{W}$

- Atualizar $u_{i j}^{n+1}$ pela Equação (3.23), levando em consideração o cálcul o de $h$ nas etapas anteriores

- Atualizar $v^{n+1}=S^{n}$ pela Equação (3.22)

Fim Para

Ajuste paramétrico via algoritmos genéticos

Os Algoritmos Genéticos (HOLLAND, 1975) são técnicas de busca e de otimização não-deterministícas inspiradas nos princípios biológicos de evolução e seleção natural das espécies. Esses métodos procuram por soluções ótimas para um dado problema por meio de uma pesquisa probabilística em um espaço de busca pré-definido. De fato, eles têm sido amplamente explorados em problemas de otimização. Uma de suas principais características é a possibilidade de encontrar soluções ótimas ou apropriadas para problemas complexos na ausência de informações específicas sobre o problema (GOLDBERG, 1989).

Cada solução do problema é representado por um indivíduo em uma população (um conjunto de possíveis soluções) e as características de um indivíduo são mapeadas por um cromossomo. Novas soluções são geradas dentro do espaço de busca, modificando os indivíduos atuais através de operadores de sel eção, recombinação e mutação, que simulam o processo reprodutivo. Além disso, uma função fitness é usada para simular as fases de sel eção natural e para atribuir uma medida de qualidade para cada indivíduo. Dessa forma, os indivíduos mais aptos têm mai ores chances de serem sel ecionados para a reprodução e também para permanecer na próxima geração. O fluxograma na Figura 32 i lustra os principais passos de um al goritmo genético (GA: genetic al gorithm).

Em nosso problema, um al goritmo genético com codificação real foi usado para obter val ores apropriados para o conjunto de parâmetros presentes na formul ação recursiva da Equa ção (3.23). Indivíduos mapeiam um determinado conj unto de parâmetros e seus cromossomos são codificados por meio de um vetor de valores reais, a saber:

$$
\mathrm{v}=(\mathrm{N} ; \mathrm{a} ; \mathrm{d} ; \mathrm{k} ; \mathrm{m} ; \mathrm{q}) ;
$$

em que N; a , d estão presentes no operador central L, k; m estão definidos na Equação (3.16) e q é usado na Equação (3.22).

A função fitness utilizada foi a métrica PSNR (Peak Snal Noise-to-Ratio), usual mente adotada em aplicações de retoque digital. De fato, existe a possibil idade de se utilizar uma mistura 


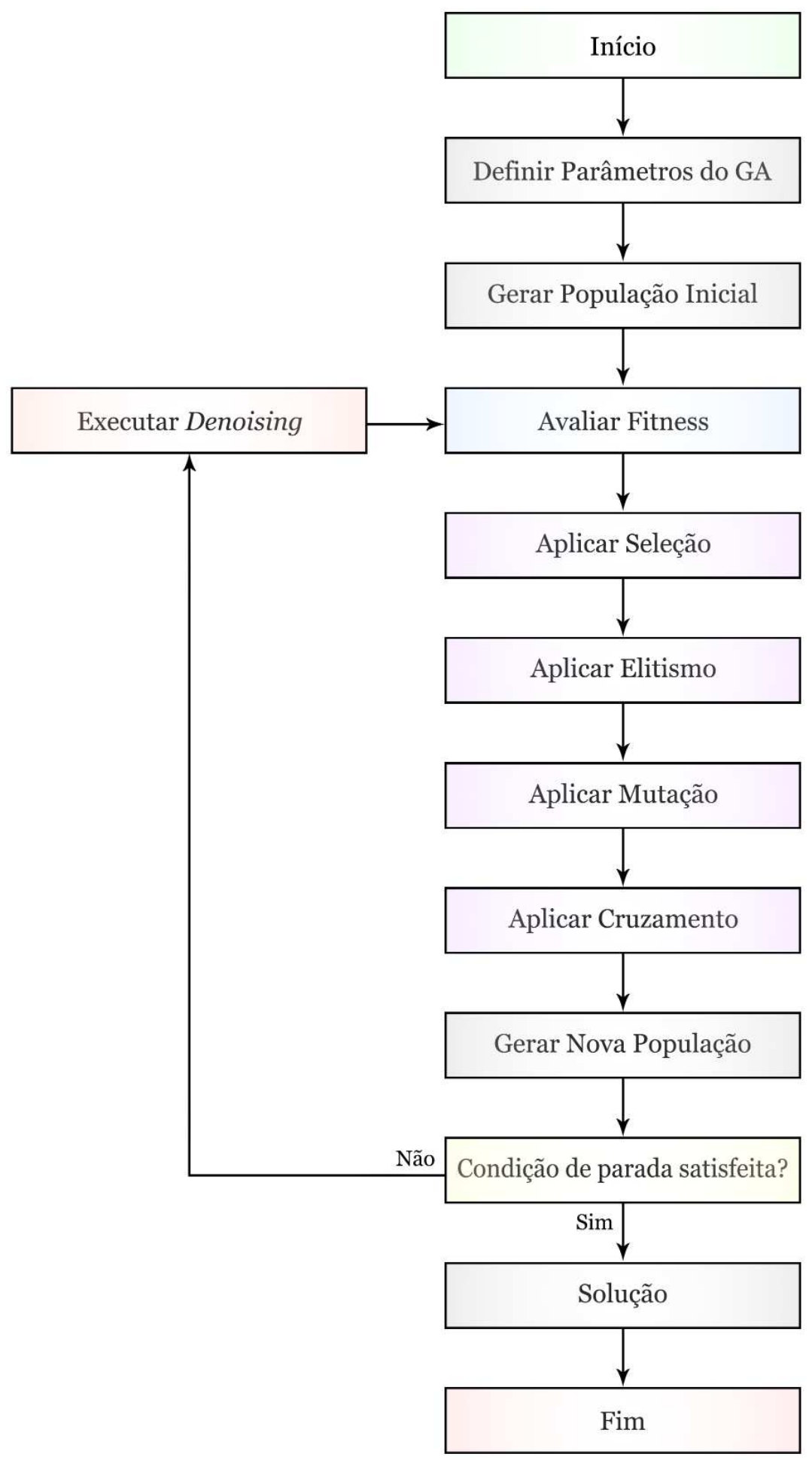

Figura 32 - Diagrama ilustrando um al goritmo genético e suas principais etapas de execução na busca por soluções ótimas.

de funções, no entanto, uma modelagem mais sofisticada através de técnicas de algoritmos genéticos está fora do escopo deste trabal ho.

A implementação do al goritmo genético foi real izada por meio da ferramenta Global Optimization Toolbox of Matlabø R2011b (MATHWORKS, 2011) com val ores padrões, exceto 
para pequenas modificações em relação aos detal hes de implementação, explicados a seguir.

Foi utilizada a função Feasible Population para criar uma popul ação inicial al eatória que satisfaz os limites de cada parâmetro. Os val ores de apti dão obtidos na função de aptidão estão em uma faixa apropriada para a função de sel eção. Assim, podemos utilizar tais val ores para elaborar um ranking, o qual baseia-se na classificação de cada indivíduo, em vez de seus val ores de fitness. O ranking de um indivíduo é a sua posi ção dentre os val ores de apti dão após serem ordenados e um indivíduo na posição $r$ tem um pontuação proporcional a $1=\sqrt{\mathrm{r}} \overline{\text { }}$.

O operador de sel eção define como o al goritmo genético escol he os indivíduos que serão usados para formar a nova popul ação. O "torneio" foi utilizado como operador de seleção. Neste caso, o indivíduo escol hido é aquel e com mel hor aval iação dentre quatro elementos, tamanho padrão do torneio, escol hidos al eatoriamente. Além disso, dois indivíduos são selecionados pelo concei to de elitismo dentro deste cenário.

Novos indivíduos são então gerados ao utilizar os operadores de mutação e cruzamento. A mutação al tera o cromossomo com pequenas mudanças al eatórias. O operador util izado foi o adaptive feasible, o qual gera direções al eatórias que são adaptativas em relação à última geração. O operador de cruzamento define como o al goritmo genético combina dois indivíduos, ou pais, para gerar os filhos para a próxima geração. A função utilizada para cruzamento foi a heurística, a qual retorna um novo indivíduo que se encontra no segmento determinado pelos dois pais, localizado de modo a ficar mais próximo do pai com melhor val or de aptidão. Foi usado o critério de parada padrão, exceto pel os val ores de número máximo de iterações, 20, e da tolerância para a função, 0.1 .

\subsection{Resultados experimentais}

Nesta seção são apresentados os resul tados numéricos fornecidos pelo modelo baseado na EDP não-linear anisotrópica regularizada (EDP-NAR) e uma comparação com diversas técnicas do estado-da-arte em eliminação de ruído sensíveis a textura, conforme apresentados em (CASACA; ALMEIDA; BOAVENTURA, 2013). Os experimentos foram realizados com imagens em escal a de cinza e também com imagens coloridas no sistema RGB. No caso de imagens col oridas, o al goritmo foi aplicado individual mente em cada canal de cor. As imagens utilizadas são representadas por matrizes de dimensões 128 × 128 e 256 × 256, (veja a Tabela 4). Em nosso filtro anisotrópico, os parâmetros $b=1$ e $D t=0: 1$ foram fixados e usados em todos os testes realizados com o modelo EDP-NAR.

As Figuras 33, 34, 35 exibem os resultados visuais obtidos ao aplicar a metodologia proposta em imagens col oridas. Em todos os casos, o método gerou resultados satisfatórios, pois os detal hes da imagem não ficam retidos nas matri zes residuai s obti das pel a subtração da imagem degradada e sua versão restaurada, apenas o ruído (Figuras 33d, 34d e 35d). Nas Figuras 33c, 34c e 35c, podemos visual izar as imagens restauradas com o método da EDP-NAR. 
Tabel a 4 - Tabela contendo as propriedades das imagens utilizadas nos testes. Todas as imagens danificadas foram geradas artificial mente a partir da sua versão original sem ruído. $O$ vetor $v$ representa os parâmetros utilizados no modelo EDP-NAR (veja Equação (3.24)). Fonte: (CASACA; ALMEIDA; BOAVENTURA, 2013).

\begin{tabular}{llcc}
\hline Imagem & Tamanho & RGB/Cinza & Vetor de par m. v \\
\hline Bola & $128 \times 128$ & RGB & $(20 ; 0: 20 ; 0: 04 ; 0: 001 ; 0: 80 ; 0: 05)$ \\
\hline Tigre & $128 \times 128$ & RGB & $(20 ; 0: 22 ; 0: 07 ; 0: 020 ; 0: 83 ; 0: 08)$ \\
\hline Zebra & $128 \times 128$ & RGB & $(20 ; 0: 15 ; 0: 17 ; 0: 016 ; 0: 67 ; 0: 07)$ \\
\hline Louvre & $256 \times 256$ & Cinza & $(27 ; 0: 16 ; 0: 47 ; 0: 002 ; 0: 34 ; 0: 15)$ \\
\hline Barco & $256 \times 256$ & Cinza & $(30 ; 0: 44 ; 0: 23 ; 0: 002 ; 0: 77 ; 0: 17)$ \\
\hline Barbara & $256 \times 256$ & Cinza & $(20 ; 0: 80 ; 0: 09 ; 0: 001 ; 0: 25 ; 0: 80)$ \\
\hline
\end{tabular}

Nos experimentos das Figuras 36 e 37, o filtro da Equação (3.13) foi aplicado em fotografias com textura. A qualidade dos resultados é bastante notória em relação ao grau de detal hes e texturas preservadas após a restauração. Por exemplo, na Figura 36a (Louvre), a orientação dos padrões (definidos por texturas em linhas) foram mantidos quase intactos na imagem recuperada. Com relação à Figura 37a, podemos observar que os padrões presentes tanto na "madeira" quanto no "barco" foram recuperados de modo satisfatório.

Na sequência aval iamos o desempenho do método baseado na EDP-NAR quando comparado com demais técnicas da literatura. Para real izar esta tarefa, adotamos uma parte texturizada da fotografia da Barbara (Figura 28), a qual é frequentemente utilizada para ilustrar técnicas presentes na literatura.

A Figura 38a contém características importantes a serem preservadas e recuperadas: a textura acima do pescoço, o plano de fundo e al guns detal hes intrínsecos da modelo, como ol hos, nariz e a mão. As Figuras 38b e 38c foram obtidas, respectivamente, utilizando a transformada rápida curvelet discreta (CANDèS; DONOHO, 2004; CANDèS et al., 2006) e uma técnica baseada em wave atom 2D discreta (DEMANET; YING, 2007b). A partir dos resul tados obtidos, pode-se notar que a textura não foi recuperada adequadamente com o uso da transformada curvelet e a técnica introduziu al guns artef atos na imagem final. Por outro lado, a transformada wave atom restaurou adequadamente as regiões com textura, porém esta produziu uma imagem borrada, resultado de um processo intenso de suavização. A Figura 38d mostra a imagem restaurada com o modelo baseado no termo de fidelidade adaptativo usando $\mathrm{C}=0$ (veja Equação (3.12)), enquanto a Figura 38e exibe a reconstrução gerada pel a equação de difusão combinada com curvelets (veja Equação (3.10)), utilizando um passo 0:0005 e 11 iterações. Embora o primeiro método tenha recuperado partes da textura, al guns detal hes importantes da imagem foram excessivamente suavizados (rosto e mãos, por exemplo). Em contraste, o segundo método não produziu qual quer suavização excessiva, mas ainda manteve bastante ruído na imagem final . $\mathrm{Na}$ Figura $38 f$ é ilustrado o resul tado obtido por meio da aplicação da EDP-NAR. Podemos observar que as texturas e os detal hes da imagem (dados intrínsecos) foram recuperados e o nível de ruído foi minimizado sem causar suavização excessiva. 


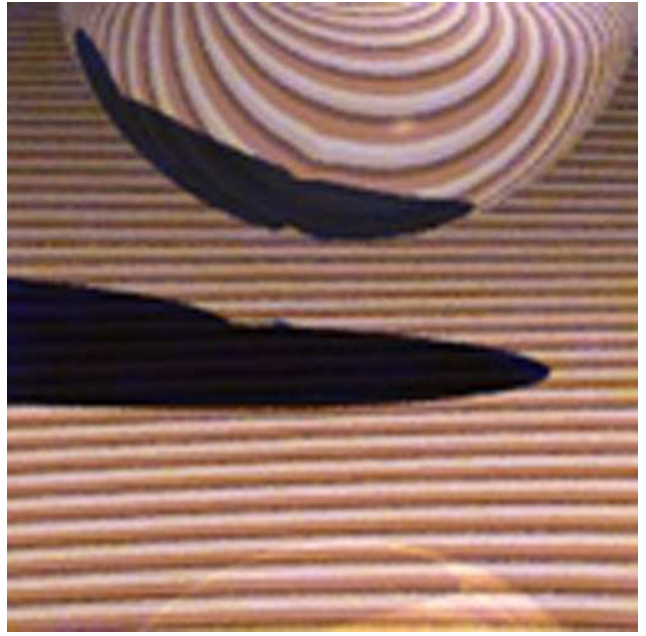

(a)

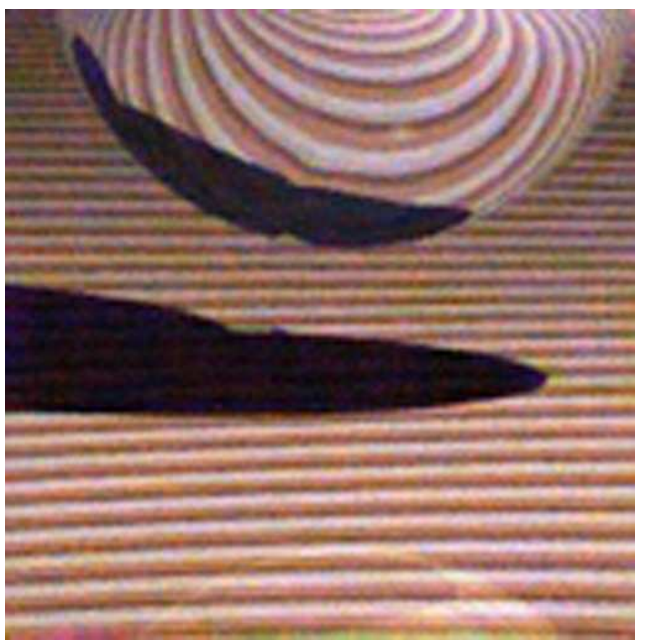

(c)

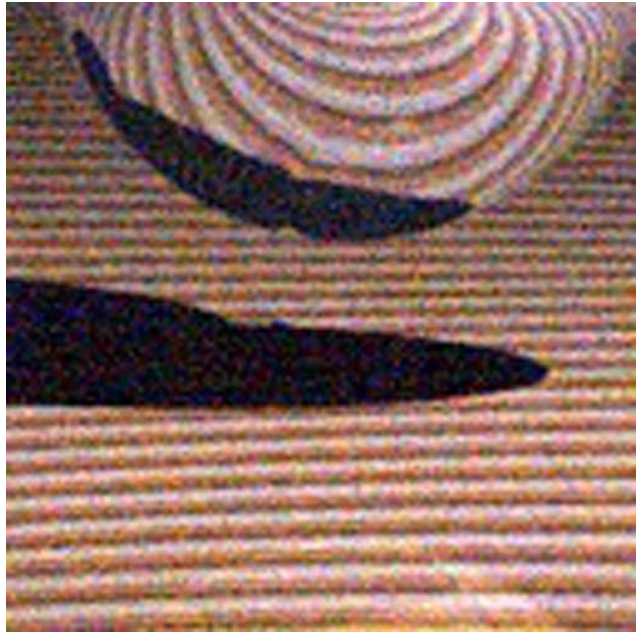

(b)

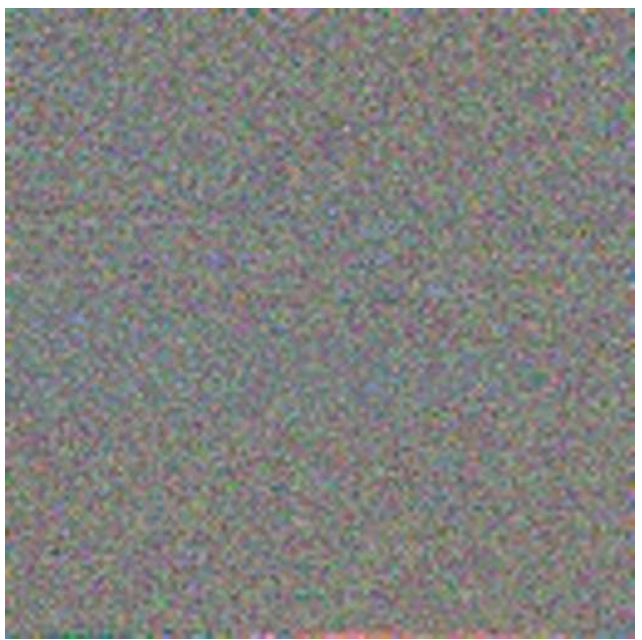

(d)

Figura 33 - Eliminação de ruído de imagem colorida. (a) Imagem original, (b) versão com ruído, (c) imagem restaurada pela EDP-NAR e (d) componente residual. Fonte: (CASACA; ALMEIDA; BOAVENTURA, 2013).

Os parâmetros utilizados em todas as técnicas citadas foram escol hi dos de acordo com a sugestão dos autores em seus trabal hos ou por meio da aplicação exaustiva de cada um destes modelos a fim de se obter um resul tado com a melhor qual idade visual possível, em relação a métrica PSNR (Tabela 5).

\subsection{Discussões e limit ações}

Neste trabal ho foi apresentada uma EDP não-linear anisotrópica regularizada (EDPNAR) di recionada à restauração de imagens com texturas e contami nadas por ruído gaussiano. O método combina um filtro baseado em difusão anisotrópica com metodologias de análise harmônica, a saber, transformadas do tipo Wave atom. Além disso, A EDP-NAR emprega um mecanismo de regularização para melhor detectar padrões oscilatórios complexos presentes na 


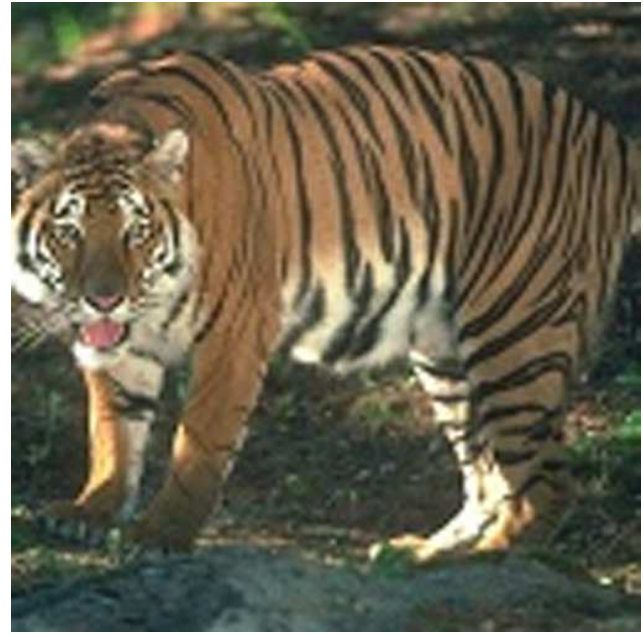

(a)

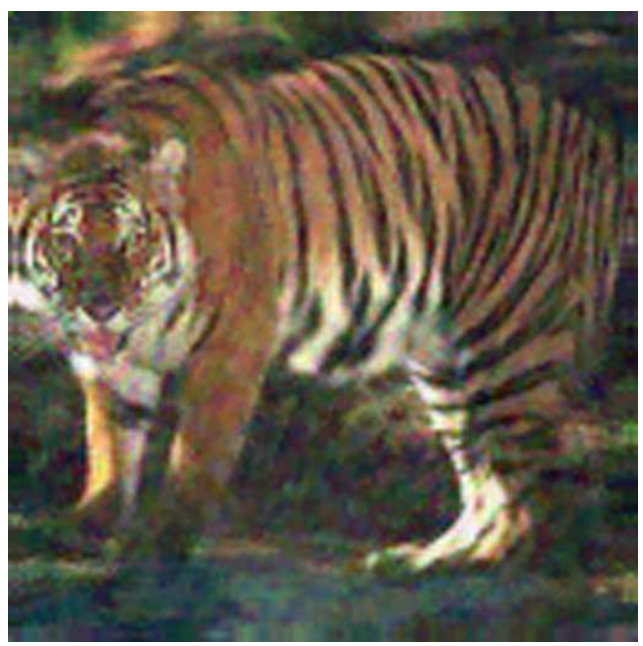

(c)

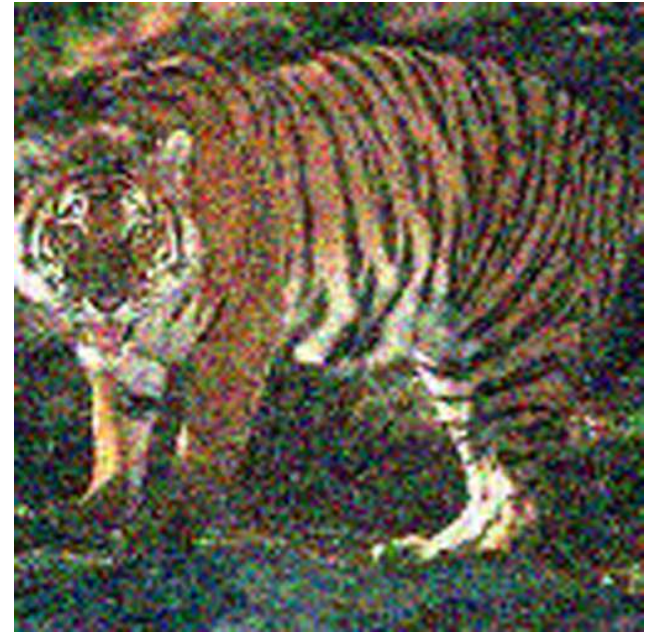

(b)

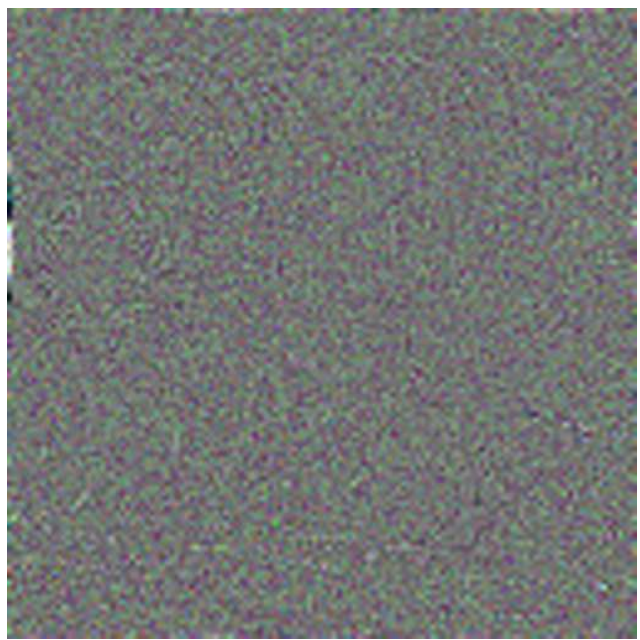

(d)

Figura 34 - Eliminação de ruído de imagem colorida (a) Imagem original, (b) imagem com ruído, (c) versão restaurada pela EDP-NAR e (d) componente residual. Fonte: (CASACA; ALMEIDA; BOAVENTURA, 2013).

imagem.

A abordagem funciona de forma sel etiva, isto é, a difusão é apl icada durante a recuperação de bordas e regi ões com texturas de acordo com uma função de mapeamento, fator regularizador h e pela atuação dos termos de reação. A EDP-NAR pode ser utilizada em uma grande gama de aplicações práticas, como processamento de impressões digitais; análise de superfícies; dados geof ísicos; retoque digital, entre outros. Além disso, foi apresentada neste trabal ho uma val idação experimental e matemática da EDP-NAR. Neste sentido, al gumas de suas propriedades matemáticas fundamentais foram investigadas, como a regularização, a estratégia de reaçãodifusão, a preservação da textura e detecção de borda e a existência e unicidade de soluções.

Os resultados experimentais mostram a eficiência da EDP-NAR quando comparado com técni cas competitivas da literatura. Apesar dos bons resultados al cançados, o método baseado na EDP-NAR possui uma limi tação com rel ação ao ajuste de parâmetros ótimos para que o método 


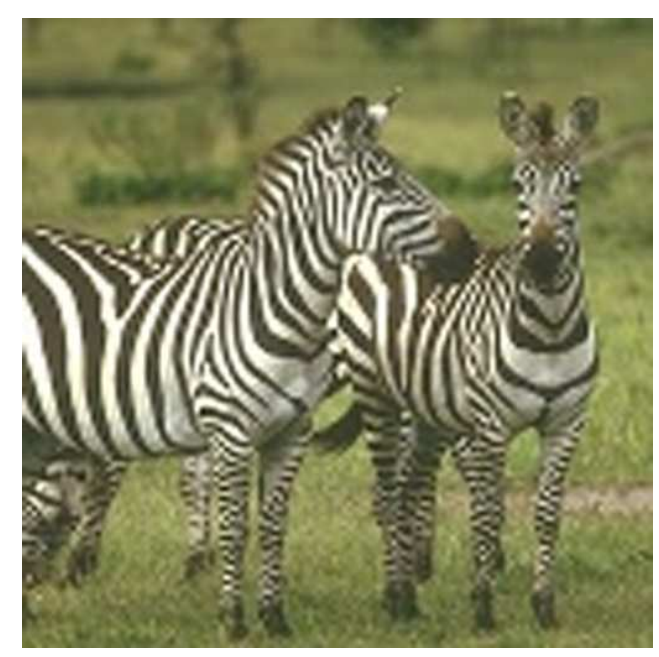

(a)

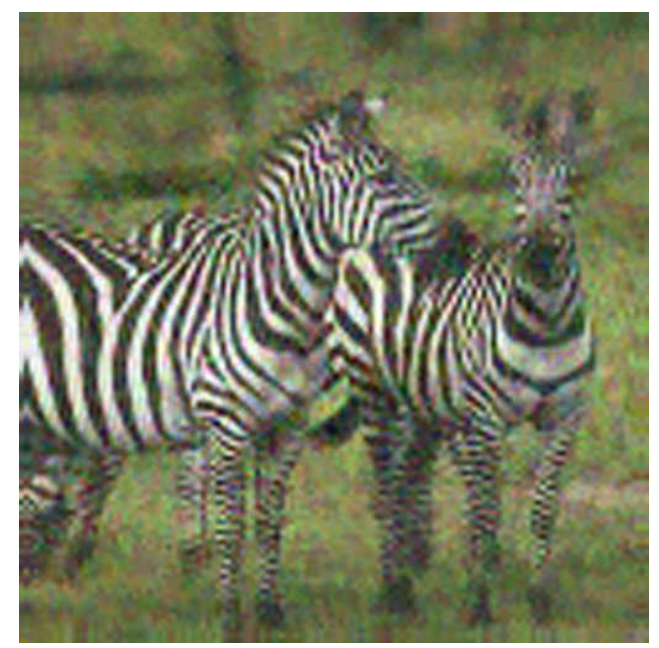

(c)

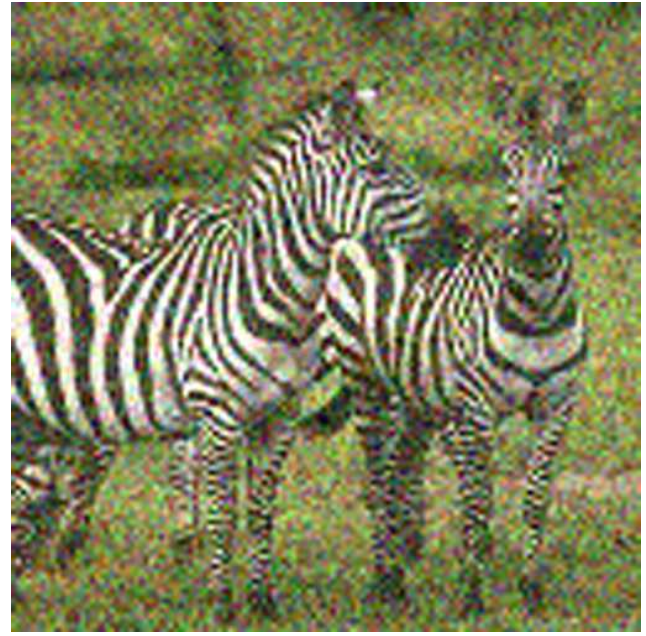

(b)

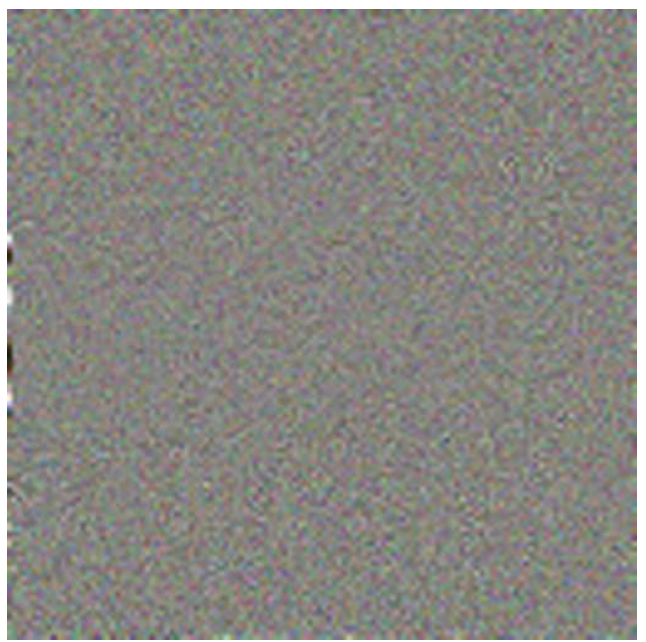

(d)

Figura 35 - Eliminação de ruído de imagem colorida. (a) Imagem original, (b) versão com ruído, (c) imagem restaurada epal EDP-NAR e (d) componente residual. Fonte: (CASACA; ALMEIDA; BOAVENTURA, 2013).

atinja seu mel hor desempenho. Contudo, conforme descrito neste trabal ho, técnicas amparadas por al goritmos genéticos podem auxiliar na busca por mel hores parâmetros para a utilização da EDP-NAR. 


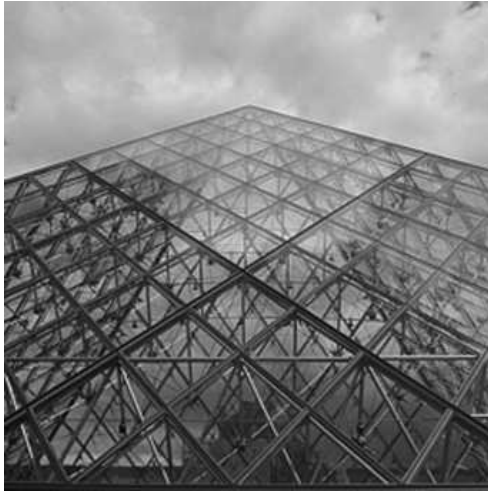

(a)

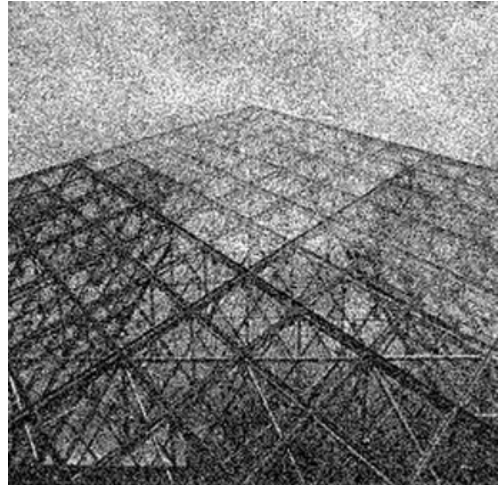

(b)

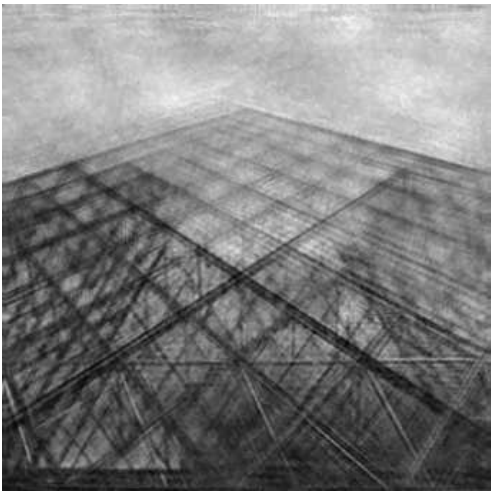

(c)

Figura 36 - Resultados experimentais obtidos pelo método da EDP-NAR aplicado em uma fotografia com textura. (a) Imagem original, (b) versão deteriorada por ruído com grande intensidade e (c) imagem restaurada pela EDP-NAR. Fonte: (CASACA; ALMEIDA; BOAVENTURA, 2013).

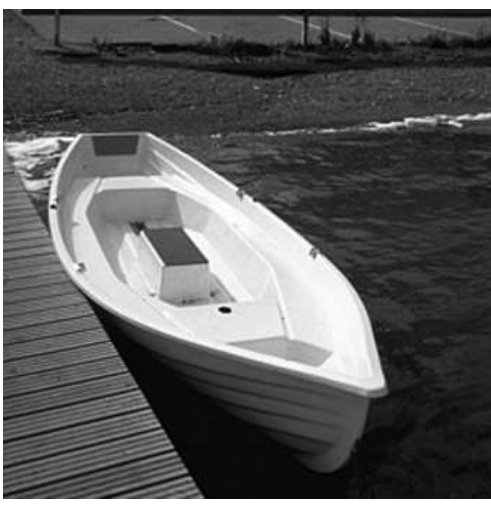

(a)

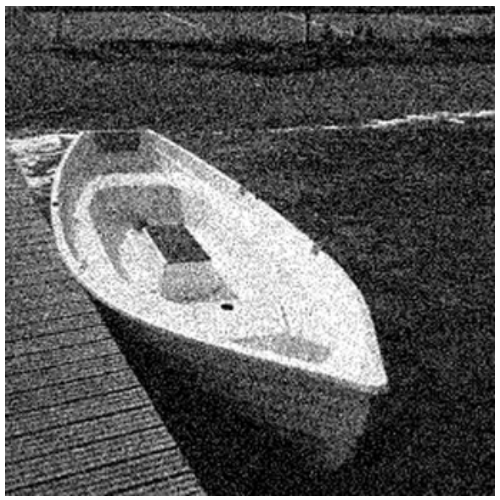

(b)

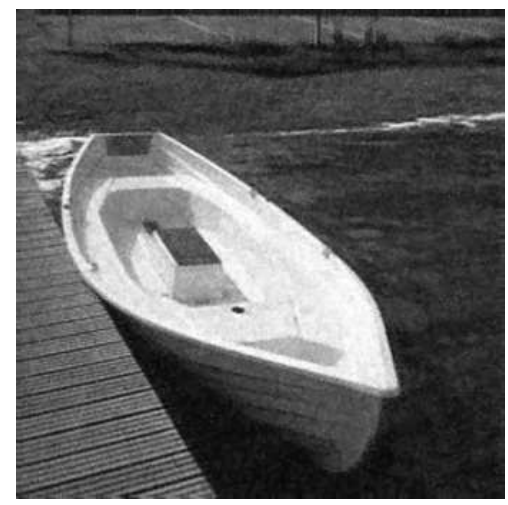

(c)

Figura 37 - Resultados experimentais pelo método EDP-NAR. (a) Imagem original, (b) versão deteriorada por ruído com grande intensidade e (c) imagem restaurada pela EDP-NAR. Fonte: (CASACA; ALMEIDA; BOAVENTURA, 2013).

Tabela 5 - Medi da quantitativa cal cul ada para as imagens restauradas com todos os métodos, em comparação com a imagem original Barbara. PSNR entre a imagem original e a imagem com ruído é 22:69 dB. Fonte: (CASACA; ALMEIDA; BOAVENTURA, 2013).

\begin{tabular}{llc}
\hline Figura & Técnica & PSNR $(\mathrm{dB})$ \\
\hline Figura 38b & Curvel et & $22: 80$ \\
\hline Figura 38c & Wave atom & $23: 54$ \\
\hline Figura 38d & Gilboa et al. & $24: 25$ \\
\hline Figura 38e & Ma et al. & $23: 43$ \\
\hline Figura 38f & Our & $25: 51$ \\
\hline
\end{tabular}




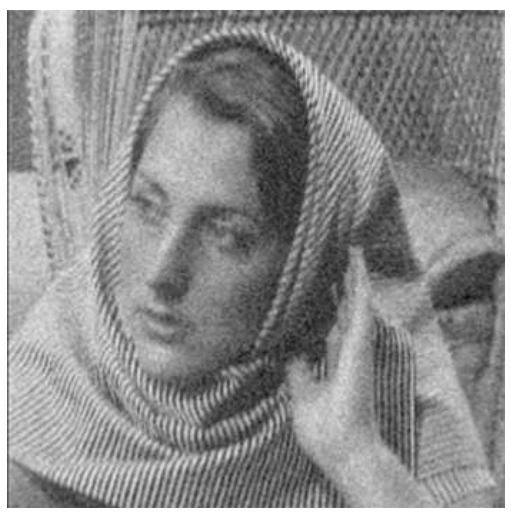

(a)

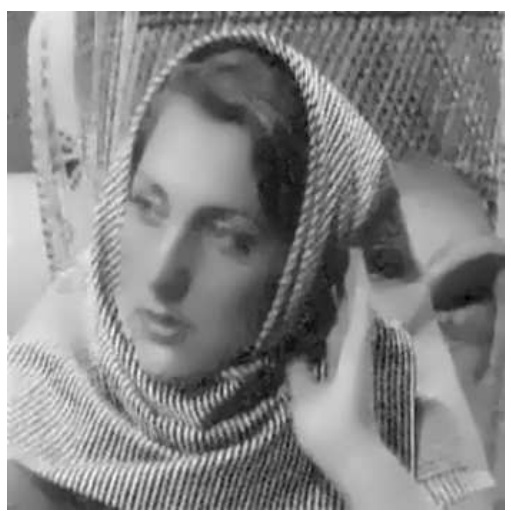

(d)

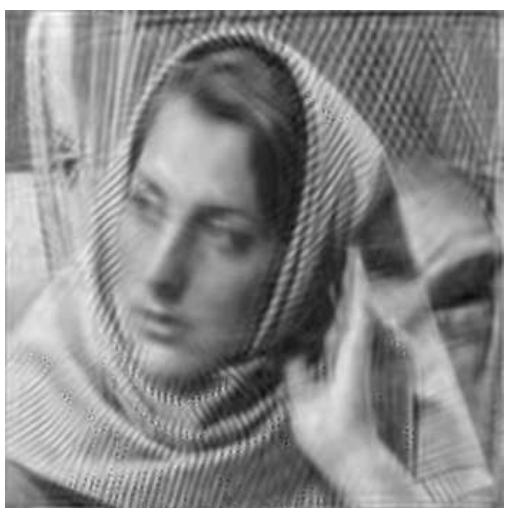

(b)

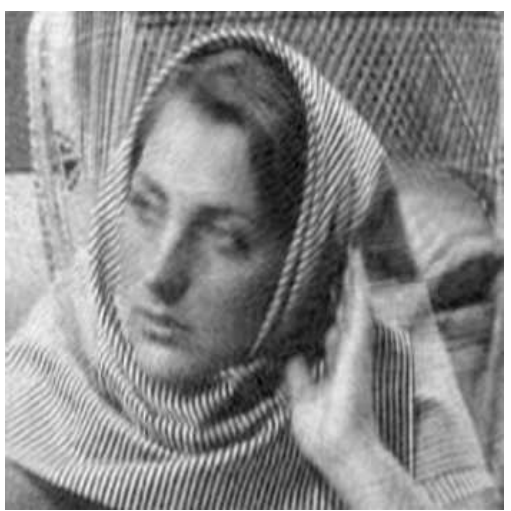

(e)

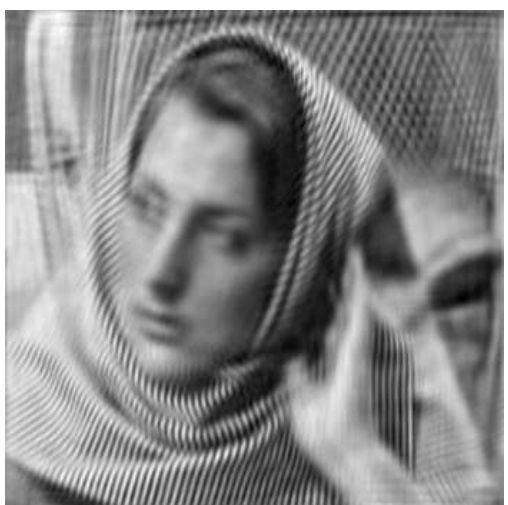

(c)

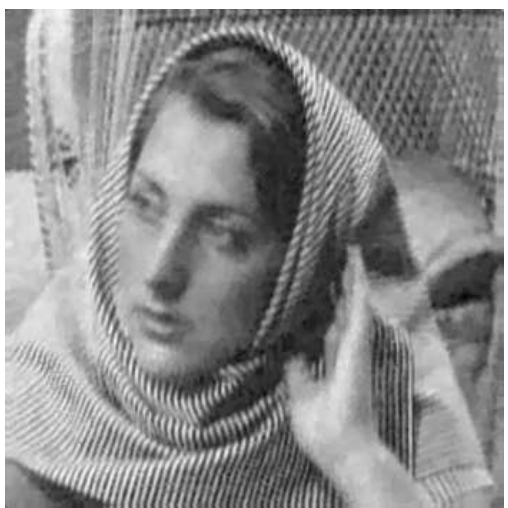

(f)

Figura 38 - Comparação dos resultados da fotografia Barbara (a) Imagem alvo, (b) restaurada por curvelets, (c) por wave atoms, (d) por difusão com termo de fidelidade adaptativa, (e) por difusão TV combinada com curvelet e (f) pela EDP-NAR. Fonte: (CASACA; ALMEIDA; BOAVENTURA, 2013). 
Neste trabal ho dois métodos baseados em difusão ani sotrópica para restaurar imagens contendo texturas e outras características de suma importancia para um referencial humano, um destinado ao problema de retoque digital de imagens e o segundo à eliminação de ruídos, foram complementados e melhorados com a elaboração de análises e validações teóricas e experimentais e também com o emprego das métricas propostas.

A técnica descrita sobre retoque digital de imagens combina difusão anisotrópica, síntese de texturas, busca di nâmica e um novo termo no mecani smo de atribuição da ordem de prioridade durante o processo de reconstrução. A tarefa consiste em "copiar e colar" blocos de pixels para restaurar imagens reais e sintéticas contendo uma grande variedade de texturas e obj etos estruturais. Os conceitos da decomposição de imagem e equação do transporte foram revistos e são empregados de modo a proporcionar um mecanismo robusto para definir a ordem de preenchimento e determinar a similaridade entre os blocos de pixels durante o processo de retoque digital. O mecani smo de amostragem dinâmica também mostrou-se bastante eficaz para reduzir o custo computacional da abordagem proposta ao empregar a métrica proposta induzida por um produto interno.

Além disso, este trabal ho também apresentou uma EDP direcionada à restauração de imagens com grande nível de detal hes e contaminadas por ruído gaussiano. O método integra um filtro baseado em difusão anisotrópica com metodologias de análise harmônica, mais especificamente por meio de transformadas do tipo wave atoms. Foi anal isado o mecanismo de regularização o qual visa detectar padrões oscilatórios compl exos na imagem tais como texturas. Além disso, foi real izada uma val idação teórica da EDP de modo a garantir a existência e a unicidade de soluções. A abordagem funciona de forma sel etiva, isto é, a difusão é aplicada durante a recuperação de bordas e regiões com texturas de acordo com uma função de mapeamento (termo regularizador) e pel a atuação de termos de reação. A EDP regularizada para tratar imagens com textura pode ser utilizada em uma grande gama de apl icações práticas e se mostrou eficiente 
quando aplicadas a diversos exemplos de imagens texturizadas.

A performance das técnica apresentadas foram atestadas por meio de anál ises experimentais quantitativas e qual itativas com outros métodos representativos da literatura Imagens reais e sintéticas de diferentes níveis de complexidade foram aval iadas com o objetivo de anal isar a eficiência de ambas as metodologias. De fato, os métodos apresentaram um bom equilíbrio entre boa qual idade visual de restauração e baixo custo computacional, al ém de também se mostrarem estáveis quando comparadas com as demais técnicas do estado-da-arte avaliadas neste trabal ho. Ainda sobre a performance de cada uma das técnicas, ambas foram flexíveis quando aplicadas a diferentes cl asses de imagens, percorrendo de imagens sintéticas ate fotografias dotadas de texturas complexas e variadas.

Como mencionado nos capítul os anteriores, como objetivos futuros al meja-se automatizar o máximo possível o número de parâmetros em cada uma das abordagens, bem como também investigar novos descritores de textura (como Gabor ou descritores baseados na técnica SIFT) no sentido de regularizar a EDP de remoção de ruído, al ém de também embutir um processo prévio de segmentação de imagens a partir de um grafo de conectividade derivado da imagem alvo na técnica de retoque digital. Neste último caso, a ideia é utilizar uma imagem previamente segmentada para di rigir o processo de retoque digital de forma a atribuir mai or prioridade de restauração às regiões consideradas de contorno na imagem-guia segmentada.

Finalmente, outro tópico de interesse dentro do escopo desta pesquisa é abordar o problema de eliminação de ruído do tipo impul sivo, buscando combinar parte da formulação da EDP proposta no âmbito do trabal ho (ALMEIDA; BOAVENTURA, 2009). A ideia é simular numericamente o operador estatístico da mediana na forma de um termo de regul arização para a equação diferencial em questão, na intenção de remover o ruído da imagem degradada. Testes preliminares tem se mostrado promissores do ponto de vista tanto da qual idade visual quanto do teórico-matemático (isto é, quanto à existencia e unicidade em termos teóricos). 
ALMEIDA, M. P.; BOAVENTURA, M. Eli minação de ruído impul sivo usando um filtro mediano sel etivo e difusão isotrópica. Revista de I nfor mática Teórica e Aplicada (RITA), v. 16, p. 129140, 2009. Citado 2 vezes nas páginas 63 e 92.

ALMEIDA, M. P.; BOAVENTURA, M. Eliminação de Ruído I mpulsivo em I magens Color idas Usando um Filtro M ediano Sel etivo e Retoque Digital. 129-140 p. Dissertação (Mestrado) - Instituto de Biociências, Letras e Ciências Exatas - Universidade Estadual Paulista "Júlio de Mesquita Filho"Campus São José do Rio Preto, 2010. Citado 3 vezes nas páginas 16, 63 e 64.

ALMEIDA, M. P. de. Combining regularized ani sotropic diffusion and harmonic anal ysis tools for denoising textured images. In: I Br azilian Congr ess of Young Resear cher s in Pure and Applied Mathematics. [S.I.: s.n.], 2011. p. -. Resumo Técnico. Citado na página 25.

ALVAREZ, L.; LIONS, P.; MOREL, J. Image selective smoothing and edge detection by nonlinear diffusion. SI AM J. Numer. Anal., v. 29, p. 845-866, 1992. Citado 5 vezes nas páginas 65, 66, 69, 70 e 79.

ANSARI, R. A.; BUDDHIRAJU, K. M. k -means based hybrid wavel et and curvel et transform approach for denoising of remotely sensed images. Remote Sensing Letter s, Informa UK Limited, v. 6, n. 12, p. 982-991, sep 2015. Disponível em: <http://dx.doi.org/10.1080/2150704X. 2015.1093184>. Citado na página 65.

ANSARI, R. A.; BUDHHIRAJU, K. M. A comparative evaluation of denoising of remotely sensed images using wavel et, curvel et and contourlet transforms. Journal of the Indian Society of Remote Sensing, Springer Nature, v. 44, n. 6, p. 843-853, mar 2016. Disponível em: <http: //dx.doi.org/10.1007/s12524-016-0552-y>. Citado na página 65.

ARBELAEZ, P.; MAIRE, M.; FOWLKES, C.; MALIK, J. Contour detection and hierarchical image segmentation. IEEE Tr ans. Pattern Anal. Mach. Intell., IEEE Computer Society, v. 33, n. 5, p. 898-916, 2011. Citado na página 48.

ASHIKHMIN, M. Synthesizing natural textures. In: ACM Symposium on Interactive 3D graphics (I3D). [S.I.: s.n.], 2001. p. 217-226. Citado na página 32.

AUJOL, J. F.; CHAMBOLLE, A. Dual norms and image decomposition models. International Journal of Computer Vision, v. 63, n. 1, p. 85-104, 2005. Citado na página 37.

AUJOL, J. F.; LADJAL, S.; MASNOU, S. Exemplar-based inpainting from a variational point of view. SI AM J. Math. Anal., v. 42, p. 1246-1285, 2010. Citado na página 35.

AZZABOU, N.; PARAGIOS, N.; GUICHARD, F. Proceedings of scal e space and variati onal methods in computer vision: First international conference. In: [S.I.]: Springer Berlin Heidel berg, 2007. cap. Uniform and Textured Regions Separation in Natural Images Towards MPM Adaptive Denoising, p. 418-429. Citado na página 24. 
BARCELOS, C. A. Z.; BOAVENTURA, M.; JR., E. C. S. Edge detection and noise removal by use of apde with automatic sel ection of parameters. Computational and Applied Mathematics, v. 24, p. 131-150, 2005. Citado na página 46.

BARCELOS, C. A. Z.; BOAVENTURA, M.; JR, E. S. A well-balanced flow equation for noise removal and edge detection. IEEE Transactions on I mage Processing, v. 12, p. 751-763, 2003. Citado 8 vezes nas pági nas 38, 39, 46, 66, 70, 73, 79 e 80.

BARNES, C.; SHECHTMAN, E.; FINKELSTEIN, A.; GOLDMAN, D. B. Patchmatch: A randomized correspondence al gorithm for structural image editing. Lecture Notes in Computer Science, ACM, v. 28, n. 3, p. 24:1-24:11, 2009. Citado 12 vezes nas pági nas 14, 15, 16, 23, 48, $51,52,53,54,55,56$ e 57.

BERTALMÍO, M.; SAPIRO, G.; CASELLES, V.; BALLESTER, C. Image inpainting. In: Annual Conference on Computer Graphics (SIGGRAPH). [S.I.: s.n.], 2000. p. 217-226. Citado 6 vezes nas páginas 25, 33, 35, 36, 39 e 41.

BERTALMÍO, M.; VESE, L. A.; SAPIRO, G.; OSHER, S. Simultaneous structure and texture image inpainting. IEEE Transactions on I mage Processing, v. 12, p. 882-889, 2003. Citado 2 vezes nas páginas 35 e 36 .

BORNEMANN, F.; MäRZ, T. Fast image inpainting based on coherence transport. J. Math. I maging Vis., v. 28, p. 259-278, 2007. Citado 3 vezes nas páginas 34, 39 e 41.

BRUNET, D.; VRSCAY, E. R.; WANG, Z. On the mathematical properties of the structural similarity index. IEEE Transactions on Image Processing, PP, p. 1-10, 2012. Citado na página 45.

BUGEAU, A.; BERTALMÍO, M. Combining texture synthesis and diffusion for image inpainting. In: VISAPP (1). [S.I.: s.n.], 2009. p. 26-33. Citado na página 35.

BUGEAU, A.; BERTALMÍO, M.; CASELLES, V.; SAPIRO, G. A comprehensive framework for image inpainting. IEEE Transactions on I mage Processing, v. 19, p. 2634-2645, 2010. Citado na página 35.

BURGER, M.; GILBOA, G.; OSHER, S.; XU, J. Nonlinear inverse scal e space methods. Communications in Mathematical Sciences, v. 4, p. 179-212, 2006. Citado 2 vezes nas páginas 38 e 65.

BURGER, M.; HE, L.; SCHöNLIEB, C.-B. Cahn-hilliard inpainting and a generalization for grayval ue images. SI AM J. Imaging Sciences, v. 2, p. 1129-1167, 2009. Citado na página 34.

CAI, J.-F.; CHAN, R.; SHEN, Z. A framelet-based image inpainting al gorithm. Applied and Computational Har monic Analysis, v. 24, p. 131-149, 2008. Citado na página 33.

CALVETTI, D.; SGALLARI, F.; SOMERSALO, E. Image inpainting with structural bootstrap priors. Image and Vision Computing, v. 24, p. 782-793, 2006. Citado na página 36.

CANDèS, E.; DEMANET, L.; DONOHO, D.; YING, L. Fast discretecurvelet transforms. SI AM J. on Multiscale Model. Simul., v. 5, p. 861-899, 2006. Citado 2 vezes nas páginas 34 e 58.

CANDèS, E. J.; DONOHO, D. L. New tight frames of curvel ets and optimal representations of objects with piecewise $c^{2}$ singularities. Communications on Pure and Applied Mathematics, v. 57, p. 219-266, 2004. Citado 2 vezes nas páginas 71 e 85. 
CANDèS, E.; DEMANET, L.; DONOHO, D.; YING, L. Fast discrete curvelet transforms. SI AM J. on Multiscale Model. Simul., v. 5, p. 861-899, 2006. Citado 2 vezes nas páginas 71 e 85.

CAO, F.; GOUSSEAU, Y.; MASNOU, S.; PÉREZ, P. Geometrically guided exemplar-based inpainting. SI AM J. Img. Sci., v. 4, p. 1143-1179, 2011. Citado 4 vezes nas páginas 33, 35, 39 e 43.

CASACA, W.; ALMEIDA, M. P.; BOAVENTURA, M. Denoising textured images via regularized anisotropic diffusion (book chapter). In: MISHRA, Z. N. A.; SHAHID, Z. (Ed.). An Intr oductory Guide to I mage and Video Processing. Brisbane, Australia: Iconcept Press Ltd., 2013. p. 48-71. Citado 18 vezes nas páginas 16, 17, 19, 24, 25, 65, 66, 68, 72, 73, 81, 84, 85, $86,87,88,89$ e 90.

CASACA, W.; BOAVENTURA, M.; ALMEIDA, M. P. D.; NONATO, L. G. Combining anisotropic diffusion, transport equation and texture synthesis for inpai nting textured images. Patter $n$ Recognition Letters, Elsevier Science Inc., v. 36, p. 36-45, 2014. ISSN 0167-8655. Citado 14 vezes nas páginas 13, 14, 16, 23, 24, 25, 31, 37, 40, 42, 44, 46, 47 e 58.

CASACA, W. C. O. Restauração de Imagens Digitais comTexturas utilizando Técnicas de Decomposição e Equações Difer enciais Par ciais. Dissertação (Mestrado) — Instituto de Biociências, Letras e Ciências Exatas - Universidade Estadual Paulista "Júlio de Mesquita Filho"Campus São José do Rio Preto, 2010. Citado 8 vezes nas páginas 24, 36, 37, 40, 41, 66, 73 e 78.

CASACA, W. C. O.; BOAVENTURA, M. A regularized nonlinear diffusion approach for texture image denoising. In: XXII Brazilian Symposium on Computer Graphics and Image Processing (Sibgr api). [S.I.]: IEEE Computer Society, 2009. p. 164-171. Citado 4 vezes nas páginas 25, 66, 72 e 73.

CASACA, W. C. O.; BOAVENTURA, M.; ALMEIDA, M. P. Classifying texture and free textured content from images using nonlinear ani sotropic diffusion. In: Proceedings of the 5th ENAM A (National M eeting of Mathematical Analysis and Applications). [S.I.: s.n.], 2011. v. 5, p. 210-211. Citado na página 25.

CASACA, W. C. O.; MOTTA, D.; TAUBIN, G.; NONATO, L. G. A user-friendly interactive image inpai nting framework using laplacian coordinates. IEEE Inter national Confer ence on I mage Processing (ICIP), 2015. Citado na página 31.

CASELLA, G.; BERGER, R. L. Statistical infer ence. Pacific Grove (Calif.): Brooks Cole, 2002. (Duxbury advanced series). ISBN 0-495-39187-5. Disponível em: <http://opac.inria.fr/record= b1134456>. Citado na página 62.

CASTRO, D. H. From images to point clouds: practical considerations for three dimensional computer vision. Tese(Doctoral Dissertation) - University of Oulu, 2015. Citado na página 23.

CATTé, F.; LIONS, P.; MOREL, J.; COLL, T. Image selective smoothing and edge detection by nonlinear diffusion. SI AM J. Numer. Anal., v. 29, p. 182-193, 1992. Citado na página 69.

CHAN, T. F.; OSHER, S.; SHEN, J. The digital tv filter and nonlinear denoising. IEEE Transactions on I mage Processing, v. 10, p. 231-241, 2001. Citado 2 vezes nas páginas 38 e 65. 
CHANJUAN, L.; HAILIN, Z.; CAIXIA, L.; YING, L.; YILEI, W.; SHIXIANG, J.; SHUSEN, Z. An adaptive texture-preserved image denoising model. Journal of Ambient Intelligence and Humanized Computing, v. 6, n. 5, p. 689-697, 2015. Citado na página 24.

CHEN, Q.; ZHANG, Y.; LIU, Y. Image inpainting with improved exemplar-based approach. In: Proc. of the int. conf. on Multimedia content analysis and mining. [S.I.: s.n.], 2007. (MCAM’ 07), p. 242-251. Citado 3 vezes nas páginas 33, 39 e 43.

CHENG, W.-H.; HSIEH, C.-W.; LIN, S.-K.; WANG, C.-W.; WU, J.-L. Robust algorithm for exemplar-based image inpainting. In: Proc. of the International Confer ence on Computer Graphics, I maging and Visualization. [S.I.: s.n.], 2005. p. 64-69. Citado 4 vezes nas páginas 33, 39, 42 e 43.

CRANDALL, M. G.; ISHII, H.; LIONS, P. L. User's guide to viscosity solutions of second order partial differential equations. Bulletin of the American Mathematical Society, v. 27, p. 1-67, 1992. Citado na página 79 .

CRIMINISI, A.; PEREZ, P.; TOYAMA, K. Object removal by exemplar-based inpainting. In: IEEE Confer ence on Computer Vision and Pattern Recognition (CVPR). [S.I.]: IEEE Computer Society, 2003. p. 721-728. ISBN 0-7695-1900-8. Citado na página 23.

Region filling and object removal by exemplar-based image inpainting. IEEE Transactions on Image Processing (TIP), IEEE Computer Society, v. 13, n. 9, p. 1200-1212, 2004. Citado 22 vezes nas páginas 13, 14, 15, 16, 23, 33, 36, 39, 41, 42, 43, 44, 48, 49, 50, 51, 52, 53, $54,55,56$ e 57.

DEMANET, L.; SONG, B.; CHAN, T. Image inpainting by correspondence maps: a determini stic approach. In: Proc. VLSM . [S.I.: s.n.], 2003. p. 1-8. Citado 2 vezes nas páginas 34 e 36.

DEMANET, L.; YING, L. Curvel ets and wave atoms for mirror-extended images. In: Proc. SPIE Wavel ets XII conf. [S.I.: s.n.], 2007. v. 6701, p. 67010J. Citado 3 vezes nas páginas 65, 66 e 78.

. Wave atoms and sparsity of oscillatory patterns. Applied and Computational Harmonic Analysis, v. 23, p. 368-387, 2007. Citado 8 vezes nas páginas 24, 25, 34, 65, 66, 78, 81 e 85.

EFROS, A. A.; FREEMAN, W. T. Image quilting for texture synthesis and transfer. In: ACM SIGGRAPH '01. [S.I.: s.n.], 2001. p. 341-346. Citado na página 32.

EFROS, A. A.; LEUNG, T. K. Texture synthesis by non-parametric sampling. In: IEEE IEEE Int. Conf. Computer Vision. [S.I.: s.n.], 1999. p. 1033-1038. Citado 15 vezes nas páginas 14, $15,16,32,35,43,48,50,51,52,53,54,55,56$ e 57.

ELAD, M.; STARCK, J.-L.; QUERRE, P.; DONOHO, D. Simultaneous cartoon and texture image inpainting using morphological component analysis(mca). Appl. Comput. Harmon. Anal., v. 19, p. 340-358, 2005. Citado 3 vezes nas páginas 16, 34 e 58.

ESEDOGLU, S.; SHEN, J. Digital inpainting based on the mumford-shah-euler image model. European Journal of Applied Mathematics, Cambridge University Press (CUP), v. 13, n. 04, aug 2002. Disponível em: <http://dx.doi.org/10.1017/S0956792502004904>. Citado na página 48. 
ESEDOGLUY, S.; CHAN, T. F.; PARKY, F. E. Image decomposition combining stai rcase reduction and texture extraction. Journal of Visual Communication and Image Representation, v. 18, p. 464-486, 2007. Citado na página 37.

EVANS, L. D. Partial Differential Equations. [S.I.]: AMS, 2010. Citado na página 78.

FADILI, M.; STARCK, J.-L.; MURTAGH, F. Inpainting and zooming using sparse representations. Comput. J., v. 52, n. 1, p. 64-79, 2009. Citado 3 vezes nas páginas 16, 35 e 58.

GARNETTA J. B.; LEA, T. M. M. Y. V. L. A. I mage decompositions using bounded variation and general ized homogeneous besov spaces. Applied and Computational Harmonic Analysis, Special I ssue on Mathematical I maging, v. 23, p. 25-56, 2007. Citado na página 37.

GILBOA, G.; SOCHEN, N.; ZEEVI, Y. Z. Variational denoising of partly textured images by spatially varying constrai nts. IEEE Transactions on I mage Processing, v. 15, p. 2281-2289, 2006. Citado 2 vezes nas páginas 72 e 73 .

GILLES, J. Noisy image decomposition: a new structure, texture and noi se model based on local adaptivity. Journal of Mathematical Imaging and Vision, v. 22, p. 285-295, 2007. Citado na página 72.

GOLDBERG, D. E. Genetic Algorithms in Search, Optimization and Machine Learning. [S.I.]: Addison-Wesley Longman Publishing Co., Inc., 1989. Citado na página 82.

GONZALEZ, R. C.; WOODS, R. E. Digital Image Processing 2nd ed. New Jersey: Printcie Hall, 2007. Citado 3 vezes nas páginas 27, 29 e 62.

GROSSAUER, H. A combined pde and texture synthesis approach to inpainting. Euro. Conf. Comp. Vision, v. 4, p. 214-224, 2004. Citado 4 vezes nas páginas 13, 32 , 33 e 35.

GU, J.; RAMAMOORTHI, R.; BELHUMEUR, P.; NAYAR, S. Removing image artifacts due to dirty camera lenses and thin occluders. ACM Transactions on Gr aphics (SI GGRAPH ASI A 09), v. 28, n. 5, 2009. Citado na página 23.

GULERYUZ, O. G. Nonlinear approximation based image recovery using adaptive sparse reconstructions and iterated denoising-part ii: adaptive algorithms. IEEE Transactions on I mage Processing, v. 15, n. 3, p. 555-571, 2006. Citado 3 vezes nas páginas 16, 34 e 58.

HARRISON, P. A non-hierarchical procedure for re-synthesis of complex textures. In: In WSCG '2001 Confer ence proceedings. [S.I.: s.n.], 2001. p. 190-197. Citado na página 39.

HAYS, J.; EFROS, A. A. Scene completion using millions of photographs. ACM Transactions on Graphics, v. 26, n. 3, 2008. Citado na página 36.

HOLLAND, J. H. Adaptation in Natural and Artificial Systems. [S.I.]: University of Michigan Press, 1975. Citado na página 82.

KANIZSA, G. Organization in Vision: Essays on Gestalt Perception. [S.I.]: Praeger, 1979. Citado na página 34.

KAWAI, N.; SATO, T.; YOKOYA, N. I mage inpainting consi dering brightness change and spatial locality of textures and its eval uation. In: Proceedings of the 3rd Pacific Rim Symp. on Adv. in Img. and Video Technology. [S.I.: s.n.], 2009. (PSIVT '09), p. 271-282. Citado na página 36. 
KOENDERINK, J. J. The struture of images. Biol. Cybernet., v. 50, p. 363-370, 1984. Citado na página 67.

KOMODAKIS, N.; TZIRITAS, G. Image completion using efficient belief propagation via priority scheduling and dynamic pruning. IEEE Transactions on I mage Processing, v. 16, p. 2649-2661, 2007. Citado 3 vezes nas páginas 33, 35 e 36.

KWOK, T.-H.; WANG, C. C. Interactive image inpainting using dct based exemplar matching. In: Proc. of the 5th International Symposium on Advances in Visual Computing: Part II. [S.I.]: Springer-Verlag, 2009. (ISVC '09), p. 709-718. Citado 2 vezes nas páginas 31 e 39.

LEVINE, S.; RAMSEY, M.; MISNER, T.; SCHWAB, S. An adaptive model for image decomposition with applications to remote sensing. Lecture Notes in Computer Science, v. 3757, p. 382-397, 2005. Citado na página 37.

LI, F.; SHEN, C.; SHEN, C.; ZHANG, G. Variational denoising of partly textured images. Journal of Visual Communication and Image Representation, v. 20, p. 293-200, 2009. Citado na página 72.

LI, H.; WANG, S.; ZHANG, W.; WU, M. Image inpainting based on scene transform and color transfer. Pattern Recogn. Lett., v. 31, n. 7, p. 582-592, 2010. Citado na página 36.

LI, S.; ZHAO, M. Image inpai nting with sal ient structure completion and texture propagation. Pattern Recogn. Lett., v. 32, n. 9, p. 1256-1266, 2011. C Citado 2 vezes nas páginas 33 e 39.

LI, X. Image recovery via hybrid sparse representations: a deterministic annealing approach. IEEE J. of Selected Topics in Signal Processing, v. 5, n. 5, p. 953-962, 2011. Citado 3 vezes nas páginas 16, 35 e 58.

LIEU, L. Contribution to problems in image restor ation, decomposition, and segmentation by variational methods and Partial Difer ential Equations. Tese(Doutorado em 'Philosophy') - University of California, 2005. Citado na página 37.

LIU, G. Variational image decomposition using wave atoms. International Conference on Optoelectronics and I mage Processing (ICOI P' 10), IEEE Computer Society, v. 1, p. 588591, 2011. Citado 2 vezes nas páginas 65 e 72.

LIU, G.; FENG, X.; BAI, J. Variational image decomposition using wave atoms. Current Development in Theory and Applications of Wavelets, v. 2, p. 277-291, 2008. Citado 2 vezes nas páginas 65 e 72 .

LIU, Y.; CASELLES, V. Exemplar based image inapinting using multiscale graph cuts. IEEE Tr ansactions on I mage Processing, v. 22, p. 1699-1711, 2013. Citado na página 36.

L.J., D.; T.Z., H.; X.L., Z. Exemplar-based image inpainting using a modified priority definition. PLoS One, v. 10, n. 10, p. e0141199, 2015. Citado 12 vezes nas páginas 14, 15, 16, 48, 50, 51, $52,53,54,55,56$ e 57.

MA, J.; PLONKA, G. Combined curvel et shrinkage and nonlinear anisotropic diffusion. IEEE Transactions on I mage Processing, v. 16, p. 2198-2206, 2007. Citado 3 vezes nas páginas 38, 65 e 71.

MAHALINGAM, V. V. Digital Inpainting algor ithms and Evaluations. Tese (Doctoral Dissertation) — University of Kentucky, 2010. Citado na página 23. 
MALLAT, S. A Wavelet Tour of Signal Processing, Third Edition: The Spar se Way. 3rd. ed. [S.I.]: Academic Press, 2008. ISBN 0123743702, 9780123743701. Citado na página 34.

MARR, D.; HILDRETH, E. Theory of edge detection. In: Proc. R. Soc. Lond. B. [S.I.: s.n.], 1980. p. 187-217. Citado 2 vezes nas páginas 39 e 67.

MATHWORKS, I. T. Matlab Optimization Toolbox User's Guide (R2011b). 2011. Disponível em: <www.mathworks.com/help/pdf_doc/gads/gads_tb.pdf >. Citado na página 83.

MEYER, Y. Oscillating patterns in image processing and nonlinear evolution equations. 1. ed. [S.I.]: University Lectures Series, Vol(22), American Mathematical Society, 2002. C Citado 2 vezes nas páginas 35 e 37.

MISHRA, A.; WONG, A.; CLAUSI, D. A.; FIEGUTH, P. W. Quasi-random nonlinear scale space. Pattern Recogn. Lett., v. 31, p. 1850-1859, 2010. Citado 2 vezes nas páginas 70 e 71.

NEWSON, A.; ALMANSA, A.; FRADET, M.; GOUSSEAU, Y.; PEREZ, P. Towards fast, generic video inpainting. In: European Confer ence on Visual Media Production (CVMP). [S.I.: s.n.], 2013. p. in print. Citado na página 23.

NORDSTROM, K. Biased anisotropic diffusion: a unified regularization and diffusion approach to edge detection. I mage Vision Comput., v. 8, p. 318-327, 1991. Citado 4 vezes nas páginas $65,66,69$ e 70.

OSHER, S.; BURGER, M.; GOLDFARB, D.; XU, J.; YIN, W. An iterative regularization method for total variation-based image restoration. SI AM Multiscale M odel. and Simu., v. 4, p. 460-489, 2005. Citado na página 65.

PARAGIOS, N.; CHEN, Y.; FAUGERAS, O. Handbook of Mathematical M odels in Computer Vision. [S.I.]: Springer-Verlag New York, Inc., 2005. Citado na página 39.

PERONA, P.; MALIK, J. Scal e-space and edge detection using anisotropic diffusion. IEEE Trans. Pattern Anal. Mach. Intell., IEEE Computer Society, v. 12, p. 629-639, 1990. Citado 5 vezes nas páginas 24, 38, 65, 67 e 70 .

PLONKA, G.; MA, J. Nonlinear regularized reaction-diffusion filters for denoising of images with textures. IEEE Transactions on I mage Processing, v. 17, p. 1283-1294, 2008. Citado 4 vezes nas páginas $65,71,72$ e 73.

RECAS, D. L.; HILSMANN, A.; EISERT, P. Near-Regular Texture Synthesis by Random Sampling and Gap Filling. The Eurographics Association, 2011. Disponível em: <https://doi . org/10.2312/PE/VMV/VMV11/089-096>. Citado 2 vezes nas páginas 13 e 32.

RUDIN, L.; OSHER, S.; FATEMI, E. Nonlinear total variation based noise removal al gorithms. Physica D, v. 60, p. 259-268, 1992. Citado 5 vezes nas páginas 38, 65, 67, 71 e 72.

SCHöNLIEB, C.-B. Partial Differential Equation Methods for Image Inpainting. [S.I.]: Cambridge University Press, 2015. Citado 12 vezes nas páginas 14, 15, 16, 48, 50, 51, 52, 53, $54,55,56$ e 57.

SHEN, J.; CHAN, T. F. Mathematical models for local nontexture inpainting. Siam Journal on Applied Mathematics, v. 62, p. 1019-1043, 2002. Citado 2 vezes nas páginas 33 e 34. 